\title{
Chronic Abdominal Pain in Children
}

Chronische buikpijn bij kinderen

\section{Carolien Gijsbers}





\section{Chronic Abdominal Pain in Children}

Chronische buikpijn bij kinderen

Carolien Gijsbers 


\title{
Promotiereeks HagaZiekenhuis
}

Het HagaZiekenhuis van Den Haag is trots op medewerkers die fundamentele bijdragen leveren aan de wetenschap en stimuleert hen daartoe. Om die reden biedt het HagaZiekenhuis promovendi de mogelijkheid hun dissertatie te publiceren in een speciale Haga uitgave, die onderdeel is van de promotiereeks van het HagaZiekenhuis. Daarnaast kunnen promovendi in het wetenschapsmagazine HagaScoop van het ziekenhuis aan het woord komen over hun promotieonderzoek.

\section{Chronic Abdominal Pain in Children}

\section{Chronische buikpijn bij kinderen}

\author{
(c) Carolien Gijsbers
}

2012 Den Haag

ISBN: 978-90-9027270-2

\section{Vormgeving en opmaak}

De VormCompagnie, Houten

\section{Druk}

DR\&DV Media Services, Amsterdam

Printing and distribution of this thesis is supported by HagaZiekenhuis.

All rights reserved. Subject to the exceptions provided for by law, no part of this publication may be reproduced, stored in a retrieval system, or transmitted in any form by any means, electronic, mechanical, photocopying, recording or otherwise, without the written consent of the author. 


\title{
Chronic Abdominal Pain in Children
}

\author{
Chronische buikpijn bij kinderen
}

\section{Carolien Gijsbers}

\section{Proefschrift}

ter verkrijging van de graad van doctor aan

de Erasmus Universiteit Rotterdam

op gezag van

de rector magnificus

Prof.dr. H.G. Schmidt

en volgens besluit van het College voor Promoties.

De openbare verdediging zal plaatsvinden op donderdag 20 december 2012 om 15.30 uur

door

Carolina Francesca Maria Gijsbers

geboren te Zierikzee 


\section{Promotiecommisie}

Promotor: $\quad$ Prof.dr. H.A. Büller

Copromotor: Dr. C.M.F. Kneepkens

Overige leden: Prof.dr. D. Tibboel

Prof.dr. A.J. van der Heijden

Prof.dr. M.Y. Berger 

Table of contents 
2 OUTLINE OF THE THESIS $\quad 48$

3 CLINICAL AND LABORATORY FINDINGS IN 220 CHILDREN WITH 50 RECURRENT ABDOMINAL PAIN

4 RECURRENT ABDOMINAL PAIN IN 200 CHILDREN: SOMATIC CAUSES AND DIAGNOSTIC CRITERIA

5 RAP AND ROME: VALIDATION OF THE ROME III CRITERIA FOR RECURRENT ABDOMINAL PAIN

6 PROTOZOA AS CAUSES OF RECURRENT ABDOMINAL PAIN IN CHILDREN

7 LACTOSE AND FRUCTOSE MALABSORPTION IN CHILDREN WITH RECURRENT ABDOMINAL PAIN: RESULTS OF DOUBLE-BLINDED TESTING

8 OCCULT CONSTIPATION: FAECAL RETENTION AS A CAUSE OF RECURRENT ABDOMINAL PAIN IN CHILDREN

9 SUMMARY AND DISCUSSION

10 SAMENVATTING EN DISCUSSIE

11 DANKWOORD 
Introduction 


\section{INTRODUCTION}

\section{Recurrent abdominal pain}

Recurrent abdominal pain (RAP) was first defined in 1958 by Apley as "at least 3 bouts of pain, severe enough to affect activities, over a period of at least 3 months" (1). This was a landmark publication with great impact, showing, that emotional disturbances played a role in many patients. Since then, several studies showed, that anxiety, depression or behavioural problems are present in patients with abdominal pain, in patients with organic causes of pain as well as in patients with supposed functional pain, as is described by Di Lorenzo et al. on behalf of NASPGHAN in an evidence based report on chronic abdominal pain in children (2). In other words, it can be suggested, that the psychological symptoms could be the result of the pain in stead of the cause.

However, in many papers RAP is considered identical to functional abdominal pain, but it is clearly not; in fact RAP is a symptom, not a diagnosis and we should carefully analyse the patients before conclusions are drawn regarding aetiology. In a follow up study, Apley et al. stated, that only "with extremely rare exceptions organic disease can be satisfactorily ruled out from a carefully taken history, ..." and that "Two facets of diagnosis are necessary and complementary: reasonable evidence against organic disease, together with evidence in favour of an emotional disturbance. It is prudent not to rely on either one alone, but on both" (3). This in fact is confirmed in more recent studies: based on data obtained from history and physical examination differentiation between organic and functional causes of pain is not possible, as is concluded by Di Lorenzo et al. in their authoritative, evidence based report (2).

Therefore, it is reasonable to state, that the diagnosis "functional abdominal pain" can only be made with certainty when organic disease has been ruled out.

\section{Functional Gastrointestinal Pain Syndromes}

Around 1980 attempts have been made to find criteria for recognizing irritable bowel syndrome (IBS) in adult patients with abdominal pain without the need of exhaustive investigations, resulting in the Manning criteria and afterwards the criteria of Kruis $(4 ; 5)$. Validation of these criteria has been performed in several studies (6-8). Talley et al, using all 6 Manning criteria, found the Manning criteria to discriminate IBS from organic gastrointestinal disease with a sensitivity of $58 \%$ and a specificity of $74 \%$ (6). Jeong et al. found the Manning criteria to discriminate from organic disease with a sensitivity of $67 \%$ and a specificity of $66 \%$, using 3 or more criteria (7). Frigerio et al. validating the Kruis criteria found a sensitivity of 47 and $60 \%$ for men and women respectively and a specificity of 94 and $95 \%$, but several important diagnoses were not identified and they considered the results as insufficient (8).

Around 1990 the Rome criteria for functional gastrointestinal disorders (FGIDs) have been published, that classified - amongst other - the functional gastrointestinal pain syndromes, followed by revisions (Rome II and Rome III criteria) in 1999 and 2006 (9-14). The diagnoses IBS, functional dyspepsia (FD), functional abdominal pain (FAP) and newly introduced for Rome III criteria - functional abdominal pain syndrome (FAPS) can be made when patients present with the symptom clusters of the specific pain syndrome in the absence of alarm symptoms. Validation has been performed in several studies. Whitehead et al. found a percentage of $84 \%$ of patients who presented with IBS symptoms to have alarm symptoms and concluded, that incorporating these "red flags" into the Rome 
criteria would not improve sensitivity and would result in too many missed IBS diagnoses. Using Rome II criteria with exclusion of the patients with red flags, they still found a low agreement with clinical diagnoses (sensitivity $54-60 \%$, specificity $67-72 \%$, positive prospective value $55-38 \%$ for primary care and gastrointestinal clinic patients respectively) (15). Ford et al. and Jellema et al. published a systematic review on the diagnostic performance of the symptom-based IBS criteria in diagnosing IBS (16;17). They found only one study on Rome I criteria; of several studies on Rome II criteria all but the study of Whitehead et al. had considerable methodological shortcomings (15;18). Spiller et al. and Camilleri published a "Pro Argument" and "Con Argument" respectively, with respect to the question if the symptom based IBS criteria lead to better diagnosis and treatment outcomes ${ }^{(19 ; 20)}$. Camilleri, referring to an article of Quigley with arguments against the use of the Rome criteria (21), concludes that the Rome criteria fall short on all expectations. Spiller et al. mention the improvement of the reproducibility of clinical trials in IBS by using the standardized entry criteria of IBS, but describe as the limitations of the criteria the unreliability of symptom-based criteria and absence of data on underlying psychological mechanisms; moreover, insufficient validation has been performed of Rome II and III criteria (19).

For children, alarm symptoms have been published in several versions since 1984 especially by the group of Rappaport - as a means to recognize organic disease in children with RAP (22;23). Boyle proposed differentiation of abdominal pain in 3 groups: 1. RAP presenting as paroxysmal periumbilical abdominal pain; 2 . RAP associated with symptoms of dyspepsia; 3. RAP associated with altered bowel pattern (23). He stated that it is not sure whether these different presentations are the result of different disorders or variable expressions of the same disorder. Hyams et al. looked for IBS using adapted Rome-criteria in adolescents and found 'abdominal pain in the last year' to be present in $75 \%$ of students, of whom $17 \%$ of high school and $8 \%$ of middle school students had symptoms of IBS (24). Walker et al included children with RAP and a control group and performed a follow up after 5 years; the patients with RAP significantly more often (18\%) fulfilled at least 3 Manning criteria of IBS than the control group (0\%) (25). Shortly afterwards, with the publication of the Rome II criteria for adults in 1999, Rome criteria were formulated for the first time for children as well (26), followed by the Rome III criteria in 2006 (27). The process of defining the Rome criteria consisted of arriving at consensus, based on clinical experience. As in adults, a Rome diagnosis of one of the functional gastrointestinal pain syndromes can be made, when patients present with the symptom clusters of IBS, FD, FAP or FAPS in the absence of alarm symptoms. However, neither the alarm symptoms nor the Rome criteria for children have been validated.

\section{EPIDEMIOLOGY}

Recurrent abdominal pain was found by Apley in 1958 in $11 \%$ of 1000 schoolchildren between the ages of 3 and 15 years (girls $12 \%$, boys $10 \%$ ). Boys had a steady incidence of $10-12 \%$ from 5 to 10 years with a fall thereafter and a small peak at 14 years. In girls there was a similar incidence up to the age of 8 years; thereafter there was a marked rise to more than $25 \%$ of all 9 year old girls, followed by a steady decrease (1). Hyams et al (24) performed a study in 1996 in which 507 middle school and high school students (mean age 13 and 16 year respectively) participated using the Bowel Disease Questionnaire (28): abdominal pain was noted by $75 \%$ of all students, occurring at least weekly in 13 and $17 \%$ respectively and severe enough to affect activities in $21 \%$. Øster found in a Danish population of 
schoolchildren, 6-19 years old, $14 \%$ of the children to answer positively when asked after abdominal pain (girls 17\%, boys 12\%) with a peak-age of 9 years for both sexes: girls $30 \%$, boys $21 \%$ (29). In a Finnish study on 2292 schoolchildren from the first and third class, 6-10 year old, $7 \%$ of the first class and $5 \%$ of the third class had abdominal pain at least once a week (30).

The same prevalence is found in non-Western parts of the world: in 1549 school-children in Malaysia, rural as well as from town, RAP (Apley criteria) appeared to occur in 10\% (31). It is estimated that $5 \%$ of all out-patient visits to paediatricians are about RAP (32). Although many authors refer to Apley for he definition of recurrent abdominal pain, often adjustments of the inclusion criteria are made, which make the prevalence data difficult to compare. Studies that adhere to the Apley inclusion criteria show less variation in the prevalence of recurrent abdominal pain, as is shown in the systematic review of Chitkara et al on the epidemiology of childhood recurrent abdominal pain in Western countries (33).

\section{LONG TERM FOLLOW UP AND RISK FACTORS FOR PERSISTENT ABDOMINAL PAIN}

The prognosis of RAP obviously depends on the situation of the individual patient, but several studies indicate that after a follow up from 5 to more than 10 years the pain had disappeared in $35-50 \%$ of the patients, while it was still more or less present in $25-65 \%$ and had been converted to other pain syndromes in about 30\% (3;34-39). In some series an organic disease had been detected in the follow up period, that could explain the abdominal pain: Crohn's disease (37), a peptic ulcer (39) or other organic diseases (3;37). Also from anecdotal information it is clear, that it is not very unusual, that the diagnosis "functional abdominal pain" has to be revised afterwards, because an organic cause is found, sometimes after many years (40-46)

In a systematic review, Gieteling et al. (47) showed from a range of rather heterogeneous studies, performed between the 1940s and the last decade, that at follow up abdominal pain was still persistent in roughly $30 \%$ of patients. No difference was found between older en more recent studies, between the way of excluding organic disease and between studies performed in secondary and tertiary centres. The studies on inpatients showed abdominal pain in $50 \%$ of the patients at follow up, studies on outpatients $27,2 \%$; the difference was significant $(p<0.01)$. In studies with a follow up of 1-5 years the pain persisted in $25 \%$, with a follow up of 5-10 years in $35 \%$, with a follow up of 10 years or more in $37,4 \%$; the difference between the studies with a follow up of 1-5 years versus a follow up of 10 years or more was significant $(p<0.001)$.

In a second systematic review, the same group sought to establish the prognostic factors for persistence of chronic abdominal pain in children (48). They examined 17 potential prognostic factors, of which 10 were studied in one study only. Female sex was not related to persistence of pain (strong evidence). Behavioural disturbances and psychological disorders do not predict persistence (weak evidence). There was conflicting and insufficient evidence, that depressive or anxiety disorders and academic competence predict persistence of abdominal pain. Severity of baseline abdominal pain was not found to be associated with persistence of pain (weak evidence). A negative life event is likely to predict persistence of pain (weak evidence). Having a parent with functional gastrointestinal symptoms predicts persistence of abdominal pain with moderate evidence. Having parents who continue to search for an organic explanation 
(expressed by a high number of consultants) and parents who refused to consider a psychological influence on the pain (expressed by disagreement with psychological referral), which is a measure of the perception of parents of the illness of their child, was associated with persistence of abdominal pain (weak evidence). Because of the small number of studies or conflicting directions of the associations, it is not clear whether age, educational level, duration of chronic abdominal pain at baseline, presence of associated symptoms, a history of 2 or more surgical operations and/or socioeconomic status of the family influenced the course of the abdominal pain (48).

Chitkara et al. (49) presented a systematic review of studies in adolescents or adults with IBS, investigating premorbid factors occurring in childhood.

1. Childhood abdominal pain persisted in adulthood in about $30 \%$, but in a higher percentage in studies with longer duration of follow up, as is mentioned in the review of Gieteling et al. As an explanation for persistence, they refer to the study of Mulvaney et al. (50), who found the long term risk group to have the highest baseline levels of anxious and depressive symptoms and stressful life events and the lowest self-esteem. Two studies mention an association between affluent childhood socioeconomic status and adult IBS; Gwee et al. proposed a " hygiene hypothesis" to explain the dissimilar prevalences of IBS reported in western countries compared to Asian countries (51-53).

2. Traumatic events during infancy are reported to play a role: premature infants with birth weight $<1500$ grams were significantly more likely to develop IBS and traumatic interventions in neonates were associated more often with a functional intestinal disorder later in life. Traumatic events in childhood included a history of physical or sexual abuse, and parental deprivation including unsatisfactory relationship between parents, loss of parents through death, divorce or separation. Childhood traumatic events are supposed to sensitise an individual to the manifestation of functional gastrointestinal symptoms later in life: traumatic events may predispose an individual to psychological stress, which would lead to exaggerated reactions to stress. Alternatively, injurious childhood life events might act as contributory factors toward the sensitisation of intestinal visceral afferents, as is demonstrated by maternal separation early in the life of rats, which induced visceral hyperalgesia and increased colonic motility as they matured. Central neuronal sensitisation is demonstrated in rats with chronic visceral hypersensitivity after colonic irritation in neonates (but not in adults), in the absence of identifiable peripheral pathology. It is suggested, that there may be a critical time period during which traumatic events are more likely to affect the development of visceral hypersensitivity. Clinical and experimental data support early childhood as a critical time period in which trauma can induce visceral sensitivity and the manifestation of a functional gastrointestinal disorder.

3. Social learning of illness behaviour occurs when parents respond to abdominal complaints of their children with increased attention (reinforcement) or when parents with IBS behave in a manner that demonstrates a preoccupation with illness (modelling). Chitkara et al. refer to the study of Levy et al. (54) who found greater concordance for IBS in monozygotic than in dizygotic twins, supporting a genetic contribution. The association of dizygotic twins with mothers with IBS was greater than with their co-twins and logistic regression analysis demonstrated that having a parent with IBS was an independent predictor for the individual having IBS. Levy et al. in another study reported, that mothers who made more statements that reinforced illness behaviour, independently reported more stomach aches (55). Walker et al demonstrated that parents utilizing distraction techniques as opposed to sympathy were able to decrease the level of discomfort of their children (56). 
Chitkara et al. concluded from this review, that paediatricians should consider interventions such as early symptom management with cognitive therapies and parent education about social learning of illness behaviour. They suggested, that early treatment might have a long-term effect (49).

\section{IMPACT OF CHRONIC ABDOMINAL PAIN ON INDIVIDUALS AND SOCIETY}

Chronic abdominal pain is likely to have much impact on the life of the patients and their families.

Children (age 11,2 $\pm 3,5$ years, tertiary centre) with functional abdominal pain had a significant lower score with the Pediatric Quality of Life Inventory (PedsQL) than healthy controls and also lower, but not significantly, than children with gastro-esophageal reflux disease and inflammatory bowel disease, indicating a lower quality of life. Interestingly, the parents of children with functional abdominal pain reported significantly lower scores compared with their children's own scores (57). Varni et al. found comparable data in children with IBS and FAP and their parents (Rome II criteria) (58).

Youssef et al. (59) reported significantly more depressive symptoms in adolescents with daily abdominal pain - female more than male - than in adolescents with rare abdominal pain. Adolescents with daily abdominal pain reported more days of missing school, less participation in social activities, in active sports and in school activities. Adolescents with daily abdominal pain were significantly more likely to feel sad, cry, feel lonely, feel low energy and consider life to be a failure than those with rare pain (59). Huntley et al. (60) in a study on sleep characteristics, found children with functional abdominal pain to have more behavioural sleep disorders, increased nightmares and daytime tiredness than a healthy control group; they argue that changes in cognition, attention and affect regulation, arising from sleep disorders or inadequate sleep could play a role in individuals' ability to cope with pain. In a systematic review, Spiegel et al. (61) reported, that patients with chronic abdominal pain syndromes are 2-11 times more likely to demonstrate suicidal behaviour, compared with matched controls; chronic abdominal pain was found to be an independent predictor of suicidal behaviour after adjusting for co-morbid psychiatric conditions. Greco et al. reported more victimization of children with frequent abdominal pain than in matched controls, which could be related to school absenteeism and diminished social competence, but the cross-sectional design of the study did not allow conclusions as to the cause-effect relation of these observations (62). Data on school non-attendance in children are in keeping with the data on absence from work in adults; both have much impact on the personal development of the patients and their participation in the society. In adults, absence from work also has economic consequences, in the literature referred to as "indirect costs". Moreover, the "direct costs" consisting of the expenditures incurred by the health-care system for chronic abdominal pain are considerable. For IBS the economic burden has been estimated and presented in several papers. Wells et al. estimate the direct cost of IBS in the UK - based on data of 1995 - to be $£ 45,6$ million, of which $£ 25,6$ million is generated by the general practitioners and $£ 20$ million is the cost of outpatient attendances and inpatient admissions (63). An American Gastroenterological Association publication estimated the total annual direct costs of IBS in 1998 to be $\$ 1,35$ billion, assuming an IBS prevalence of 15\% (64). Nyrop et al estimated the annual direct cost of IBS to be $\$ 5000$ per patient, including out of pocket expenses (64). Dhroove calculated the average direct cost for children with abdominal pain to be $\$ 6000$ (65). 


\section{ETIOLOGY}

Many organic diseases can present with chronic abdominal pain. However, chronic abdominal pain is considered to have a functional character in the majority of the patients. When patients fulfil the symptom criteria of IBS, FD, FAP or FAPS and somatic causes of pain can be sufficiently excluded, they are considered to have one of these functional gastrointestinal pain syndromes.

\section{Physiology and pathophysiology of functional gastrointestinal pain syndromes}

In a review for the occasion of the presentation of the Rome III criteria, Kellow et al describe physiology and pathophysiology of functional gastrointestinal disorders (FGIDs) (66). Heightened visceral sensitivity, whether by transmission of aberrant sensory signals to the brain or by inappropriate interpretation of normal signals by the brain or a combination of both, is a hallmark of FGIDs.

Perception pathways can be activated by mechanical distension of the gut, but the final conscious perception is modulated by various interacting factors, for instance intestinal nutrients, especially fat. After organ insult, mechanically insensitive afferent fibres from the viscera also can have important contribution to the input of signals to the CNS. Descending modulatory pathways are influenced by cognitive, affective, and stressful influences and by expectation and prior experience.

Motility is controlled by reflexes and by descending modulation from the brain-gut axis. Communication between various regions of the gut is facilitated by transmission of myogenic and neurogenic signals along the gut.

Gut sensation is influenced by tonic or phasic contractions, probably via their effect on wall tension, resulting from interaction between intraluminal content and elasticity of the wall (66).

Several sensory and motor abnormalities are present in FGIDs and may interact to produce specific symptoms. In FD, early satiety is associated with impaired accommodation of the proximal stomach and early redistribution of liquids in the antrum; the symptom of fullness was related to late proxixmal gastric retention. Hypersensitivity is related to fundic distension in patients with postprandial symptoms and with antral distension in painpredominant FD. In IBS, hypersensitivity to rectal or sigmoid distension can be shown in $50-70 \%$ of the patients. At least half of the patients also perceive the stimuli over a wider area than healthy people. This hypersensitivity is associated with augmented activity in parts of the brain and increased subjective pain report; brain areas involved in descending pain inhibition are reported to show underactivity. Rectal and small bowel hypersensitivity in IBS patients are found to be associated with motor hyperreactivity in response to gut stimuli. Alterations in the colonic motor and sensory response to feeding are reported. A temporal correlation between high-amplitude propagating contractions and abdominal pain is reported, but this is an inconsistent finding. The colorectal tonic reflex (increase of rectal tone in response to distension of the descending colon) has been found to be diminished in patients with IBS (66).

\section{Several causes of dysfunction in FGIDs have been recognised} Various genetic factors have been documented with respect to FD and IBS. Early-life experiences and social learning are considered to be important as well. Secretion and handling of serotonin in the gut mucosa also seems to contribute to sensorimotor dysfunction. Post-infectious IBS especially after bacterial gastroenteritis is found in up to $30 \%$ and 
is reported to be more frequent in women, after a prolonged or severe illness and in patients with more anxiety, depression, somatisation and neurosis. An increase of mast cells in the mucosa is documented in terminal ileum and colon, often in close proximity with enteric nerves. In FD also an increase in mucosal mast cells have been found and a relation with impaired fundic accommodation in at least some patients is suggested. Enteric flora can influence motor activity, can modulate the host immune system and can enhance epithelial barrier function. Therefore, bacterial overgrowth as well as the use of antibiotics can be assumed to influence gut function.

Food or components of food often are reported to cause symptoms. Patients with FD and IBS both mention postprandial symptoms. In case of a temporal relationship of symptoms with specific food, patients often assume food allergy to play a role. Fat is mentioned by many patients with FD or IBS as a cause of symptoms. Malabsorption of fructose and other incompletely digestible carbohydrates can cause symptoms of IBS. Elimination diets are reported, but show conflicting results.

Psychosocial stress and cognitive factors have been well documented to play a role in FD and IBS. In adults, severe chronic life stress threat, such as relationship difficulties, divorce and business failures, together with prolonged and effortful coping associated with the stressor, are shown to have significant effects on symptom onset and exacerbation over time. In this process, mast cells, norepinephrine and corticotrophin releasing factor (CRF) play a role. Two CRF-receptors have been found: CRF-1 mediates stress induced increase in colonic contractility, CRF-2 mediates stress induced gastric hypomotility.

Autonomic dysfunction has been suggested in FD (vagal dysfunction). In IBS vagal dysfunction is found in constipation predominant patients and sympathetic adrenergic dysfunction in diarrhea predominant patients (66).

\section{Organic diseases}

Organic diseases that could be the cause of recurrent abdominal pain are listed in the table. Diagnostic tests are available for most of these diseases. However, an abnormal test - and even an organic diagnosis - does not always indicate a causal relation with the abdominal pain. For example, a positive result of Helicobacter pylori (Hp) serology does not always implicate an infection with $\mathrm{Hp}$ (false positive test) and, moreover, an endoscopically proven $\mathrm{Hp}$-gastritis appears to be causally related to the abdominal pain in only a small percentage.

Therefore, disappearance of the abdominal pain with treatment of the supposed causal disease (i.e. elimination of the supposed cause) is a prerequisite for a diagnosis. But even then the placebo-effect of any intervention, reported to be between 13 and $73 \%$ in functional dyspepsia and up to $70 \%$ in IBS, has to be taken into account (67). For this reason, challenges are obligatory whenever possible, as in case of food intolerance or allergy. Otherwise, a long term follow up should be pursued, taking into account, that a placebo effect is supposed to diminish after three months and to be disappeared after about 6 months ${ }^{(68)}$. However, this proof of causal relations by diagnosis per patient never can be made $100 \%$ sure. Randomised controlled trials should be performed to answer the question if a specific diagnosis can be the cause of the pain. This type of study also has its limitation: in practice, rare diagnoses can not be proven in this way. In addition, it could be statistically complicated to establish causal relations for diagnoses, that are only causally related with abdominal pain in a certain percentage.

Some diagnoses deserve more discussion. 


\section{Protozoa}

Dientamoeba fragilis (Df) and Giardia lamblia (Gl) have a worldwide distribution, in both Western countries and developing countries; Blastocystis hominis (Bh) is suggested to be more frequent in developing countries (69-71).

Although Bh has been described for the first time as early as 1911 and Df in 1918 (72;73), it is only since the last decades that some information has come to light about the role of these protozoa. Knowledge of pathogenicity of these intestinal parasites is mainly based on studies performed from a microbiological point of view, establishing the prevalence of protozoan gastrointestinal infections with or without clinical features in patients from whom stool samples were obtained $(70 ; 71 ; 74-82)$. Presentation with the specific symptom clusters of irritable bowel syndrome (IBS) and dyspepsia have been mentioned (79;82-85). Df as well as Bh have been found in patients with appendicitis or 'suspected' appendicitis (86-89) and have been linked to colitis as cause of the colitis or inducing exacerbations in patients with colitis ulcerosa $(90 ; 91)$.

Several studies describe the result of therapeutic interventions (70;75-78;80;83;92;93). However, most of these studies have major limitations with respect to the number of patients, the way of selecting patients and therapeutic methods, which makes interpretation difficult. Studies with a long term follow up or prospective double-blind placebocontrolled intervention studies are not available.

Only scarce information is available as to the relation of protozoan gastrointestinal infections with abdominal pain, specifically in children (76;81;92-96).

Gl has been accepted as a pathogen since many years. Approximately $50 \%$ of people clear Gl without any untoward effect, 5-15\% shed cysts asymptomatically. The remaining people have acute or chronic infection.

Diarrhea may have an acute onset, with nausea, but may last for years and may be continuous or intermittent. Abdominal pain may be present, independent of the presence of diarrhea (70;85). Chronic Gl infection can present as IBS (84); Grazioli et al found Gl in 7\% of patients with IBS and dyspepsia (79). Other symptoms can be flatulence, anorexia, nausea, vomiting, weight loss and general malaise.

Nowadays, Df is accepted as a pathogen by many authors (70;71;74;76;78;81-83;85-87;90;92-103), but its role in disease is still subject of discussion. Stark et al in a study on patients (age 3-75 years) with gastrointestinal symptoms or routine faecal occult blood testing, found abdominal pain or discomfort in $78 \%$ of 36 patients with Df and in $15 \%$ of 539 patients without Df. Symptoms disappeared in $94 \%$ after successful treatment (71). Vandenberg et al in a study on patients who were clinically suspected to have a gastrointestinal infection caused by parasites, found abdominal pain in $69 \%$ of 26 patients (age 1-90 years) with Df and in $72 \%$ of 29 patients with Gl (70). Bosman et al in a retrospective study found $82 \%$ of 33 patients with Df and gastrointestinal complaints to have considerably less or no complaints after eradication of Df; of 10 patients with failed eradication only two had (almost) disappearance of complaints (92). Infection with Df can present with symptoms of IBS (82;83). Spencer et al found gastrointestinal complaints in 31 of 35 children with Df (94). In another study, the same group detected Df in $21 \%$ and $\mathrm{Gl}$ in $17 \%$ of 104 children from general pediatric and dental clinics and they found a significant proportion of them to have abdominal pain and other gastrointestinal complaints (95). In contrast, Soon et al did not find more parasites in children with abdominal pain than in a control group (81). 
Pathogenicity of Bh is subject of even more discussion (69;85). Bh has been found in considerable amounts as sole identified potential pathogen in many patients with gastrointestinal symptoms; their symptoms disappeared with eradication of the parasite $(69 ; 75 ; 77 ; 80 ; 85)$. A role of Bh as a cause of IBS like symptoms is suggested, but is still controversial ${ }^{855)}$. Windsor et al commented not to overlook Df in these patients, because Df could be the cause of the symptoms, but is more difficult to detect (99). In a recent double blind placebo controlled study children with RAP as their only complaint and $\mathrm{Bh}$ as the only pathological finding were treated with trimethoprim / sulfamethoxazol (TMP/SMX) or placebo. Eradication was around 30\% in both groups. Decrease of the pain score was comparable in both groups and independent of the detection of $\mathrm{Bh}$ at the end of treatment. The authors did not mention the number of patients that was pain free after eradication of the parasite ${ }^{(104)}$.

\section{Helicobacter pylori}

The prevalence of Helicobacter pylori $(\mathrm{Hp})$ in the general population is quite different from one country to another and increases with age (105-108). The infection is considered to be chronic, but spontaneous clearance has been reported (109-111). In the last decades a decrease of the prevalence has been found (108;112). The prevalence of $\mathrm{Hp}$ in children with RAP is 6-60\% in various studies (113-129), using culture, histology and urease tests, mostly a combination of some tests. Most studies are from tertiary referral centres, so the populations are selected. When only serology is performed, the prevalence in children with RAP is found to be $3-71 \%$ (105;106;117;119;124;130-134), often not significant different from an asymptomatic control group. In studies in which serology and endoscopy are both performed, the real prevalence of infection is much lower than the serology-yield (117;119). The European Helicobacter Study Group in the Maastricht III Consensus Report recommend a "test and treat" strategy for adults under 45 years of age with non-ulcer dyspepsia; eradication of $\mathrm{Hp}$ gives modest but significant benefit in non-ulcer dyspepsia. Twelve to 15 patients need to be treated to cure one patient with non-ulcer-dyspepsia. Eradication leads to long term symptom improvement and also reduces the risk of developing peptic ulcer disease, atrophic gastritis and gastric cancer (135). For children with recurrent abdominal pain, a "test and treat" strategy is not recommended, but children with upper intestinal symptoms should be tested and treated when positive (135). Spee et al. in a meta-analysis found no evidence for a relation of Hp to RAP in children. However, in 2 of 3 studies on $\mathrm{Hp}$ and epigastric pain in children a statistic significant association has been found. Therefore they - partially - agree with the conclusions of the Maastricht III Consensus Report (136). The recent evidence based guidelines from ESPGHAN and NASPGHAN recommend not to test for $\mathrm{Hp}$ in children with abdominal pain consistent with the criteria of functional abdominal pain, unless upper endoscopy is performed during the diagnostic work up in search for organic disease (108). These recommendations are based on a small number of case-control studies on this subject 1 (137;138) and one doubleblind randomised placebo-controlled trial (110). Several intervention studies show improvement of symptoms after treatment, but all have more or less limitations which restrict their impact (139-142). However, in the study of Ashom et al. the patients in the placebo group had - beside 2 placebo-antibiotics - a proton pump inhibitor, which in fact could influence their symptoms. Moreover, in a few uncontrolled studies with follow up the pain is still absent after 6 months to more than 2 years (113;143). Therefore, Hp cannot be excluded as one of the possible causes of recurrent abdominal pain in some children, unless appropriate double blind controlled studies or studies with sufficient follow up prove the contrary. 


\section{Yersinia enterocolitica}

Literature on chronic abdominal pain as a result of an infection with Yersinia enterocolitica is scant. Hoogkamp-Korstanje in 1988 reported 3 patients, who had chronic ileitis or proctitis during 1-2 years after an acute gastroenteritis (144); in 1991 the same authors reported ileitis and several other chronic infections with Yersinia, that could persist for months or years (145). Hoogkamp et al performed a prospective study aimed at description of the presentation of infections with Yersinia enterocolitica in children (146). Of 125 patients, 84 presented with enteritis, 8 with enteritis in combination with extraintestinal symptoms, 20 with "pseudoappendicular syndrome", an acute disease with appendicitis or mesenteric lymphadenitis, and 2 teenagers with chronic relapsing ileitis; 11 patients only had extraintestinal symptoms. The children with chronic ileitis had abdominal pain and diarrhoea, sometimes rectal blood loss, fever and weight loss. At endoscopy the mucosa appeared diffusely swollen and erythematous; chronic non-specific lymphocytic inflammation and bacteria were found in mucosa, submucosa and the muscular layers of the bowel, with necrosis and some granulomas; giant cells and fistulas were not observed. The incidence of yersiniosis was estimated to be about $20 \%$ of the incidence of salmonellosis in the Dutch area in question.

Saebø et al presented a 10-year follow up of 458 hospitalized patients with Yersinia enterocolitica infection. Hundred and sixty patients had been readmitted, of whom 38 with chronic abdominal pain (9 of these also had chronic diarrhoea) (147). Thus, the role of Yersinia enterocolitica in RAP is difficult to ascertain.

\section{Lactose intolerance}

Lactose intolerance is a consequence of lactose malabsorption, resulting from deficiency of $\beta$ galactosidase (lactase) in the intestinal epithelium. Lactose intolerance is assumed to be one of the causes of RAP (148-157). Malabsorbed carbohydrate is fermented by the colonic microbiota, which may result in symptoms of carbohydrate intolerance, including abdominal pain, bloating, borborygmi, flatulence and diarrhoea $(148 ; 154 ; 158)$. For detection of lactose malabsorption a hydrogen breath test with a lactose load (lactose- $\mathrm{H}_{2} \mathrm{BT}$ ) has to be performed $(159 ; 160)$.

From many studies it is evident that not all patients with lactose malabsorption are symptomatic when ingesting lactose $(150 ; 161-164)$. Lactose intolerance can not be predicted adequately by symptoms or dietary history (153;154;165-168). Lactose intolerance, as the causal relation between lactose malabsorption and RAP, seems plausible, when elimination of lactose from the diet leads to disappearance of the pain and provocation with lactose causes reappearance of pain. A limited number of studies fulfil these criteria for lactose intolerance as a cause of recurrent abdominal pain (150;151;156;162;163).

Analysis of factors determining why some people with lactose malabsorption are intolerant and other are not, led to the observation, that adaptation of the intestinal flora takes place in people consuming a daily amount of lactose. Daily lactose intake ( $25-50 \mathrm{~g}$ lactose per day during 10-14 days or 8-20 g lactose during 6-12 weeks) stimulates the proliferation of bifidobacteria and lactobacilli in combination with reduction of faecal $\mathrm{pH}$ and reduction of $\mathrm{H}_{2}$ production, leading to reduced breath $\mathrm{H}_{2}$ excretion after a lactose load and decrease of intolerance (158;169-173). Vonk et al suggested, that the degree of lactose digestion in adults with genetically determined low lactase activity is determined by residual lactase activity and by the time available for hydrolysis (orocaecal transit time). Other, still incompletely understood, host-specific factors were supposed to be responsible for intolerance $(174 ; 175)$. Studies performed by the Barcelona group on the handling of gas by the intestine, suggested, that production of gas results in bloating without pain, but that gas retention 
in combination with impaired outflow can result in abdominal pain (176;177). Quigley, referring to the work of the Barcelona group, supposed distension to be the consequence of gas production, in combination with motor and sensory responses, most evident in patients with irritable bowel syndrome (178).

Many patients with lactose malabsorption do not become pain free with elimination of milk products. Probably, another cause than lactose malabsorption is (partially) responsible for the symptoms of these patients. The remaining amount of lactose in the diet (from "hidden milk") is unlikely as an explanation for their therapy-failure, because many studies show, that most people with lactose intolerance tolerate a certain amount of lactose (179-181). During the breath test some patients are symptomatic whilst having a normal test result (160). This could be caused by a falsely negative breath test as a result of non $\mathrm{H}_{2}$ producing microbiota (caused by low intraluminal $\mathrm{pH}$, recent use of antibiotics, acute diarrhea during or just before the test or colon preparation for endoscopy), predominant methanogenic $\left(\mathrm{H}_{2}\right.$ utilising) flora, hyperventilation or exercise (148;182-185). Alternatively, abdominal pain during the test could be the usual pain of the patient, not related to lactose ingestion (186).

In some controlled studies a few patients without lactose malabsorption became pain free with a lactose free diet $(151 ; 152 ; 187)$. This could be the consequence of a falsely negative breath test ${ }^{(159)}$ or blood-glucose test ${ }^{(188 ; 189)}$ which probably failed to detect lactose malabsorption in some patients. Alternatively, it could be a placebo-effect or could be related to cow's milk protein allergy. Spontaneous recovery from another cause of pain could happen by chance, without causal relation with lactose elimination.

Despite a host of literature on lactose malabsorption and intolerance, there still is a need of more research to find the factors that play a role in the intolerance of lactose in lactose malabsorbing people.

\section{Fructose and FODMAPs}

Fructose is a monosaccharide, that is absorbed passively by the apical GLUT5 transporter protein along a concentration gradient. Fructose absorption is known to be incomplete in many people, resulting in abnormal hydrogen breath tests after a fructose load in a high percentage of healthy people. Hoekstra et al. found an abnormal breath test $\left(\Delta \mathrm{H}_{2} \geq 20\right.$ $\mathrm{ppm}$ ) in $100 \%$ of 57 healthy children (age 0,1-6 years) after a fructose load of $2 \mathrm{~g} / \mathrm{kg}$ ( $20 \%$ solution) and in $44 \%$ of 57 children after a fructose load of $1 \mathrm{~g} / \mathrm{kg}$, not discriminating between children with and without a history of gastrointestinal symptoms (190). Jones et al. in a population of 1093 children who were tested because of gastrointestinal complaints, found the tolerance of fructose to increase with age: the odds of having an abnormal hydrogen breath test with fructose load (fructose- $\mathrm{H}_{2} \mathrm{BT} ; 0,5 \mathrm{gram}$ fructose $/ \mathrm{kg}$, maximum $10 \mathrm{~g}$; abnormal when $\Delta \mathrm{H}_{2} \geq 10 \mathrm{ppm}$ ) decreased by $0,82 /$ year in patients of 15 years old or younger: $88 \%$ abnormal at age younger than 1 year, $67 \%$ at age 1-5 year, $40 \%$ at age 6-10 year and $27 \%$ at age $10-15$ year (191).

In healthy adults the percentage of abnormal fructose- $\mathrm{H}_{2} \mathrm{BT}$ varies with the fructose load: $40-80 \%$ abnormal with a 50 gram load or $10-50 \%$ abnormal with a 25 gram load (192). Despite these apparently falsely abnormal results, fructose can cause gastrointestinal symptoms including abdominal pain in the same way as lactose in patients with lactose malabsorption (193-196).

The collective term 'fermentable oligosaccharides, disaccharides, monosaccharides and polyols' (FODMAPs) includes lactose and fructose in patients with lactose or fructose malabsorbtion, but also encompasses oligosaccharides like fructans (fructose oligomers and polymers with glucose-terminal end, in cereals and several vegetables), 
fructo-oligosaccharides (FOS, fructans with limited number of fructose units), galactooligosaccharides (GOS, including raffinose and stachyose in beans) and polyols (such as sorbitol, xylitol and mannitol). All these FODMAPs have in common that they are metabolized by intestinal microbiota and can cause gastrointestinal symptoms, such as - possibly - RAP $(197 ; 198)$.

\section{Celiac disease}

Celiac disease has been found in $1 \%$ of the population of Western countries. In children older than 3-5 years of age, abdominal pain is the most frequent presenting symptom (199;200). In adults abdominal pain is found to be present in $40-77 \%$ (201-203). Several studies are performed to find the prevalence of celiac disease in patients with abdominal pain or - especially in adults - with irritable bowel syndrome. Results vary from $0,4 \%$ (same as controls) to $5 \%$ (Odds ratio to controls 7,0 ) and an exceptionally high percentage of $11 \%$ in a study on adults of Shahbazkhani et al (204) (children: (205;206), adults: (207-212)). In a systematic review Ford et al found an Odds ratio of 4.34 for celiac disease in adult patients with irritable bowel syndrome compared to healthy controls (213).

\section{Food allergy}

As to the role of adverse food reactions in IBS, only a few studies are available in which suspected foods are eliminated, followed by a double blind challenge (214;215). None of these fulfilled all criteria for ideal clinical trials according to a review by Niec et al (216), but some conclusions can be drawn: diarrhea-predominant IBS patients are more likely to respond to an elimination diet than constipation-predominant patients. Many foods are identified to cause adverse reactions, especially milk, egg, wheat and a lot of foods that have in common that they contain salicylates or amines (216-218).

In most studies the possible role of lactose intolerance in cases of cow's milk intolerance is not mentioned, nor is the role considered of fructose or sorbitol.

In only one of these studies was the allergic character of the intolerance confirmed by positive skin prick tests (SPTs) (218).

In a double blind cross over trial of high dose disodiumcromoglycate in patients with diarrhoea-type IBS a significant effect of disodiumcromoglycate was found, suggesting histamine release to be involved in the etiology (219).

Stefanini et al found in a study of patients with diarrheic type IBS and food intolerance (proven by elimination and open challenge with the main food families) a positive skin prick test (SPT) in 74/101 patients and disappearance of symptoms with disodiumcromoglycate in 50/74 patients $(67,5 \%)$ with a positive SPT and in $11 / 27$ patients (40\%) with a negative SPT. This rather poor correlation between positive SPT and positive disodiumcromoglycate-response restricts the diagnostic value of the SPT(220). A multicenter study was performed in diarrheic type IBS patients, of whom $35 \%$ of the 409 patients had a personal history of atopy and $21 \%$ had a positive family history of atopy. Thirty-three percent had a positive SPT for at least one food allergen. They were treated with an elimination diet or disodiumcromoglycate; with both therapies patients showed a significant effect on symptoms, more in the SPT positive patients $(75 \%$ and $81 \%$ respectively) than in the SPT negative patients (54\% and 58\%) (218).

This study confirmed the poor predictive value of the SPT.

Establishing the diagnosis food allergy is still complicated. Uz et el (221) found positive skin prick tests to food allergens to be far more frequent in patients with irritable bowel syndrome (25\%) than in healthy controls (1\%), but in other studies specific lgE and skin prick tests did not correlate very well with the results of elimination and food challenge (222). 
Measurement of eosinophil activation markers in stool, urine and blood showed insufficient correlation with the results of double blind placebo controlled food challenge (223). Lymphonodular hyperplasia is suggested to be an indicator of food allergy in several studies (224;225). In a study with 20 patients, Arslan et al performed intestinal provocations, followed by endosonography, showing increased mucosal thickness, and in a few patients a new echogenic layer or sustained duodenal contractions in response to food. These duodenal contractions, lasting 15-20 minutes, were associated with abdominal pain (226). The same group described intraduodenal food challenge in a young woman with food allergy (double blind placebo controlled provocation with egg was positive, specific lgE and skin prick test negative); both abdominal ultrasound and MRI showed intestinal wall thickening and influx of large amounts of fluid into the proximal intestine within 10 minutes of duodenal challenge with egg (227). Hagel et al found several non-erosive and erosive lesions in 12 of 15 patients with confirmed food allergy who underwent small bowel capsule endoscopy (228). For daily practice, elimination and double blind placebo controlled challenge are standard care for the diagnosis food allergy (229;230). However, in gastrointestinal food allergy, which is often a delayed type allergy, this is less easy to perform than in extraintestinal IgE-mediated food allergy.

More recently, eosinophilic esophagitis (EoE), eosinophilic gastroenteritis and eosinophilic colitis are recognized as causes of abdominal pain. EoE, characterised by at least 15 eosinophils per high power field in esophageal biopsies, needs to be differentiated from gastroesophageal reflux. Prolonged therapy is needed, with elimination of the offending food or topical fluticasone (231;232). On the long term, subepithelial fibrosis and strictures have been found in patients with untreated EoE (233). Eosinophilic gastroenteritis and eosinophilic colitis can result from food allergy, but can be a manifestation of another primary disease. When presenting in older children, as distinct from presentation in infancy, these diseases are often chronic waxing and waning disorders (231).

\section{Appendicopathy}

Notwithstanding the feeling of many doctors that 'chronic appendicitis' is non-existent, quite a number of papers is available on this subject and other causes of 'appendicopathy' that could lead to recurrent abdominal pain. According to the literature, pain originating from the appendix can have many causes, that can roughly be classified in 4 groups:

1. Recurrent inflammation is reported to present as episodes of pain, compatible with appendicitis and spontaneously resolving. It is suggested, that these resolving episodes represent attacks of non-perforating appendicitis, as opposed to perforating appendicitis, which seems to be a separate entity (234). Chronic appendicitis is described as thickened appendix with local adhesions; histological findings consist of infiltration with eosinophils and lymphocytes; it is reported to be present in $1-2 \%$ of appendectomies. (235-237). Sometimes specific inflammation is observed, e.g. Crohn's disease of the appendix (238-241), or schistosomiasis (intramuscular oviposition with acute appendicitis and serosal involvement resulting in peritoneal adhesions, especially in patients from Egypt and West Africa).

2. Obstruction of the appendix by inspissated faecal material (242-247), parasites (especially pinworms) (248;249), or tumor (carcinoid tumor, in a series of 25 cases carcinoid was detected incidentally at operation in $12 / 25$ children or after histological examination in the other 13/25; mucous cystadenoma; eosinophilic granuloma) (250-252);

3. Intussusception of the appendix, with or without a specific lead point around the basis of the appendix (253-256);

4. Neurogenic appendicopathy, in which condition larger amounts of Substance P (SP) 
immunoreactive nerves and Vasoactive Intestinal Peptide (VIP) immunoreactive nerves can be observed in the mucosal layer of the appendix than in patients with acute appendicitis or normal controls; these nerves also show a close spatial relation with lymphoid cells in lymph follicles (257-261). Patients with neurogenic appendicopathy present with the clinical picture of acute appendicitis, but are often assessed as "normal appendix" by the pathologist.

Altogether, sufficient data can be found in the literature to justify that the possibility of appendicopathy is taken into account in children with recurrent abdominal pain, especially when located in the right lower quadrant.

\section{Abdominal migraine}

Abdominal migraine is supposed to be a variant of migraine. Criteria for migraine are established by the International Headache Society (IHS); abdominal migraine is not included in the classification of the IHS because of lack of markers (262). Subsequently, criteria are formulated by Symon and Russell (263;264): recurrent episodes of midline abdominal pain, lasting for at least 2 hours, with complete recovery between the episodes. The pain is severe, interfering with normal activities. The attacks can be accompanied by vasomotor symptoms, especially facial pallor or flushing, anorexia, nausea, vomiting and headache. Attacks may be terminated by sleep or occasionally by vomiting. Often there is a positive family history for migraine. The Committee on Childhood Functional Gastrointestinal Disorders (Rome Il criteria) defined abdominal migraine as 1 ) in the preceding 12 months, 3 or more paroxysmal episodes of intense, acute midline abdominal pain lasting two hours to several days, with symptom free intervals lasting weeks to months; and 2) absence of evidence of metabolic, gastrointestinal and central nervous system structural or biochemical diseases; and 3) two of the following features: (a) headache during episodes, (b) photophobia during episodes, (c) family history of migraine, (d) headache confined to one side only, (e) an aura or warning period consisting of either visual disturbances (e.g. blurred or restricted vision), sensory symptoms (e.g. numbness or tingling), or motor abnormalities (e.g. slurred speech, inability to speak, paralysis) (26). Revision of the Rome criteria resulted in an adjusted definition of abdominal migraine (Rome III criteria): in the preceding 12 months, 2 or more times 1) paroxysmal episodes of intense, acute periumbilical pain that lasts for 1 hour or more; and 2) intervening periods of usual health lasting weeks to months; and 3) the pain interferes with normal activities; and 4) the pain is associated with 2 or more of the following: a. anorexia, b. nausea, c. vomiting, d. headache, e. photophobia, f.pallor; and 5) no evidence of an inflammatory, anatomic, metabolic, or neoplastic process considered that explains the subject's symptoms (27). In 368 children with non-organic abdominal pain, Baber et al. found a greater percentage of children to fulfil Rome III criteria compared to Rome II criteria for abdominal migraine ( $23.1 \%$ vs $5.7 \%)$ (265).

The relation between headache and abdominal pain is mentioned in many papers, initially by Apley, who found 'pain families' (1), followed by other authors who found many children to have headaches beside their abdominal pain (1;24;29;34;35;37;262;266). In addition, many children with abdominal pain develop headache when they grow older (267;268) and many children with abdominal pain have parents with headache $(1 ; 29 ; 34 ; 262 ; 269)$.

The influence of food in migraine was investigated by Monro et al. (270). He showed by dietary exclusion and subsequent challenge 23 of 33 patients with migraine headaches to be allergic to certain foods; oral sodium cromoglycate protected these patients from headache after ingestion of the offending foods. Mavromichalis et al. found inflammation in the upper digestive tract in 29 of 31 patients with migrainous headaches; a placebo-controlled therapeutic trial with antacids resulted in disappearance of symptoms in all treated patients but not in the small placebo group (267). They suggested migraine headache to have a gastrointestinal origin and proposed, that 
recurrent abdominal pain is an early expression of migraine.Therapeutic intervention studies, such as a placebo-controlled trial with pizotifen (264), a trial with pizotifen with a control group that is treated by explanation and reassurance (263) and an uncontrolled trial with propranolol or cyproheptadine (271) pointed to the possibility of abdominal migraine as a cause of attacks of abdominal pain.

Therefore, the diagnosis in individual cases should be based on the characteristic presentation of symptoms and the absence of organic diseases that could explain the symptoms. A family history of migraine and disappearance of symptoms with antimigrainous therapy support the diagnosis (27).

\section{Abdominal epilepsy}

Anecdotal information about abdominal epilepsy is available from some well-documented cases, children as well as adults (272-275). It concerns paroxysmal attacks of abdominal pain, with a frequency that varies from several times a week to several times a year. The attacks can last from minutes to hours. The pain is periumbilical and can be accompanied by pallor, dizziness, visual symptoms, nausea, vomiting or diarrhea. Postictal lowered consciousness is seen in some, but not all patients.

After an abnormal EEG, that points to epilepsy, the patients are treated with antiepileptica. In one patient therapy was discontinued because of a rash, leading to returning of symptoms; with another anticonvulsant drug she was asymptomatic again (272). Thus, abdominal epilepsy can be the cause of abdominal pain, but is very rare.

\section{Constipation and occult constipation}

Many paediatricians feel, that constipation plays a role in functional abdominal pain: patients often present with symptoms related to their defaecation pattern, although they do not fulfil the Rome criteria of functional constipation. Very few studies are performed on this subject (140;276-278), but the results of these studies suggest a role of faecal retention in abdominal pain.

Eidlitz-Markus et al defined 'occult constipation' as absence of spontaneous complaints of constipation and no criteria of constipation according to Loening-Baucke, but at least one of the following signs: hard consistency of stools (rock-like or pellet-like) on rectal examination and plain abdominal X-ray showing distended large intestines loaded with faecal material; overt constipation was defined according to the Loening-Baucke criteria (279). In 68 patients they found 29 patients with occult constipation, 10 patients with overt constipation, 20 patients with an organic cause and 9 with functional abdominal pain, defined as absence of a somatic cause. In 24 of 29 patients with occult constipation, the pain subsided considerably or disappeared, while 5 patients did not comply with therapy or had insufficient result. This study showed result of laxative therapy in children with signs of a faecal retention, though not fulfilling the Rome criteria for functional constipation. Alfvén defined constipation as the cause of RAP if there was a combination of defaecation difficulties, a stool frequency of less than every three days and the patient became symptom free and remained so after normalization of stools (not explicated). With this definition he found 3 patients with constipation in 100 children with RAP.

Størdal et al found constipation in 7 of 44 patients (16\%) with RAP, based on a history of hard stools with or without painful defaecation and/or faecal masses in the left lower quadrant; abdominal X-ray confirmed the diagnosis in these 7 children. Evaluation of the treatment effect was based on symptom relief and a total of 1 year of follow-up (treatment not explicated).

Boccia described 42 patients with functional dyspepsia as defined by the Rome II criteria. 
Functional constipation was present in 28 of $42(66.6 \%)$ patients. Ultrasonographic measurement of the total gastric emptying time (TGEt) was performed at baseline and after 3 months. Constipated dyspeptic children had significantly more prolonged TGEt than subjects without constipation. Constipated dyspeptic patients were treated with osmotic laxatives for 3 months; the control group consisted of the dyspeptic children without constipation. Patients on osmotic laxatives had a significant decrease in TGEt and a significant improvement of dyspeptic symptom score and of number and consistency of stools at 3 months.

These studies suggest, that constipation and occult constipation, which is not unequivocally defined as a kind of faecal retention, play a role in a certain percentage of patients with RAP, including upper abdominal pain.

\section{THERAPY}

Huertas-Ceballos et al. published a Cochrane review on pharmacological interventions for recurrent abdominal pain and irritable bowel syndrome in children (280). The most striking result was the paucity of placebo-controlled trials for all of the drugs used in children with RAP. They found three trials. A small study with famotidine in children with dyspepsia was insufficient effective (281). A small study with pizotifen in children with abdominal migraine gave some support to the belief, that pizotifen is effective in reducing the number and severity of attacks of abdominal pain in patients with abdominal migraine (264). A small study on the efficacy of peppermint oil provided no evidence of benefit (282).

Studies on the benefit of therapy in functional abdominal pain always have to deal with placebo effect and spontaneous recovery or waxing and waning of the symptoms. Spiller published a study on the placebo effect in 25 clinical trials with at least 30 IBS patients included; he found the placebo effect starting to recede after approximately 12 weeks and to disappear at about 6 months (68). He concluded, that the length of trials should be at least 3 months. Krogsbøll et al. published a meta-analysis of three-armed trials comparing no-treatment, placebo and active intervention. The relative contribution of spontaneous improvement and of placebo were $24 \%$ and $20 \%$ respectively (283).

Several categories of pharmacological agents are used for therapy of FGIDs, especially in adults. Nonpsychotropic agents are directed to amine receptors, such as serotonin, acetylcholine (muscarinic), adrenaline and dopamine receptors, or to peptide receptors, such as the motilin receptor agonist erythromycin. Serotonine (5-hydroxytryptamine, 5-HT) plays a key-role in the control of gastrointestinal motility, sensitivity and secretion. Drugs with activity at 5-HT receptors are used for patients with IBS, $5-\mathrm{HT}_{3}$ receptor antagonists in patients with diarrhea-predominant IBS and 5- $\mathrm{HT}_{4}$ receptor agonists in constipation-predominant IBS (284). Several important pitfalls are recognized as to the principle of drug selectivity. First, drug selectivity is a relative concept, because many molecules have several biological targets. Second, because of the multifactorial pathophysiology of FGIDs a single-receptor modulating drug may be less likely to achieve a substantial therapeutic effect. Moreover, the mechanisms responsible for symptoms in FGIDs may differ from patient to patient and a single target may not achieve adequate efficacy in a patient population. Because of these limitations, relieving symptoms with $5-\mathrm{HT}_{3}$ receptor antagonists or $5-\mathrm{HT}_{4}$ receptor agonists is achieved in less than $70 \%$ of patients (284).

Two other classes of nonpsychotropic agents that are commonly used in FGIDs are laxatives, of which the highly selective $5-\mathrm{HT}_{4}$ agonist prucalopride is the most recent promising agent, and probiotics (lactobacillus and bifidobacterium), of which 
Bifidobacterium infantis is reported to alleviate symptoms in IBS (284-288).

Psychotropic agents are used to treat patients with IBS, the most important being tricyclic antidepressants and selective serotonin re-uptake inhibitors (SSRIs). Controlled studies with these drugs show trends towards improvement of complaints, but these results are not statistically significant ${ }^{(284)}$.

Table Organic causes of recurrent abdominal pain

\section{GASTROINTESTINAL DISEASE}

Inflammation/infection

gastroesophageal reflux (289-291)

gastritis (e.g. Helicobacter pylori, Crohn's disease, collagenous gastritis) $(108 ; 135 ; 136 ; 292 ; 293)$

eosinophilic oesophagitis, gastroenteritis or colitis $(231 ; 294-296)$

peptic ulcer (297-301)

yersinia/campylobacter jejuni infection $(144 ; 146 ; 147 ; 302)$

intestinal parasites (protozoa, ascaris, toxocara) $(70 ; 71 ; 85 ; 303-306)$

nodular lymphoid hyperplasia (307)

chronic appendicitis $(234-237 ; 241)$

appendiceal colics/appendicopathy (242;247;249;250;256;257)

inflammatory bowel disease (ileitis terminalis: Crohn's disease, yersinia, tuberculosis; colitis)

Meckel diverticulum

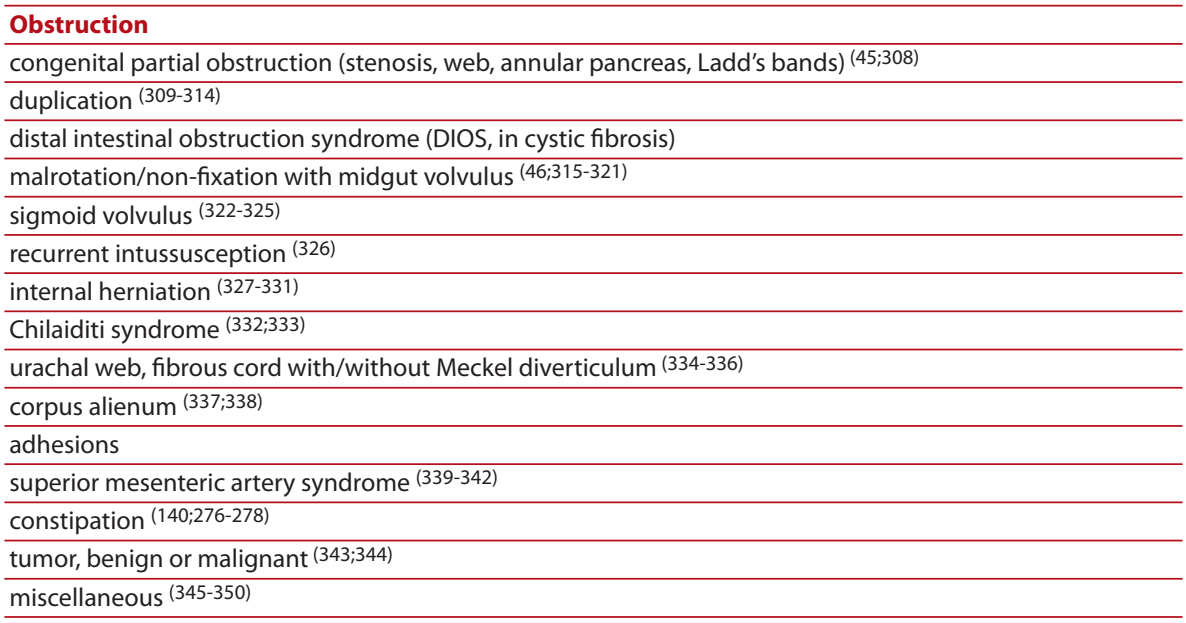

\section{Food intolerance}

food allergy/food intolerance (214-216;226;228,351)

carbohydrate intolerance: lactose $(155 ; 167 ; 174)$, fructose and FODMAPs $(197 ; 198 ; 352)$

celiac disease $(205 ; 206 ; 213)$

\section{Gastrointestinal miscellaneous}

aerophagia (353)

bacterial contamination of the small intestine (354;355)

pancreatic metaplasia of gastric mucosa ${ }^{(356)}$

duodenal heterotopic pancreas (357) 


\section{DISEASES OF LIVER, BILE DUCTS AND SPLEEN}

gallstone (358-360)

bile duct cysts (361-364)

abnormal pancreatic bile duct junction (365-369)

common bile duct obstruction

biliary dyskinesia (370-373)

hepatomegaly, M Wilson (374)

splenomegaly

heart failure

wandering spleen with torsion (375-378)

miscellaneous (379-382)

\section{PANCREAS}

chronic recurrent pancreatitis $(41 ; 383-390)$

pancreas divisum ${ }^{(391)}$

annular pancreas (392)

pseudocyst

idiopathic fibrosing pancreatitis (393;394)

cystic fibrosis (recurrent pancreatitis/hepatobiliary disease/distal intestinal obstruction syndrome, DIOS)

(384;395-397)

duplication cyst of pancreas (398)

\section{DISEASES OF THE GENITOURINARY TRACT}

hydronephrosis (ureteropelvic junction obstruction and other) (43;399-401)

stones, microlithiasis (402-406)

hypercalciuria, hyperuricosuria $(406 ; 407)$

infections

tumour urinary tract

miscellaneous renal malformations (408)

dysmenorrhoe

endometriosis (409-412)

ovarium cyst ${ }^{(40)}$

pregnancy

haematocolpos

gynaecological tumour (413-416)

miscellaneous gynaecological disorders (417)

\section{DISEASES OF THE PERITONEUM AND ABDOMINAL WALL}

diseases of the abdominal wall, ACNES (418-420)

mesenteric lymphadenitis

adhesions (421)

panniculitis (Weber Christian disease)

sclerosing mesenteritis (422)

familial mediterranean fever (FMF) (423;424)

miscellaneous (425) 


\section{VASCULAR DISEASES}

migraine abdominal (27;262-265;267;268;271;426;427)

anaphylactic purpura (Henoch Schönlein disease)

hypertensive crises (428)

sickle cell crises

nephrotic syndrome: hypovolemia

mesenterial thrombosis, superior mesenteric artery thrombosis (429)

ischemic disease (430;431)

celiac artery compression syndrome ${ }^{(432-434)}$

malrotation/non-fixation with midgut volvulus

\section{EXTRA-ABDOMINAL DISEASE}

intrathoracic pathology

vertebral osteomyelitis/discitis (435-439)

epidural abscess

intra/extraspinal tumor (42;440-443)

vertebral arthritis with radiculitis

psoas abscess

abdominal epilepsy (272-275;444;445)

arthritis (446)

\section{METABOLIC/ENDOCRINE DISEASE}

porphyria (447)

lead poisoning

hereditary fructose intolerance

hyperlipidemia (448;449)

hyperparathyrioidism

urea cycle disorders, e.g. ornithine transcarbamylase deficiency ${ }^{(450)}$

Fabry disease (451)

\section{OTHER}

rheumatic fever

juvenile rheumatoid arthritis

dermatomyositis (452)

systemic lupus erythematosus

polyarteritis nodosa

c1-esterase inhibitor deficiency (453-457)

hemophilia: bleeding in intestinal wall or retroperitoneal bleeding

hemolytic anemias

adverse reactions to drugs 


\section{REFERENCE LIST}

(1) Apley J, Naish N. Recurrent abdominal pains: a field survey of 1,000 school children. Arch Dis Child 1958;33:165-70.

(2) Di Lorenzo C, Colletti RB, Lehmann HP, Boyle JT, Gerson WT, Hyams JS, et al. Chronic Abdominal Pain In Children: a Technical Report of the American Academy of Pediatrics and the North American Society for Pediatric Gastroenterology, Hepatology and Nutrition. J Pediatr Gastroenterol Nutr 2005;40:249-61.

(3) Apley J, Hale B. Children with recurrent abdominal pain: how do they grow up? Br Med J 1973;3:7-9.

(4) Manning AP, Thompson WG, Heaton KW, Morris AF. Towards positive diagnosis of the irritable bowel. Br Med J 1978;2:653-4.

(5) Kruis W, Thieme C, Weinzierl M, Schussler P, Holl J, Paulus W. A diagnostic score for the irritable bowel syndrome. Its value in the exclusion of organic disease. Gastroenterology 1984;87:1-7.

(6) Talley NJ, Phillips SF, Melton LJ, Mulvihill C, Wiltgen C, Zinsmeister AR. Diagnostic value of the Manning criteria in irritable bowel syndrome. Gut 1990;31:77-81.

(7) Jeong H, Lee HR, Yoo BC, Park SM. Manning criteria in irritable bowel syndrome: its diagnostic significance. Korean J Intern Med 1993;8:34-9.

(8) Frigerio G, Beretta A, Orsenigo G, Tadeo G, Imperiali G, Minoli G. Irritable bowel syndrome. Still far from a positive diagnosis. Dig Dis Sci 1992;37:164-7.

(9) Drossman DA, Thompson WG, Talley NJ, Funch-Jensen P, Janssens J, Whitehead WE. Identification of sub-groups of functional gastrointestinal disorders. Gastroenterology International 1990;3:159-72.

(10) Thompson WG, Creed F, Drossman DA, Heaton KW, Mazzacca G. Functional bowel disease and functional abdominal pain. Gastroenterology International 1992;5:75-91.

(11) Thompson WG, Longstreth GF, Drossman DA, Heaton KW, Irvine EJ, Muller-Lissner SA. Functional bowel disorders and functional abdominal pain. Gut 1999;45 Suppl 2:I143-II47.

(12) Longstreth GF, Thompson WG, Chey WD, Houghton LA, Mearin F, Spiller RC. Functional bowel disorders. Gastroenterology 2006;130:1480-91.

(13) Tack J, Talley NJ, Camilleri M, Holtmann G, Hu P, Malagelada JR, et al. Functional gastroduodenal disorders. Gastroenterology 2006;130:1466-79.

(14) Clouse RE, Mayer EA, Aziz Q, Drossman DA, Dumitrascu DL, Monnikes H, et al. Functional abdominal pain syndrome. Gastroenterology 2006;130:1492-7.

(15) Whitehead WE, Palsson OS, Feld AD, Levy RL, VON KM, Turner MJ, et al. Utility of red flag symptom exclusions in the diagnosis of irritable bowel syndrome. Aliment Pharmacol Ther 2006;24:137-46.

(16) Ford AC, Talley NJ, Veldhuyzen van Zanten SJ, Vakil NB, Simel DL, Moayyedi P. Will the history and physical examination help establish that irritable bowel syndrome is causing this patient's lower gastrointestinal tract symptoms? JAMA 2008;300:1793-805.

(17) Jellema P, van der Windt DA, Schellevis FG, van der Horst HE. Systematic review: accuracy of symptom-based criteria for diagnosis of irritable bowel syndrome in primary care. Aliment Pharmacol Ther 2009;30:695-706.

(18) Tibble JA, Sigthorsson G, Foster R, Forgacs I, Bjarnason I. Use of surrogate markers of inflammation and Rome criteria to distinguish organic from nonorganic intestinal disease. Gastroenterology 2002;123:450-60.

(19) Spiller R, Camilleri M, Longstreth GF. Do the symptom-based, Rome criteria of irritable bowel syndrome lead to better diagnosis and treatment outcomes? Clin Gastroenterol Hepatol 2010;8:125-9.

(20) Camilleri M. Do the Symptom-Based, Rome Criteria of Irritable Bowel Syndrome Lead to Better Diagnosis and Treatment Outcomes? The Con Argument. Clin Gastroenterol Hepatol 2009;8:129.

(21) Quigley EM. The 'con' case. The Rome process and functional gastrointestinal disorders: the barbarians are at the gate! Neurogastroenterol Motil 2007;19:793-7.

(22) Oberlander TF, Rappaport LA. Recurrent abdominal pain during childhood. Pediatr Rev 1993;14:313-9.

(23) Boyle JT. Recurrent abdominal pain: an update. Pediatr Rev 1997;18:310-20. 
(24) Hyams JS, Burke G, Davis PM, Rzepski B, Andrulonis PA. Abdominal pain and irritable bowel syndrome in adolescents: a community- based study. J Pediatr 1996;129:220-6.

(25) Walker LS, Guite JW, Duke M, Barnard JA, Greene JW. Recurrent abdominal pain: a potential precursor of irritable bowel syndrome in adolescents and young adults. J Pediatr 1998;132:1010-5.

(26) Rasquin-Weber A, Hyman PE, Cucchiara S, Fleisher DR, Hyams JS, Milla PJ, et al. Childhood functional gastrointestinal disorders. Gut 1999;45 Suppl 2:I160-II68.

(27) Rasquin A, Di Lorenzo C, Forbes D, Guiraldes E, Hyams JS, Staiano A, et al. Childhood functional gastrointestinal disorders: child/adolescent. Gastroenterology 2006;130:1527-37.

(28) Talley NJ, Phillips SF, Wiltgen CM, Zinsmeister AR, Melton LJ, III. Assessment of functional gastrointestinal disease: the bowel disease questionnaire. Mayo Clin Proc 1990;65:1456-79.

(29) Øster J. Recurrent abdominal pain, headache and limb pains in children and adolescents. Pediatrics 1972;50:429-36.

(30) Hultin H, Langinvainio H, Kilpinen C, Aura M. Recurrent indeterminate abdominal pain in schoolchildren in Helsinki at a conventional school and at the Waldorf school. Offentl Gesundheitswes 1984;46:25-9.

(31) Boey C, Yap S, Goh KL. The prevalence of recurrent abdominal pain in 11- to 16-year-old Malaysian schoolchildren. J Paediatr Child Health 2000;36:114-6.

(32) Wyllie R, Kay M. Causes of recurrent abdominal pain [editorial]. Clin Pediatr (Phila) 1993;32:369-71.

(33) Chitkara DK, Rawat DJ, Talley NJ. The epidemiology of childhood recurrent abdominal pain in Western countries: a systematic review. Am J Gastroenterol 2005;100:1868-75.

(34) Stone RT, Barbero GJ. Recurrent abdominal pain in childhood. Pediatrics 1970;45:732-8.

(35) Christensen MF, Mortensen O. Long-term prognosis in children with recurrent abdominal pain. Arch Dis Child 1975;50:110-4.

(36) Liebman WM. Recurrent abdominal pain in children: a retrospective survey of 119 patients. Clin Pediatr (Phila) 1978;17:149-53.

(37) Stickler GB, Murphy DB. Recurrent abdominal pain. Am J Dis Child 1979;133:486-9.

(38) Bury RG. A study of 111 children with recurrent abdominal pain. Aust Paediatr J 1987;23:117-9.

(39) Magni G, Pierri M, Donzelli F. Recurrent abdominal pain in children: a long term follow-up. Eur J Pediatr 1987;146:72-4.

(40) Ahmed S. Ovarian cysts in childhood. Aust N Z J Surg 1975;45:398-404.

(41) Black PR, Welch KJ, Eraklis AJ. Juxtapancreatic intestinal duplications with pancreatic ductal communication: a cause of pancreatitis and recurrent abdominal pain in childhood. J Pediatr Surg 1986;21:257-61.

(42) Buck E, Bodensteiner J. Thoracic cord tumor appearing as recurrent abdominal pain. Am J Dis Child 1981;135:574-5.

(43) Byrne WJ, Arnold WC, Stannard MW, Redman JF. Ureteropelvic junction obstruction presenting with recurrent abdominal pain: diagnosis by ultrasound. Pediatrics 1985;76:934-7.

(44) Chaussain M, Kheddari K, Roche R, Giusti B, Habib F, Badoual J, et al. Abdominal pain in children caused by lactose intolerance. Prospective use of the hydrogen breath test. Presse Med 1994;23:881-5.

(45) Ellenberg DJ, delCastillo J. Duodenal obstruction from peritoneal (Ladd's) bands in a ten-year-old child. Ann Emerg Med 1984;13:56-9.

(46) Knudtzon J, Svane S. Chronic recurrent abdominal pain in childhood due to mesenterium ileocolicum commune. Two cases with normal rotation of the intestine. Acta Chir Scand 1985;151:291-5.

(47) Gieteling MJ, Bierma-Zeinstra SM, Passchier J, Berger MY. Prognosis of chronic or recurrent abdominal pain in children. J Pediatr Gastroenterol Nutr 2008;47:316-26.

(48) Gieteling MJ, Bierma-Zeinstra SM, van LY, Passchier J, Berger MY. Prognostic factors for persistence of chronic abdominal pain in children. J Pediatr Gastroenterol Nutr 2011;52:154-61.

(49) Chitkara DK, van Tilburg MA, Blois-Martin N, Whitehead WE. Early life risk factors that contribute to irritable bowel syndrome in adults: a systematic review. Am J Gastroenterol 2008;103:765-74. 
(50) Mulvaney S, Lambert EW, Garber J, Walker LS. Trajectories of symptoms and impairment for pediatric patients with functional abdominal pain: a 5-year longitudinal study. J Am Acad Child Adolesc Psychiatry 2006;45:737-44.

(51) Mendall MA, Kumar D. Antibiotic use, childhood affluence and irritable bowel syndrome (IBS). Eur J Gastroenterol Hepatol 1998;10:59-62.

(52) Howell S, Talley NJ, Quine S, Poulton R. The irritable bowel syndrome has origins in the childhood socioeconomic environment. Am J Gastroenterol 2004;99:1572-8.

(53) Gwee KA. Irritable bowel syndrome in developing countries--a disorder of civilization or colonization? Neurogastroenterol Motil 2005;17:317-24.

(54) Levy RL, Jones KR, Whitehead WE, Feld SI, Talley NJ, Corey LA. Irritable bowel syndrome in twins: heredity and social learning both contribute to etiology. Gastroenterology 2001;121:799-804.

(55) Levy RL, Whitehead WE, Walker LS, VON KM, Feld AD, Garner M, et al. Increased somatic complaints and health-care utilization in children: effects of parent IBS status and parent response to gastrointestinal symptoms. Am J Gastroenterol 2004;99:2442-51.

(56) Walker LS, Williams SE, Smith CA, Garber J, Van Slyke DA, Lipani TA. Parent attention versus distraction: impact on symptom complaints by children with and without chronic functional abdominal pain. Pain 2006;122:43-52.

(57) Youssef NN, Murphy TG, Langseder AL, Rosh JR. Quality of life for children with functional abdominal pain: a comparison study of patients' and parents' perceptions. Pediatrics 2006;117:54-9.

(58) Varni JW, Lane MM, Burwinkle TM, Fontaine EN, Youssef NN, Schwimmer JB, et al. Health-related quality of life in pediatric patients with irritable bowel syndrome: a comparative analysis. J Dev Behav Pediatr 2006;27:451-8.

(59) Youssef NN, Atienza K, Langseder AL, Strauss RS. Chronic abdominal pain and depressive symptoms: analysis of the national longitudinal study of adolescent health. Clin Gastroenterol Hepatol 2008;6:329-32.

(60) Huntley ED, Campo JV, Dahl RE, Lewin DS. Sleep characteristics of youth with functional abdominal pain and a healthy comparison group. J Pediatr Psychol 2007;32:938-49.

(61) Spiegel B, Schoenfeld P, Naliboff B. Systematic review: the prevalence of suicidal behaviour in patients with chronic abdominal pain and irritable bowel syndrome. Aliment Pharmacol Ther 2007;26:183-93.

(62) Greco LA, Freeman KE, Dufton L. Overt and relational victimization among children with frequent abdominal pain: links to social skills, academic functioning, and health service use. J Pediatr Psychol 2007;32:319-29.

(63) Wells NE, Hahn BA, Whorwell PJ. Clinical economics review: irritable bowel syndrome. Aliment Pharmacol Ther 1997;11:1019-30.

(64) Nyrop KA, Palsson OS, Levy RL, Korff MV, Feld AD, Turner MJ, et al. Costs of health care for irritable bowel syndrome, chronic constipation, functional diarrhoea and functional abdominal pain. Aliment Pharmacol Ther 2007;26:237-48.

(65) Dhroove G, Chogle A, Saps M. A million-dollar work-up for abdominal pain: is it worth it? J Pediatr Gastroenterol Nutr 2010;51:579-83.

(66) Kellow JE, Azpiroz F, Delvaux M, Gebhart GF, Mertz HR, Quigley EM, et al. Applied principles of neurogastroenterology: physiology/motility sensation. Gastroenterology 2006;130:1412-20.

(67) Veldhuyzen van Zanten SJO, Talley NJ, Bytzer P, Klein KB, Whorwell PJ, Zinsmeister AR. Design of treatment trials for functional gastrointestinal disorders. Gut 1999;45:69-77.

(68) Spiller RC. Problems and challenges in the design of irritable bowel syndrome clinical trials: experience from published trials. Am J Med 1999;107:91S-7S.

(69) Stenzel DJ, Boreham PF. Blastocystis hominis revisited. Clin Microbiol Rev 1996;9:563-84.

(70) Vandenberg O, Peek R, Souayah H, Dediste A, Buset M, Scheen R, et al. Clinical and microbiological features of dientamoebiasis in patients suspected of suffering from a parasitic gastrointestinal illness: a comparison of Dientamoeba fragilis and Giardia lamblia infections. Int J Infect Dis 2006;10:255-61. 
(71) Stark D, Barratt J, Roberts T, Marriott D, Harkness J, Ellis J. A review of the clinical presentation of dientamoebiasis. Am J Trop Med Hyg 2010;82:614-9.

(72) Alexeieff A. Sur la nature des formations dites "kystes de Trichomonas intestinalis". C R Soc Biol 1911;71:296-8.

(73) Jepps MW, Dobell C. Dientamoeba fragilis n.g.,n.sp.,new intestinal amoeba from man. Parasitology 1918;10:352-67.

(74) Yang J, Scholten T. Dientamoeba fragilis: a review with notes on its epidemiology, pathogenicity, mode of transmission, and diagnosis. Am J Trop Med Hyg 1977;26:16-22.

(75) Qadri SM, al Okaili GA, al Dayel F. Clinical significance of Blastocystis hominis. J Clin Microbiol 1989;27:2407-9.

(76) Preiss U, Ockert G, Broemme S, Otto A. On the clinical importance of Dientamoeba fragilis infections in childhood. J Hyg Epidemiol Microbiol Immunol 1991;35:27-34.

(77) Telalbasic S, Pikula ZP, Kapidzic M. Blastocystis hominis may be a potential cause of intestinal disease. Scand J Infect Dis 1991;23:389-90.

(78) Norberg A, Nord CE, Evengard B. Dientamoeba fragilis--a protozoal infection which may cause severe bowel distress. Clin Microbiol Infect 2003;9:65-8.

(79) Grazioli B, Matera G, Laratta C, Schipani G, Guarnieri G, Spiniello E, et al. Giardia lamblia infection in patients with irritable bowel syndrome and dyspepsia: a prospective study. World J Gastroenterol 2006;12:1941-4.

(80) Kaya S, Cetin ES, Aridogan BC, Arikan S, Demirci M. Pathogenicity of Blastocystis hominis, a clinical reevaluation. Turkiye Parazitol Derg 2007;31:184-7.

(81) Soon GS, Saunders N, Ipp M, Sherman PM, Macarthur C. Community-based case-control study of childhood chronic abdominal pain: role of selected laboratory investigations. J Pediatr Gastroenterol Nutr 2007;44:524-6.

(82) Yakoob J, Jafri W, Beg MA, Abbas Z, Naz S, Islam M, et al. Blastocystis hominis and Dientamoeba fragilis in patients fulfilling irritable bowel syndrome criteria. Parasitol Res 2010;107:679-84.

(83) Borody TJ, Warren EF, Wettstein A, Robertson G, Recabarren P, Fontela A, et al. Eradication of dientamoeba fragilis can resolve IBS-like symptoms. J Gastroenterol Hepatol 2002;17:A103.

(84) D'Anchino M, Orlando D, De FL. Giardia lamblia infections become clinically evident by eliciting symptoms of irritable bowel syndrome. J Infect 2002;45:169-72.

(85) Stark D, van HS, Marriott D, Ellis J, Harkness J. Irritable bowel syndrome: a review on the role of intestinal protozoa and the importance of their detection and diagnosis. Int J Parasitol 2007;37:11-20.

(86) Cerva L, Schrottenbaum M, Kliment V. Intestinal parasites: a study of human appendices. Folia Parasitol (Praha) 1991;38:5-9.

(87) Schwartz MD, Nelson ME. Dientamoeba fragilis infection presenting to the emergency department as acute appendicitis. J Emerg Med 2003;25:17-21.

(88) Andiran N, Acikgoz ZC, Turkay S, Andiran F. Blastocystis hominis--an emerging and imitating cause of acute abdomen in children. J Pediatr Surg 2006;41:1489-91.

(89) Deniz K, Sokmensuer LK, Sokmensuer C, Patiroglu TE. Significance of intraepithelial lymphocytes in appendix. Pathol Res Pract 2007;203:731-5.

(90) Shein R, Gelb A. Colitis due to Dientamoeba fragilis. Am J Gastroenterol 1983;78:634-6.

(91) Yamamoto-Furusho JK, Torijano-Carrera E. Intestinal protozoa infections among patients with ulcerative colitis: prevalence and impact on clinical disease course. Digestion 2010;82:18-23.

(92) Bosman DK, Benninga MA, van de BP, Kooijman GC, van Gool T. Dientamoeba fragilis: possibly an important cause of persistent abdominal pain in children. Ned Tijdschr Geneeskd 2004;148:575-9.

(93) Vandenberg O, Souayah H, Mouchet F, Dediste A, van Gool T. Treatment of Dientamoeba fragilis infection with paromomycin. Pediatr Infect Dis J 2007;26:88-90.

(94) Spencer MJ, Garcia LS, Chapin MR. Dientamoeba fragilis. An intestinal pathogen in children? Am J Dis Child 1979;133:390-3. 
(95) Spencer MJ, Millet VE, Garcia LS, Rhee L, Masterson L. Parasitic infections in a pediatric population. Pediatr Infect Dis 1983;2:110-3.

(96) Preiss U, Ockert G, Bromme S, Otto A. Dientamoeba fragilis infection, a cause of gastrointestinal symptoms in childhood. Klin Padiatr 1990;202:120-3.

(97) Johnson EH, Windsor JJ, Clark CG. Emerging from obscurity: biological, clinical, and diagnostic aspects of Dientamoeba fragilis. Clin Microbiol Rev 2004;17:553-70.

(98) Ito R, Sakagami J, Kataoka K, Nakamura H, Motoyoshi T, Takada R, et al. Chronic diarrhea and protein-losing gastroenteropathy caused by Dientamoeba fragilis. J Gastroenterol 2004;39:1117-9.

(99) Windsor JJ, Macfarlane L. Irritable bowel syndrome: the need to exclude Dientamoeba fragilis. Am J Trop Med Hyg 2005;72:501-2.

(100) Lagace-Wiens PR, VanCaeseele PG, Koschik C. Dientamoeba fragilis: an emerging role in intestinal disease. CMAJ 2006;175:468-9.

(101) Stark DJ, Beebe N, Marriott D, Ellis JT, Harkness J. Dientamoebiasis: clinical importance and recent advances. Trends Parasitol 2006;22:92-6.

(102) Kurt O, Girginkardesler N, Balcioglu IC, Ozbilgin A, Ok UZ. A comparison of metronidazole and single-dose ornidazole for the treatment of dientamoebiasis. Clin Microbiol Infect 2008;14:601-4.

(103) Hussein EM, Al-Mohammed HI, Hussein AM. Genetic diversity of Dientamoeba fragilis isolates of irritable bowel syndrome patients by high-resolution melting-curve (HRM) analysis. Parasitol Res 2009;105:1053-60.

(104) Heyland K, Friedt M, Buehr P, Braegger CP. No advantage for antibiotic treatment over placebo in Blastocystis hominis-positive children with recurrent abdominal pain. J Pediatr Gastroenterol Nutr 2012;54:677-9.

(105) Hardikar W, Feekery C, Smith A, Oberklaid F, Grimwood K. Helicobacter pylori and recurrent abdominal pain in children. J Pediatr Gastroenterol Nutr 1996;22:148-52.

(106) Wewer V, Andersen LP, Paerregaard A, Gernow AB, Hart Hansen JP, Matzen P, et al. The prevalence and related symptomatology of Helicobacter pylori in children with recurrent abdominal pain. Acta Paediatr 1998;87:830-5.

(107) Rowland M, Daly L, Vaughan M, Higgins A, Bourke B, Drumm B. Age-specific incidence of Helicobacter pylori. Gastroenterology 2006;130:65-72.

(108) Koletzko S, Jones NL, Goodman KJ, Gold B, Rowland M, Cadranel S, et al. Evidence-based guidelines from ESPGHAN and NASPGHAN for Helicobacter pylori infection in children. J Pediatr Gastroenterol Nutr 2011;53:230-43.

(109) Tindberg Y, Blennow M, Granstrom M. Clinical symptoms and social factors in a cohort of children spontaneously clearing Helicobacter pylori infection. Acta Paediatr 1999;88:631-5.

(110) Ashorn M, Rago T, Kokkonen J, Ruuska T, Rautelin H, Karikoski R. Symptomatic response to Helicobacter pylori eradication in children with recurrent abdominal pain: double blind randomized placebo-controlled trial. J Clin Gastroenterol 2004;38:646-50.

(111) Duque X, Vilchis J, Mera R, Trejo-Valdivia B, Goodman KJ, Mendoza ME, et al. Natural History of Helicobacter pylori Infection in Mexican Schoolchildren: Incidence and Spontaneous Clearance. J Pediatr Gastroenterol Nutr 2012.

(112) Elitsur Y, Dementieva Y, Rewalt M, Lawrence Z. Helicobacter pylori infection rate decreases in symptomatic children: a retrospective analysis of 13 years (1993-2005) from a gastroenterology clinic in West Virginia. J Clin Gastroenterol 2009;43:147-51.

(113) Bujanover Y, Konikoff F, Baratz M. Nodular gastritis and Helicobacter pylori. J Pediatr Gastroenterol Nutr 1990;11:41-4.

(114) Blecker U, Lanciers S, Peeters S, Vandenplas Y. Helicobacter pylori infections in children. Tijdschr Kindergeneeskd 1992;60:35-9.

(115) Mahony MJ, Wyatt Jl, Littlewood JM. Management and response to treatment of Helicobacter pylori gastritis. Arch Dis Child 1992;67:940-3. 
(116) Quak SH, Wee A, Quah TC, Quek SC, Lam SK. Helicobacter pylori infection in children with recurrent abdominal pain. Ann Trop Paediatr 1994;14:267-70.

(117) Wewer V, Christiansen KM, Andersen LP, Henriksen FW, Hansen JP, Tvede M, et al. Helicobacter pylori infection in children with recurrent abdominal pain. Acta Paediatr 1994;83:1276-81.

(118) Lamireau T, Rigot A, Megraud F, de Mascarel A. Helicobacter pylori gastritis in children. Arch Pediatr 1995;2:310-6.

(119) Chong SK, Lou Q, Asnicar MA, Zimmerman SE, Croffie JM, Lee CH, et al. Helicobacter pylori infection in recurrent abdominal pain in childhood: comparison of diagnostic tests and therapy. Pediatrics 1995;96:211-5.

(120) Heldenberg D, Wagner Y, Heldenberg E, Keren S, Auslaender L, Kaufshtein M, et al. The role of Helicobacter pylori in children with recurrent abdominal pain. Am J Gastroenterol 1995;90:906-9.

(121) Aanpreung P, Atisook K, Suwangool P, Theerabutra C, Vajaradul C. Helicobacter pylori infection in Thai children with recurrent abdominal pain. J Med Assoc Thai 1996;79:137-41.

(122) Oderda G, Vaira D, Holton J, Dowsett JF, Ansaldi N. Serum pepsinogen I and IgG antibody to Campylobacter pylori in non- specific abdominal pain in childhood. Gut 1989;30:912-6.

(123) Fiedorek SC, Casteel HB, Pumphrey CL, Evans DJ, Jr., Evans DG, Klein PD, et al. The role of Helicobacter pylori in recurrent, functional abdominal pain in children. Am J Gastroenterol 1992;87:347-9.

(124) Andersen LP, Wewer AV, Christiansen KM, Tvede M, Hansen JP, Henriksen FW, et al. The humoral immune response to Helicobacter pylori infection in children with recurrent abdominal pain. APMIS 1994;102:457-64.

(125) Benhamou PH, Kalach N, Raymond J, Abdallah C, Dupont C. Helicobacter pylori gastric infections in children. Presse Med 1994;23:1703-7.

(126) Blecker U, Mehta DI, Lanciers S, Dahodwala ID, Lebenthal E. Low incidence of Helicobacter pylori infection in children with recurrent abdominal pain in Philadelphia. Pediatrics 1995;95:618.

(127) Maherzi A, Fendri C, Ben Jilani S, Bousnina S. Symptomatic Helicobacter pylori infection: prospective study of epidemiological, diagnostic and therapeutic aspects in children in Tunisia. Arch Pediatr 1996;3:329-34.

(128) Yoshida NR, Webber EM, Fraser RB, Ste-Marie MT, Giacomantonio JM. Helicobacter pylori is not associated with nonspecific abdominal pain in children. J Pediatr Surg 1996;31:747-9.

(129) Roma E, Panayiotou J, Kafritsa Y, Van Vliet C, Gianoulia A, Constantopoulos A. Upper gastrointestinal disease, Helicobacter pylori and recurrent abdominal pain. Acta Paediatr 1999;88:598-601.

(130) McCallion WA, Bailie AG, Ardill JE, Bamford KB, Potts SR, Boston VE. Helicobacter pylori, hypergastrinaemia, and recurrent abdominal pain in children. J Pediatr Surg 1995;30:427-9.

(131) O'Donohoe JM, Sullivan PB, Scott R, Rogers T, Brueton MJ, Barltrop D. Recurrent abdominal pain and Helicobacter pylori in a community-based sample of London children. Acta Paediatr 1996;85:961-4.

(132) Bansal D, Patwari AK, Malhotra VL, Malhotra V, Anand VK. Helicobacter pylori infection in recurrent abdominal pain. Indian Pediatr 1998;35:329-35.

(133) Gunel E, Findik D, Caglayan O, Caglayan F, Topgac Z. Helicobacter pylori and hypergastrinemia in children with recurrent abdominal pain. Pediatr Surg Int 1998;14:40-2.

(134) Macarthur C, Saunders N, Feldman W, Ipp M, Winders-Lee P, Roberts S, et al. Helicobacter pylori and childhood recurrent abdominal pain: community based case-control study. BMJ 1999;319:822-3.

(135) Malfertheiner P, Megraud F, O'Morain C, Bazzoli F, El-Omar E, Graham D, et al. Current concepts in the management of Helicobacter pylori infection: the Maastricht III Consensus Report. Gut 2007;56:772-81.

(136) Spee LA, Madderom MB, Pijpers M, van LY, Berger MY. Association between helicobacter pylori and gastrointestinal symptoms in children. Pediatrics 2010;125:e651-e669.

(137) Bode G, Brenner H, Adler G, Rothenbacher D. Recurrent abdominal pain in children: evidence from a population-based study that social and familial factors play a major role but not Helicobacter pylori infection. J Psychosom Res 2003;54:417-21. 
(138) Tindberg Y, Nyren O, Blennow M, Granstrom M. Helicobacter pylori infection and abdominal symptoms among Swedish school children. J Pediatr Gastroenterol Nutr 2005;41:33-8.

(139) Ozen H, Dinler G, Akyon Y, Kocak N, Yuce A, Gurakan F. Helicobacter pylori infection and recurrent abdominal pain in Turkish children. Helicobacter 2001;6:234-8.

(140) Alfvén G. One hundred cases of recurrent abdominal pain in children: diagnostic procedures and criteria for a psychosomatic diagnosis. Acta Paediatr 2003;92:43-9.

(141) Das BK, Kakkar S, Dixit VK, Kumar M, Nath G, Mishra OP. Helicobacter pylori infection and recurrent abdominal pain in children. J Trop Pediatr 2003;49:250-2.

(142) Ukarapol N, Lertprasertsuk N, Wongsawasdi L. Recurrent abdominal pain in children: the utility of upper endoscopy and histopathology. Singapore Med J 2004;45:121-4.

(143) Shamaly H, Berkowitz D, Rosenthal E, Naveh Y. Efficacy of bismuth-based triple therapy in children with abdominal pain and Helicobacter pylori gastritis. J Pediatr Gastroenterol Nutr 2000;30:198-200.

(144) Hoogkamp-Korstanje JA, de KJ, Heesemann J. Persistence of Yersinia enterocolitica in man. Infection 1988;16:81-5.

(145) Hoogkamp-Korstanje JA, de Koning J. [Yersinia enterocolitica infections; clinical and histological characteristics, diagnosis and therapy]. Ned Tijdschr Geneeskd 1991;135:2218-23.

(146) Hoogkamp-Korstanje JAA, Stolk-Engelaar VMM. Yersinia enterocolitica infection in children. Pediatr Infect Dis J 1995;14:771-5.

(147) Saebo A, Lassen J. Acute and chronic gastrointestinal manifestations associated with Yersinia enterocolitica infection. A Norwegian 10-year follow-up study on 458 hospitalized patients. Ann Surg 1992;215:250-5.

(148) Saavedra JM, Perman JA. Current concepts in lactose malabsorption and intolerance. Annu Rev Nutr 1989;9:475-502.

(149) Bayless TM, Huang SS. Recurrent abdominal pain due to milk and lactose intolerance in school- aged children. Pediatrics 1971;47:1029-32.

(150) Barr RG, Levine MD, Watkins JB. Recurrent abdominal pain of childhood due to lactose intolerance. N Engl J Med 1979;300:1449-52.

(151) Wald A, Chandra R, Fisher SE, Gartner JC, Zitelli B. Lactose malabsorption in recurrent abdominal pain of childhood. J Pediatr 1982;100:65-8.

(152) Ceriani R, Zuccato E, Fontana M, Zuin G, Ferrari L, Principi N, et al. Lactose malabsorption and recurrent abdominal pain in Italian children. J Pediatr Gastroenterol Nutr 1988;7:852-7.

(153) Webster RB, DiPalma JA, Gremse DA. Lactose maldigestion and recurrent abdominal pain in children. Dig Dis Sci 1995;40:1506-10.

(154) Shaw AD, Davies GJ. Lactose intolerance: problems in diagnosis and treatment. J Clin Gastroenterol 1999;28:208-16.

(155) Böhmer CJ, Tuynman HA. The effect of a lactose-restricted diet in patients with a positive lactose tolerance test, earlier diagnosed as irritable bowel syndrome: a 5-year follow-up study. Eur J Gastroenterol Hepatol 2001;13:941-4.

(156) Gremse DA, Greer AS, Vacik J, DiPalma JA. Abdominal pain associated with lactose ingestion in children with lactose intolerance. Clin Pediatr (Phila) 2003;42:341-5.

(157) Savaiano DA, Boushey CJ, McCabe GP. Lactose intolerance symptoms assessed by meta-analysis: a grain of truth that leads to exaggeration. J Nutr 2006;136:1107-13.

(158) Gudmand-Hoyer E. The clinical significance of disaccharide maldigestion. Am J Clin Nutr 1994;59:735S-41S.

(159) Gasbarrini A, Corazza GR, Gasbarrini G, Montalto M, Di SM, Basilisco G, et al. Methodology and indications of $\mathrm{H}_{2}$-breath testing in gastrointestinal diseases: the Rome Consensus Conference. Aliment Pharmacol Ther 2009;29 Suppl 1:1-49.

(160) Veligati LN, Treem WR, Sullivan B, Burke G, Hyams JS. Delta 10 ppm versus delta 20 ppm: a reappraisal of diagnostic criteria for breath hydrogen testing in children. Am J Gastroenterol 1994;89:758-61. 
(161) Blumenthal I, Kelleher J, Littlewood JM. Recurrent abdominal pain and lactose intolerance in childhood. Br Med J (Clin Res Ed) 1981;282:2013-4.

(162) Lebenthal E, Rossi TM, Nord KS, Branski D. Recurrent abdominal pain and lactose absorption in children. Pediatrics 1981;67:828-32.

(163) Bhan MK, Arora NK, Ghai OP, Dhamija NK, Nayyar S, Fotedar A. Lactose and milk intolerance in recurrent abdominal pain of childhood. Indian J Pediatr 1982;49:199-202.

(164) Ladas S, Papanikos J, Arapakis G. Lactose malabsorption in Greek adults: correlation of small bowel transit time with the severity of lactose intolerance. Gut 1982;23:968-73.

(165) Barr RG, Watkins JB, Perman JA. Mucosal function and breath hydrogen excretion: comparative studies in the clinical evaluation of children with nonspecific abdominal complaints. Pediatrics 1981;68:526-33.

(166) Vernia P, Ricciardi MR, Frandina C, Bilotta T, Frieri G. Lactose malabsorption and irritable bowel syndrome. Effect of a long- term lactose-free diet. Ital J Gastroenterol 1995;27:117-21.

(167) Böhmer CJ, Tuynman HA. The clinical relevance of lactose malabsorption in irritable bowel syndrome. Eur J Gastroenterol Hepatol 1996;8:1013-6.

(168) Vesa TH, Seppo LM, Marteau PR, Sahi T, Korpela R. Role of irritable bowel syndrome in subjective lactose intolerance. Am J Clin Nutr 1998;67:710-5.

(169) Johnson AO, Semenya JG, Buchowski MS, Enwonwu CO, Scrimshaw NS. Adaptation of lactose maldigesters to continued milk intakes. Am J Clin Nutr 1993;58:879-81.

(170) Hertzler SR, Savaiano DA. Colonic adaptation to daily lactose feeding in lactose maldigesters reduces lactose intolerance. Am J Clin Nutr 1996;64:232-6.

(171) Hertzler SR, Savaiano DA, Levitt MD. Faecal hydrogen production and consumption measurements. Response to daily lactose ingestion by lactose maldigesters. Dig Dis Sci 1997;42:348-53.

(172) Briet F, Pochart P, Marteau P, Flourie B, Arrigoni E, Rambaud JC. Improved clinical tolerance to chronic lactose ingestion in subjects with lactose intolerance: a placebo effect? Gut 1997;41:632-5.

(173) Szilagyi A, Shrier I, Heilpern D, Je J, Park S, Chong G, et al. Differential impact of lactose/lactase phenotype on colonic microflora. Can J Gastroenterol 2010;24:373-9.

(174) Vonk RJ, Priebe MG, Koetse HA, Stellaard F, Lenoir-Wijnkoop I, Antoine JM, et al. Lactose intolerance: analysis of underlying factors. Eur J Clin Invest 2003;33:70-5.

(175) He T, Venema K, Priebe MG, Welling GW, Brummer RJ, Vonk RJ. The role of colonic metabolism in lactose intolerance. Eur J Clin Invest 2008;38:541-7.

(176) Hernando-Harder AC, Serra J, Azpiroz F, Malagelada JR. Sites of symptomatic gas retention during intestinal lipid perfusion in healthy subjects. Gut 2004;53:661-5.

(177) Hernando-Harder AC, Serra J, Azpiroz F, Mila M, Aguade S, Malagelada C, et al. Colonic responses to gas loads in subgroups of patients with abdominal bloating. Am J Gastroenterol 2010;105:876-82.

(178) Quigley EM. From comic relief to real understanding; how intestinal gas causes symptoms. Gut 2003;52:1659-61.

(179) Lisker R, Aguilar L, Zavala C. Intestinal lactase deficiency and milk drinking capacity in the adult. Am J Clin Nutr 1978;31:1499-503.

(180) Lisker R, Aguilar L. Double blind study of milk lactose intolerance. Gastroenterology 1978;74:1283-5.

(181) Newcomer AD, McGill DB, Thomas PJ, Hofmann AF. Tolerance to lactose among lactase-deficient American Indians. Gastroenterology 1978;74:44-6.

(182) Arola H. Diagnosis of hypolactasia and lactose malabsorption. Scand J Gastroenterol Suppl 1994;202:26-35.

(183) Gilat T, Ben HH, Gelman-Malachi E, Terdiman R, Peled Y. Alterations of the colonic flora and their effect on the hydrogen breath test. Gut 1978;19:602-5.

(184) Perman JA, Modler S, Olson AC. Role of $\mathrm{pH}$ in production of hydrogen from carbohydrates by colonic bacterial flora. Studies in vivo and in vitro. J Clin Invest 1981;67:643-50. 
(185) Thompson DG, Binfield P, De BA, O'Brien J, Warren S, Wilson M. Extra intestinal influences on exhaled breath hydrogen measurements during the investigation of gastrointestinal disease. Gut 1985;26:1349-52.

(186) Vernia P, Di Camillo M, Foglietta T, Avallone VE, De Carolis A. Diagnosis of lactose intolerance and the "nocebo" effect: the role of negative expectations. Dig Liver Dis 2010;42:616-9.

(187) Winter B, Nothjunge J, Stern M. Hydrogen $\left(\mathrm{H}_{2}\right)$ breath test following lactose loading in children with recurrent abdominal pain. Klin Padiatr 1990;202:413-6.

(188) Newcomer AD, McGill DB, Thomas PJ, Hofman AF. Prospective comparison of indirect methods for detecting lactase deficiency. N Engl J Med 1975;293:1232-6.

(189) Douwes AC, Fernandes J, Degenhart HJ. Improved accuracy of lactose tolerance test in children, using expired $\mathrm{H}_{2}$ measurement. Arch Dis Child 1978;53:939-42.

(190) Hoekstra JH, van Kempen AA, Bijl SB, Kneepkens CM. Fructose breath hydrogen tests. Arch Dis Child 1993;68:136-8.

(191) Jones HF, Burt E, Dowling K, Davidson G, Brooks DA, Butler RN. Effect of age on fructose malabsorption in children presenting with gastrointestinal symptoms. J Pediatr Gastroenterol Nutr 2011;52:581-4.

(192) Latulippe ME, Skoog SM. Fructose malabsorption and intolerance: effects of fructose with and without simultaneous glucose ingestion. Crit Rev Food Sci Nutr 2011;51:583-92.

(193) Andersson DE, Nygren A. Four cases of long-standing diarrhoea and colic pains cured by fructose-free diet--a pathogenetic discussion. Acta Med Scand 1978;203:87-92.

(194) Moukarzel AA, Lesicka H, Ament ME. Irritable bowel syndrome and nonspecific diarrhea in infancy and childhood--relationship with juice carbohydrate malabsorption. Clin Pediatr (Phila) 2002;41:145-50.

(195) Choi YK, Johlin FC, Jr., Summers RW, Jackson M, Rao SS. Fructose intolerance: an under-recognized problem. Am J Gastroenterol 2003;98:1348-53.

(196) Corlew-Roath M, Di Palma JA. Clinical impact of identifying lactose maldigestion or fructose malabsorption in irritable bowel syndrome or other conditions. South Med J 2009;102:1010-2.

(197) Gibson PR, Newnham E, Barrett JS, Shepherd SJ, Muir JG. Review article: fructose malabsorption and the bigger picture. Aliment Pharmacol Ther 2007;25:349-63.

(198) Shepherd SJ, Parker FC, Muir JG, Gibson PR. Dietary triggers of abdominal symptoms in patients with irritable bowel syndrome: randomized placebo-controlled evidence. Clin Gastroenterol Hepatol 2008;6:765-71.

(199) Stone ML, Bohane TD, Whitten KE, Tobias VH, Day AS. Age related clinical features of childhood coeliac disease in Australia. BMC Pediatr 2005;5:11.

(200) Savilahti E, Kolho KL, Westerholm-Ormio M, Verkasalo M. Clinics of coeliac disease in children in the 2000s. Acta Paediatr 2010;99:1026-30.

(201) Bode S, Gudmand-Hoyer E. Symptoms and haematologic features in consecutive adult coeliac patients. Scand J Gastroenterol 1996;31:54-60.

(202) Zipser RD, Patel S, Yahya KZ, Baisch DW, Monarch E. Presentations of adult celiac disease in a nationwide patient support group. Dig Dis Sci 2003;48:761-4.

(203) Fernandez A, Gonzalez L, de la Fuente J. Coeliac disease: clinical features in adult populations. Rev Esp Enferm Dig 2010;102:466-71.

(204) Shahbazkhani B, Forootan M, Merat S, Akbari MR, Nasserimoghadam S, Vahedi H, et al. Coeliac disease presenting with symptoms of irritable bowel syndrome. Aliment Pharmacol Ther 2003;18:231-5.

(205) Fitzpatrick KP, Sherman PM, Ipp M, Saunders N, Macarthur C. Screening for celiac disease in children with recurrent abdominal pain. J Pediatr Gastroenterol Nutr 2001;33:250-2.

(206) Kokkonen J, Haapalahti M, Tikkanen S, Karttunen R, Savilahti E. Gastrointestinal complaints and diagnosis in children: a population-based study. Acta Paediatr 2004;93:880-6.

(207) Cash BD, Rubenstein JH, Young PE, Gentry A, Nojkov B, Lee D, et al. The prevalence of celiac disease among patients with nonconstipated irritable bowel syndrome is similar to controls. Gastroenterology 2011;141:1187-93. 
(208) Locke GR, III, Murray JA, Zinsmeister AR, Melton LJ, III, Talley NJ. Celiac disease serology in irritable bowel syndrome and dyspepsia: a population-based case-control study. Mayo Clin Proc 2004;79:476-82.

(209) Jadallah KA, Khader YS. Celiac disease in patients with presumed irritable bowel syndrome: a case-finding study. World J Gastroenterol 2009;15:5321-5.

(210) Korkut E, Bektas M, Oztas E, Kurt M, Cetinkaya H, Ozden A. The prevalence of celiac disease in patients fulfilling Rome III criteria for irritable bowel syndrome. Eur J Intern Med 2010;21:389-92.

(211) Sanders DS, Carter MJ, Hurlstone DP, Pearce A, Ward AM, McAlindon ME, et al. Association of adult coeliac disease with irritable bowel syndrome: a case-control study in patients fulfilling ROME II criteria referred to secondary care. Lancet 2001;358:1504-8.

(212) Sanders DS, Patel D, Stephenson TJ, Ward AM, McCloskey EV, Hadjivassiliou M, et al. A primary care cross-sectional study of undiagnosed adult coeliac disease. Eur J Gastroenterol Hepatol 2003;15:407-13.

(213) Ford AC, Chey WD, Talley NJ, Malhotra A, Spiegel BM, Moayyedi P. Yield of diagnostic tests for celiac disease in individuals with symptoms suggestive of irritable bowel syndrome: systematic review and meta-analysis. Arch Intern Med 2009;169:651-8.

(214) Alun Jones V, McLaughlan P, Shorthouse M, Workman E, Hunter JO. Food intolerance: a major factor in the pathogenesis of irritable bowel syndrome. Lancet 1982;1115-7.

(215) Bentley SJ, Pearson DJ, Rix KJ. Food hypersensitivity in irritable bowel syndrome. Lancet 1983;2:295-7.

(216) Niec AM, Frankum B, Talley NJ. Are adverse food reactions linked to irritable bowel syndrome? Am J Gastroenterol 1998;93:2184-90.

(217) Nanda R, James R, Smith H, Dudley CR, Jewell DP. Food intolerance and the irritable bowel syndrome. Gut 1989;30:1099-104.

(218) Stefanini GF, Saggioro A, Alvisi V, Angelini G, Capurso L, di Lorenzo G, et al. Oral cromolyn sodium in comparison with elimination diet in the irritable bowel syndrome, diarrheic type. Multicenter study of 428 patients. Scand J Gastroenterol 1995;30:535-41.

(219) Lunardi C, Bambara LM, Biasi D, Cortina P, Peroli P, Nicolis F, et al. Double-blind cross-over trial of oral sodium cromoglycate in patients with irritable bowel syndrome due to food intolerance. Clin Exp Allergy 1991;21:569-72.

(220) Stefanini GF, Prati E, Albini MC, Piccinini G, Capelli S, Castelli E, et al. Oral disodium cromoglycate treatment on irritable bowel syndrome: an open study on 101 subjects with diarrheic type. Am J Gastroenterol 1992;87:55-7.

(221) Uz E, Turkay C, Aytac S, Bavbek N. Risk factors for irritable bowel syndrome in Turkish population: role of food allergy. J Clin Gastroenterol 2007;41:380-3.

(222) Maloney J, Nowak-Wegrzyn A. Educational clinical case series for pediatric allergy and immunology: allergic proctocolitis, food protein-induced enterocolitis syndrome and allergic eosinophilic gastroenteritis with protein-losing gastroenteropathy as manifestations of non-lgE-mediated cow's milk allergy. Pediatr Allergy Immunol 2007;18:360-7.

(223) van Odijk J, Peterson CG, Ahlstedt S, Bengtsson U, Borres MP, Hulthen L, et al. Measurements of eosinophil activation before and after food challenges in adults with food hypersensitivity. Int Arch Allergy Immunol 2006;140:334-41.

(224) Kokkonen J, Karttunen TJ, Niinimaki A. Lymphonodular hyperplasia as a sign of food allergy in children. J Pediatr Gastroenterol Nutr 1999;29:57-62.

(225) Mansueto P, lacono G, Seidita A, D'Alcamo A, Sprini D, Carroccio A. Review article: intestinal lymphoid nodular hyperplasia in children - the relationship to food hypersensitivity. Aliment Pharmacol Ther 2012.

(226) Arslan G, Odegaard S, Elsayed S, Florvaag E, Berstad A. Food allergy and intolerance: response to intestinal provocation monitored by endosonography. Eur J Ultrasound 2002;15:29-36.

(227) Arslan G, Lillestol K, Mulahasanovic A, Florvaag E, Berstad A. Food hypersensitivity reactions visualised by ultrasonography and magnetic resonance imaging in a patient lacking systemic food-specific lgE. Digestion 2006;73:111-5. 
(228) Hagel AF, de Rossi TM, Zopf Y, Lindner AS, Dauth W, Neurath MF, et al. Small-bowel capsule endoscopy in patients with gastrointestinal food allergy. Allergy 2011.

(229) Størdal K, Bentsen BS. Recurrent abdominal pain in school children revisited: fitting adverse food reactions into the puzzle. Acta Paediatr 2004;93:869-71.

(230) Eswaran S, Tack J, Chey WD. Food: the forgotten factor in the irritable bowel syndrome. Gastroenterol Clin North Am 2011;40:141-62.

(231) Rothenberg ME. Eosinophilic gastrointestinal disorders (EGID). J Allergy Clin Immunol 2004;113:11-28.

(232) Kalach N, Huvenne H, Gosset P, Papadopoulos S, Dehecq E, Decoster A, et al. Eosinophil counts in upper digestive mucosa of Western European children: variations with age, organs, symptoms, Helicobacter pylori status, and pathological findings. J Pediatr Gastroenterol Nutr 2011;52:175-82.

(233) Li-Kim-Moy JP, Tobias V, Day AS, Leach S, Lemberg DA. Esophageal subepithelial fibrosis and hyalinization are features of eosinophilic esophagitis. J Pediatr Gastroenterol Nutr 2011;52:147-53.

(234) Barber MD, McLaren J, Rainey JB. Recurrent appendicitis. Br J Surg 1997;84:110-2.

(235) Crabbe MM, Norwood SH, Robertson HD, Silva JS. Recurrent and chronic appendicitis. Surg Gynecol Obstet 1986;163:11-3.

(236) Hawes AS, Whalen GF. Recurrent and chronic appendicitis: the other inflammatory conditions of the appendix. Am Surg 1994;60:217-9.

(237) Mattei P, Sola JE, Yeo CJ. Chronic and recurrent appendicitis are uncommon entities often misdiagnosed. J Am Coll Surg 1994;178:385-9.

(238) Yang SS, Gibson P, McCaughey RS, Arcari FA, Bernstein J. Primary Crohn's disease of the appendix: report of 14 cases and review of the literature. Ann Surg 1979;189:334-9.

(239) Prieto-Nieto I, Perez-Robledo JP, Hardisson D, Rodriguez-Montes JA, Larrauri-Martinez J, GarciaSancho-Martin L. Crohn's disease limited to the appendix. Am J Surg 2001;182:531-3.

(240) Ariel I, Vinograd I, Hershlag A, Olsha O, Argov S, Klausner JM, et al. Crohn's disease isolated to the appendix: truths and fallacies. Hum Pathol 1986;17:1116-21.

(241) Bischoff A, Gupta A, D'Mello S, Mezoff A, Podberesky D, Barnett S, et al. Crohn's disease limited to the appendix: a case report in a pediatric patient. Pediatr Surg Int 2010;26:1125-8.

(242) Schisgall RM. Appendiceal colic in childhood: the role of inspissated casts of stool within the appendix. Ann Surg 1980;192:687-93.

(243) Lee AW, Bell RM, Griffen WO, Jr., Hagihara PF. Recurrent appendiceal colic. Surg Gynecol Obstet 1985;161:21-4.

(244) Schisgall RM. Radiographic features of appendiceal colic in children. Pediatr Radiol 1986;16:392-9.

(245) Donnellan W. Recurrent abdominal pain due to appendiceal obstruction and its relief by appendectomy. S D J Med 1988;41:25-9.

(246) Seidman JD, Andersen DK, Ulrich S, Hoy GR, Chun B. Recurrent abdominal pain due to chronic appendiceal disease. South Med J 1991;84:913-6.

(247) Gorenstein A, Serour F, Katz R, Usviatsov I. Appendiceal colic in children: a true clinical entity? J Am Coll Surg 1996;182:246-50.

(248) Dahlstrom JE, Macarthur EB. Enterobius vermicularis: a possible cause of symptoms resembling appendicitis. Aust N Z J Surg 1994;64:692-4.

(249) Arca MJ, Gates RL, Groner Jl, Hammond S, Caniano DA. Clinical manifestations of appendiceal pinworms in children: an institutional experience and a review of the literature. Pediatr Surg Int 2004;20:372-5.

(250) Andersson A, Bergdahl L. Carcinoid tumors of the appendix in children. A report of 25 cases. Acta Chir Scand 1977;143:173-5.

(251) Blecha MJ, Gupta A, Hoover JD, Madonna MB. Chronic abdominal pain secondary to a mucous cystadenoma of the appendix in a 10-year-old boy. J Pediatr Surg 2005;40:1792-4.

(252) Blereau RP. Eosinophilic granuloma of the appendix. Pediatr Emerg Care 1985;1:85-6. 
(253) Bailey DJ, Courington KR, Andres JM, Bagwell CE, Hitchcock CL. Cecal polyp and appendiceal intussusception in a child with recurrent abdominal pain: diagnosis by colonoscopy. J Pediatr Gastroenterol Nutr 1987;6:818-20.

(254) Nyam DC, Davendran K, Seow-Choen F. An endoscopic diagnosis of appendicular intussusception in chronic appendicitis. Singapore Med J 1997;38:131.

(255) Ryu BY, Kim TH, Jeon JY, Kim HK, Choi YH, Baik GH. Colonoscopic diagnosis of appendiceal intussusception: a case report. J Korean Med Sci 2005;20:680-2.

(256) Tavakkoli H, Sadrkabir SM, Mahzouni P. Colonoscopic diagnosis of appendiceal intussusception in a patient with intermittent abdominal pain: a case report. World J Gastroenterol 2007;13:4274-7.

(257) Di Sebastiano P, Fink T, di Mola FF, Weihe E, Innocenti P, Friess H, et al. Neuroimmune appendicitis. Lancet 1999;354:461-6.

(258) Franke C, Gerharz CD, Bohner H, Ohmann C, Heydrich G, Kramling HJ, et al. Neurogenic appendicopathy: a clinical disease entity? Int J Colorectal Dis 2002;17:185-91.

(259) Franke C, Gerharz CD, Bohner H, Ohmann C, Heydrich G, Kramling HJ, et al. Neurogenic appendicopathy in children. Eur J Pediatr Surg 2002;12:28-31.

(260) Höfler H, Kasper M, Heitz PU. The neuroendocrine system of normal human appendix, ileum and colon, and in neurogenic appendicopathy. Virchows Arch A Pathol Anat Histopathol 1983;399:127-40.

(261) Quell M, Horvath W. Neurogenic appendicopathy--long-term results following appendectomy. Chirurg 1987;58:597-600

(262) Mortimer MJ, Kay J, Jaron A. Clinical epidemiology of childhood abdominal migraine in an urban general practice. Dev Med Child Neurol 1993;35:243-8.

(263) Symon DN, Russell G. Abdominal migraine: a childhood syndrome defined. Cephalalgia 1986;6:223-8.

(264) Symon DN, Russell G. Double blind placebo controlled trial of pizotifen syrup in the treatment of abdominal migraine. Arch Dis Child 1995;72:48-50.

(265) Baber KF, Anderson J, Puzanovova M, Walker LS. Rome II versus Rome III classification of functional gastrointestinal disorders in pediatric chronic abdominal pain. J Pediatr Gastroenterol Nutr 2008;47:299-302.

(266) Hyams JS, Treem WR, Justinich CJ, Davis P, Shoup M, Burke G. Characterization of symptoms in children with recurrent abdominal pain: resemblance to irritable bowel syndrome. J Pediatr Gastroenterol Nutr 1995;20:209-14.

(267) Mavromichalis I, Zaramboukas T, Giala MM. Migraine of gastrointestinal origin. Eur J Pediatr 1995;154:406-10.

(268) Blau JN, MacGregor EA. Is abdominal pain a feature of adult migraine? Headache 1995;35:207-9.

(269) Mortimer MJ, Kay J, Jaron A, Good PA. Does a history of maternal migraine or depression predispose children to headache and stomach-ache? Headache 1992;32:353-5.

(270) Monro J, Brostoff J, Carini C, Zilkha K. Food allergy in migraine; study of dietary exclusion and RAST. Lancet 1980;ii:1-4.

(271) Worawattanakul M, Rhoads JM, Lichtman SN, Ulshen MH. Abdominal migraine: prophylactic treatment and follow-up. J Pediatr Gastroenterol Nutr 1999;28:37-40.

(272) Zarling EJ. Abdominal epilepsy: an unusual cause of recurrent abdominal pain. Am J Gastroenterol 1984;79:687-8.

(273) Singhi PD, Kaur S. Abdominal epilepsy misdiagnosed as psychogenic pain. Postgrad Med J 1988;64:281-2.

(274) Garcia-Herrero D, Fernandez-Torre JL, Barrasa J, Calleja J, Pascual J. Abdominal epilepsy in an adolescent with bilateral perisylvian polymicrogyria. Epilepsia 1998;39:1370-4.

(275) Mendler MH, Sautereau D, Pillegand B, Ravon R. A case of digestive epilepsy with late diagnosis: a disease not to be disregarded. Gastroenterol Clin Biol 1998;22:235-9.

(276) Eidlitz-Markus T, Mimouni M, Zeharia A, Nussinovitch M, Amir J. Occult constipation: a common cause of recurrent abdominal pain in childhood. Isr Med Assoc J 2004;6:677-80. 
(277) Størdal K, Nygaard EA, Bentsen B. Organic abnormalities in recurrent abdominal pain in children. Acta Paediatr 2001;90:638-42.

(278) Boccia G, Buonavolonta R, Coccorullo P, Manguso F, Fuiano L, Staiano A. Dyspeptic symptoms in children: the result of a constipation-induced cologastric brake? Clin Gastroenterol Hepatol 2008;6:556-60.

(279) Loening-Baucke V. Chronic constipation in children. Gastroenterology 1993;105:1557-64.

(280) Huertas-Ceballos A, Logan S, Bennett C, Macarthur C. Pharmacological interventions for recurrent abdominal pain (RAP) and irritable bowel syndrome (IBS) in childhood. Cochrane Database Syst Rev 2008;CD003017.

(281) See MC, Birnbaum AH, Schechter CB, Goldenberg MM, Benkov KJ. Double-blind, placebo-controlled trial of famotidine in children with abdominal pain and dyspepsia: global and quantitative assessment. Dig Dis Sci 2001;46:985-92.

(282) Kline RM, Kline JJ, Di PJ, Barbero GJ. Enteric-coated, pH-dependent peppermint oil capsules for the treatment of irritable bowel syndrome in children. J Pediatr 2001;138:125-8.

(283) Krogsbøll LT, Hróbjartsson A, Gøtzsche PC. Spontaneous improvement in randomised clinical trials: meta-analysis of three-armed trials comparing no treatment, placebo and active intervention. BMC Med Res Methodol 2009;9:1.

(284) Camilleri M, Bueno L, de PF, Fioramonti J, Lydiard RB, Tack J. Pharmacological and pharmacokinetic aspects of functional gastrointestinal disorders. Gastroenterology 2006;130:1421-34.

(285) Lembo A, Camilleri M. Chronic constipation. N Engl J Med 2003;349:1360-8.

(286) O'Mahony L, McCarthy J, Kelly P, Hurley G, Luo F, Chen K, et al. Lactobacillus and bifidobacterium in irritable bowel syndrome: symptom responses and relationship to cytokine profiles. Gastroenterology 2005;128:541-51.

(287) Quigley EM. Prucalopride: safety, efficacy and potential applications. Therap Adv Gastroenterol 2012;5:23-30.

(288) Clarke G, Cryan JF, Dinan TG, Quigley EM. Review article: probiotics for the treatment of irritable bowel syndrome--focus on lactic acid bacteria. Aliment Pharmacol Ther 2012;35:403-13.

(289) van der Meer SB, Forget PP, Kuijten RH, Arends JW. Gastroesophageal reflux in children with recurrent abdominal pain. Acta Paediatr 1992;81:137-40.

(290) Corrado G, Cavaliere M, Frandina G, Rea P, Pacchiarotti C, Capocaccia P, et al. Primary gastrooesophageal reflux disease and irritable oesophagus syndrome as causes of recurrent abdominal pain in children. Ital J Gastroenterol 1996;28:462-9.

(291) Levine A, Milo T, Broide E, Wine E, Dalal I, Boaz M, et al. Influence of Helicobacter pylori eradication on gastroesophageal reflux symptoms and epigastric pain in children and adolescents. Pediatrics 2004;113:54-8.

(292) Colletti RB, Trainer TD. Collagenous gastritis. Gastroenterology 1989;97:1552-5.

(293) Mahjoub FE, Farahmand F, Pourpak Z, Asefi H, Amini Z. Mast cell gastritis: children complaining of chronic abdominal pain with histologically normal gastric mucosal biopsies except for increase in mast cells, proposing a new entity. Diagn Pathol 2009;4:34.

(294) Putnam PE, Rothenberg ME. Eosinophilic esophagitis: concepts, controversies, and evidence. Curr Gastroenterol Rep 2009;11:220-5.

(295) Alfadda AA, Storr MA, Shaffer EA. Eosinophilic colitis: epidemiology, clinical features, and current management. Therap Adv Gastroenterol 2011;4:301-9.

(296) Alfadda AA, Storr MA, Shaffer EA. Eosinophilic colitis: an update on pathophysiology and treatment. $\mathrm{Br}$ Med Bull 2011;100:59-72.

(297) Liebman WM. Gastric acid secretion and serum gastrin levels in children with recurrent abdominal pain, gastric and duodenal ulcers. J Clin Gastroenterol 1980;2:243-6.

(298) Nord KS, Rossi TM, Lebenthal E. Peptic ulcer in children: the predominance of gastric ulcers. Am J Gastroenterol 1981;75:153-7. 
(299) Benkov KJ, Becker N, Rose J, Shen S, LeLeiko NS. Failure to thrive associated with chronic ulcer disease in a 9-year-old boy. Am J Gastroenterol 1985;80:542-6.

(300) Collins JS, Glasgow JF, Trouton TG, McFarland RJ. Twenty year review of duodenal ulcer. Arch Dis Child 1986;61:407-8.

(301) Drumm B, Rhoads JM, Stringer DA, Sherman PM, Ellis LE, Durie PR. Peptic ulcer disease in children: etiology, clinical findings, and clinical course. Pediatrics 1988;82:410-4.

(302) Saebo A, Lassen J. Yersinia enterocolitica: an inducer of chronic inflammation. Int J Tissue React 1994;16:51-7.

(303) Konate A, Duhamel O, Basset D, Ayral J, Poirette A, Granier P, et al. Toxocariasis and functional intestinal disorders. Presentation of 4 cases. Gastroenterol Clin Biol 1996;20:909-11.

(304) Burke JA. Strongyloidiasis in childhood. Am J Dis Child 1978;132:1130-6.

(305) Cohen RP, Jones TC. Eosinophilia, elevated immunoglobulin E level and chronic enteritis due to intestinal helminthiasis. Am J Med 1979;67:909-12.

(306) Loukas A, Croese J, Opdebeeck J, Prociv P. Detection of antibodies to secretions of Ancylostoma caninum in human eosinophilic enteritis. Trans R Soc Trop Med Hyg 1992;86:650-3.

(307) Atwell JD, Burge D, Wright D. Nodular lymphoid hyperplasia of the intestinal tract in infancy and childhood. J Pediatr Surg 1985;20:25-9.

(308) Liebman WM. Recurrent abdominal pain: apparent association with annular pancreas. Am J Gastroenterol 1979;71:522-3.

(309) Lee JY, Shuster M, Duran H, Lupini B. Enteric cyst and recurrent abdominal pain in an adult. J Med Soc N J 1975;72:141-4.

(310) Drott C, Jansson R. Duplication cyst of the jejunum. Report of a case. Acta Chir Scand 1981;147:731-3.

(311) Case records of the Massachusetts General Hospital. Weekly clinicopathological exercises. Case 28-1985. Recurrent abdominal pain and an epigastric mass in a 21-year-old woman. N Engl J Med 1985;313:104-10.

(312) Diaz-Cano SJ, Rivera-Hueto F, Mesa-Navarro A. Double duplication in a nonrotational colon. Study of a case associated with mucinous adenoma. Pathol Res Pract 1995;191:415-9.

(313) Keramidas DC, Demetriades DM. Total tubular duplication of the colon and distal ileum combined with transmesenteric hernia: surgical management and long-term-results. Eur J Pediatr Surg 1996;6:243-4.

(314) Andronikou S, Sinclair-Smith C, Millar AJ. An enteric duplication cyst of the pancreas causing abdominal pain and pancreatitis in a child. Pediatr Surg Int 2002;18:190-2.

(315) Gohl ML, DeMeester TR. Midgut nonrotation in adults. An aggressive approach. Am J Surg 1975; 129:319-23.

(316) Janik JS, Ein SH. Normal intestinal rotation with non-fixation: a cause of chronic abdominal pain. J Pediatr Surg 1979;14:670-4.

(317) Yanez R, Spitz L. Intestinal malrotation presenting outside the neonatal period. Arch Dis Child 1986;61:682-5.

(318) Pandya RV. Chronic organo axial volvulus of stomach. East Afr Med J 1990;67:452-4.

(319) Lin JN, Lou CC, Wang KL. Intestinal malrotation and midgut volvulus: a 15-year review. J Formos Med Assoc 1995;94:178-81.

(320) Walsh DS, Crombleholme TM. Superior mesenteric venous thrombosis in malrotation with chronic volvulus. J Pediatr Surg 2000;35:753-5.

(321) Kanazawa T, Kasugai K, Miyata M, Miyashita M, Mizuno M, Nagase F, et al. Midgut malrotation in adulthood. Intern Med 2000;39:626-31.

(322) Cook ES, Allison EJ, Jr. Sigmoid volvulus in a young patient. Ann Emerg Med 1984;13:963-6.

(323) Krupsky S, Halevy A, Orda R. Sigmoid volvulus in adolescence. J Clin Gastroenterol 1987;9:467-9.

(324) Koto Z. Spontaneous untwisting in sigmoid volvulus--the case for 'prophylactic' surgery. A report of 3 cases. S Afr J Surg 1994;32:94-6. 
(325) Salas S, Angel CA, Salas N, Murillo C, Swischuk L. Sigmoid volvulus in children and adolescents. J Am Coll Surg 2000;190:717-23.

(326) Lerner A, Rossi TM, Hodge C, Riddlesberger MM, Jr. A CT sign: the "disappearing mass" as a clue to the diagnosis of intermittent intestinal intussusception in children. Comput Radiol 1984;8:387-90.

(327) Benson JE, Strauch ED. Retropsoas hernia as a cause of chronic abdominal pain: CT diagnosis. Pediatr Radiol 1998;28:312-4.

(328) Patil R, Smith C, Brown MD. Paraduodenal hernia presenting as unexplained recurrent abdominal pain. Am J Gastroenterol 1999;94:3614-5.

(329) Ramachandran P, Sridharan S. Strangulated left paraduodenal hernia in an infant. Pediatr Surg Int 2003;19:120-1.

(330) Moran JM, Salas J, Sanjuan S, Amaya JL, Rincon P, Serrano A, et al. Paramesocolic hernias: consequences of delayed diagnosis. Report of three new cases. J Pediatr Surg 2004;39:112-6.

(331) Teng BP, Yamout SZ. Left paraduodenal hernia causing small bowel obstruction in an adolescent patient. J Pediatr Surg 2009;44:2417-9.

(332) Havenstrite KA, Harris JA, Rivera DE. Splenic flexure volvulus in association with Chilaiditi syndrome: report of a case. Am Surg 1999;65:874-6.

(333) White JJ, Chavez EP, Souza J. Internal hernia of the transverse colon-Chilaiditi syndrome in a child. J Pediatr Surg 2002;37:802-4.

(334) Khan K, Sharp HL. Urachal web: a rare cause for recurrent abdominal pain in a child. Clin Pediatr (Phila) 2001;40:625-7.

(335) Kapischke M, Bley K, Deltz E. Meckel's diverticulum: a disease associated with a colored clinical picture. Surg Endosc 2003;17:351.

(336) Jalil O, Radwan R, Rasheed A, Nutt MR. Congenital band of the vitelline artery remnant as a cause of chronic lower abdominal pain in an adult: Case report. Int J Surg Case Rep 2012;3:207-8.

(337) Ewert P, Keim L, Schulte-Markwort M. Trichobezoar. A rare cause of recurrent upper abdominal pain. Monatsschr Kinderheilkd 1992;140:811-3.

(338) Chroustova D, Volf V, Dzupa V, Kryl P, Mandys V. The unusual cause of recurrent abdominal pain in an 11-year-old boy. Nucl Med Rev Cent East Eur 2006;9:77-80.

(339) Burrington JD. Superior mesenteric artery syndrome in children. Am J Dis Child 1976;130:1367-70.

(340) Shandling B. The so-called superior mesenteric artery syndrome. Am J Dis Child 1976;130:1371-3.

(341) Berquist WE, Gomes AS, Ament ME, Sparkes RS, Diehl D. Superior mesenteric artery stenosis: cause of recurrent ischemic bowel syndrome in an infant. J Pediatr 1986;109:496-9.

(342) Penco JM, Murillo JC, De La Calle PU, Masjoan D. A possible case of superior mesenteric artery syndrome of congenital origin. Cir Pediatr 2008;21:228-31.

(343) Mahl M, Schonfeld J, Lange R, Eising EG, Kind EM, Neumann K, et al. Carcinoid syndrome. Recurrent upper abdominal pain, diarrhea and flush in a 15-year-old girl. Med Klin 1997;92:739-43.

(344) Pillai RB, Tolia V. Colonic polyps in children: frequently multiple and recurrent. Clin Pediatr (Phila) 1998;37:253-7.

(345) Bell MJ, Ternberg JL, Bower RJ. Ileal dysgenesis in infants and children. J Pediatr Surg 1982;17:395-9.

(346) Aunan E, Naess A. Torsion of intra-abdominal lipoma--a rare cause of recurrent or acute abdominal pain. Case report. Acta Chir Scand 1988;154:539-40.

(347) Parr NJ, Crosbie RB. Intermittent omental torsion--an unusual cause of recurrent abdominal pain? Postgrad Med J 1989;65:114-5.

(348) Rust C, Pratschke E, Hartl W, Kessler M, Weibecke B, Sauerbruch T, et al. Fibrotic entrapment of the small bowel in congenital intestinal lymphangiectasia. Am J Gastroenterol 1998;93:1980-3.

(349) Poll LW, Lackmann GM, May P, Willnow U, Braunstein S, Engelbrecht V, et al. Follicular lymphoid hyperplasia simulating intussusception in a 6-year-old boy: clinical, radiological and histopathological findings. Australas Radiol 2003;47:453-6. 
(350) Khoddami M, Sanae S, Nikkhoo B. Rectal and appendiceal inflammatory myofibroblastic tumors. Arch Iran Med 2006;9:277-81.

(351) Bischoff SC, Mayer JH, Manns MP. Allergy and the gut. Int Arch Allergy Immunol 2000;121:270-83.

(352) Symons P, Jones MP, Kellow JE. Symptom provocation in irritable bowel syndrome. Effects of differing doses of fructose-sorbitol. Scand J Gastroenterol 1992;27:940-4.

(353) Hwang JB, Choi WJ, Kim JS, Lee SY, Jung CH, Lee YH, et al. Clinical features of pathologic childhood aerophagia: early recognition and essential diagnostic criteria. J Pediatr Gastroenterol Nutr 2005;41:612-6.

(354) Davidson GP, Robb TA, Kirubakaran CP. Bacterial contamination of the small intestine as an important cause of chronic diarrhea and abdominal pain: diagnosis by breath hydrogen test. Pediatrics 1984;74:229-35.

(355) Jones HF, Davidson GP, Brooks DA, Butler RN. Is small-bowel bacterial overgrowth an underdiagnosed disorder in children with gastrointestinal symptoms? J Pediatr Gastroenterol Nutr 2011;52:632-4.

(356) Integlia MJ, Krishnamurthy S, Berhane R, Grand RJ, Dayal Y. Pancreatic metaplasia of the gastric mucosa in pediatric patients. Am J Gastroenterol 1997;92:1553-6.

(357) Zheng LD, Tong QS, Tang ST, Du ZY, Ruan QL. Duodenal heterotopic pancreas in a child. World J Pediatr 2009;5:146-8.

(358) Chapoy P, Pierron H, Seriat-Gautier B, Aubrespy P, Louchet E. A clinical survey on 17 cases of cholelithiasis in childhood. Sem Hop 1979;55:367-74.

(359) Shemesh E, Klein E, Friedman E, Pines A, Brook O, Bat L. Endoscopic retrograde cholangiography in the detection of small stones in the gallbladder. J Clin Gastroenterol 1987;9:424-6.

(360) Kumar R, Nguyen K, Shun A. Gallstones and common bile duct calculi in infancy and childhood. Aust N Z J Surg 2000;70:188-91.

(361) Fagundes-Neto U, Schettini ST, Wehba J, Pinus J, Patricio FR. Caroli's disease in childhood: report of two new cases. J Pediatr Gastroenterol Nutr 1983;2:708-11.

(362) Tandon RK, Grewal H, Anand AC, Vashisht S. Caroli's syndrome: a heterogeneous entity. Am J Gastroenterol 1990;85:170-3.

(363) Rizzo RJ, Szucs RA, Turner MA. Congenital abnormalities of the pancreas and biliary tree in adults. Radiographics 1995;15:49-68.

(364) Lenriot JP, Gigot JF, Segol P, Fagniez PL, Fingerhut A, Adloff M. Bile duct cysts in adults: a multiinstitutional retrospective study. French Associations for Surgical Research. Ann Surg 1998;228:159-66.

(365) Matsusue S, Kashihara S, Nakamura Y, Masumoto H. Role of unusually long common pancreaticobiliary channel as a cause of relapsing pancreatitis in children. Z Kinderchir 1982;36:69-72.

(366) Doty J, Hassall E, Fonkalsrud EW. Anomalous drainage of the common bile duct into the fourth portion of the duodenum. Clinical sequelae. Arch Surg 1985;120:1077-9.

(367) Barker AP, Ford WD, Le Quesne GW, Moore DJ. The common bilio-pancreatic channel syndrome in childhood. Aust N Z J Surg 1992;62:70-3.

(368) Ando H, Ito T, Nagaya M, Watanabe Y, Seo T, Kaneko K. Pancreaticobiliary maljunction without choledochal cysts in infants and children: clinical features and surgical therapy. J Pediatr Surg 1995;30:1658-62.

(369) Miyano T, Ando K, Yamataka A, Lane G, Segawa O, Kohno S, et al. Pancreaticobiliary maljunction associated with nondilatation or minimal dilatation of the common bile duct in children: diagnosis and treatment. Eur J Pediatr Surg 1996;6:334-7.

(370) Misra S, Treanor MR, Vegunta RK, Chen CC. Sphincter of Oddi dysfunction in children with recurrent abdominal pain: 5-year follow-up after endoscopic sphincterotomy. J Gastroenterol Hepatol 2007;22:2246-50.

(371) Constantinou C, Sucandy I, Ramenofsky M. Laparoscopic cholecystectomy for biliary dyskinesia in children: report of 100 cases from a single institution. Am Surg 2008;74:587-92.

(372) Halata MS, Berezin SH. Biliary dyskinesia in the pediatric patient. Curr Gastroenterol Rep 2008;10:332-8. 
(373) Haricharan RN, Proklova LV, Aprahamian CJ, Morgan TL, Harmon CM, Barnhart DC, et al. Laparoscopic cholecystectomy for biliary dyskinesia in children provides durable symptom relief. J Pediatr Surg 2008;43:1060-4.

(374) Rao SV, Greene CA, Ellinoff V. Recurrent abdominal colic as the sole symptom of Wilson's Disease: case report. Mil Med 1981;146:584-5.

(375) Riebel T, Lambrecht W, Amon O, Bromel T. Torsion of a wandering spleen. Monatsschr Kinderheilkd 1985;133:300-3.

(376) Mallmann R, Kania U, Rollmann O, Knopfle G. A girl with congenital adrenal hyperplasia and recurrent abdominal pain. Eur J Pediatr 1997;156:889-90.

(377) Vural M, Kacar S, Kosar U, Altin L. Symptomatic wandering accessory spleen in the pelvis: sonographic findings. J Clin Ultrasound 1999;27:534-6.

(378) Tan HH, Ooi LL, Tan D, Tan CK. Recurrent abdominal pain in a woman with a wandering spleen. Singapore Med J 2007;48:e122-e124.

(379) Leyman P, Saint-Marc O, Hannoun L, Parc R. Heterotopic gastric mucosa presenting as gallbladder polyps. Acta Chir Belg 1996;96:128-9.

(380) Fleming CR, Dickson ER, Harrison EG, Jr. Splenosis: autotransplantation of splenic tissue. Am J Med 1976;61:414-9.

(381) Bamboat ZM, Masiakos PT. Sclerosing angiomatoid nodular transformation of the spleen in an adolescent with chronic abdominal pain. J Pediatr Surg 2010;45:E13-E16.

(382) Demirpolat G, Duygulu G, Tamsel S. Multiseptate gallbladder in a child with recurrent abdominal pain. Diagn Interv Radiol 2010;16:306-7.

(383) Ghishan FK, Greene HL, Avant G, O'Neill J, Neblett W. Chronic relapsing pancreatitis in childhood. J Pediatr 1983;102:514-8.

(384) Masaryk TJ, Achkar E. Pancreatitis as initial presentation of cystic fibrosis in young adults. A report of two cases. Dig Dis Sci 1983;28:874-8.

(385) Rothstein FC, Wyllie R, Gauderer MW. Hereditary pancreatitis and recurrent abdominal pain of childhood. J Pediatr Surg 1985;20:535-7.

(386) Hilmer RS, Nayanar VV, Bohane TD. Hereditary pancreatitis presenting in childhood: case report with family studies. Aust Paediatr J 1985;21:201-3.

(387) Buchta RM, Bell L. Chronic fibrosing pancreatitis in a 12-year-old female. J Adolesc Health 1991;12:395-7.

(388) Mathew P, Wyllie R, Caulfield M, Steffen R, Kay M. Chronic pancreatitis in late childhood and adolescence. Clin Pediatr (Phila) 1994;33:88-94.

(389) Mattioli G, Buffa P, Pesce F, Barabino A, Ganduglia P, Fratino G, et al. Pancreatitis caused by duodenal duplication [see comments]. J Pediatr Surg 1999;34:645-8.

(390) Patel RS, Johlin FC, Jr., Murray JA. Celiac disease and recurrent pancreatitis. Gastrointest Endosc 1999;50:823-7.

(391) Blom H, Bochner A, Vervloessem D, Desimpelaere J, Deviere J, Veereman-Wauters G. A two-year old boy with recurrent bouts of acute abdominal pain. Acta Gastroenterol Belg 2010;73:517-20.

(392) Urushihara N, Fukumoto K, Fukuzawa H, Suzuki K, Matsuoka T, Kawashima S, et al. Recurrent pancreatitis caused by pancreatobiliary anomalies in children with annular pancreas. J Pediatr Surg 2010;45:741-6.

(393) Sclabas G, Kirschstein T, Uhl W, Hurlimann R, Ruchti C, Buchler MW. Juvenile idiopathic fibrosing pancreatitis. Dig Dis Sci 2002;47:1230-5.

(394) Harb R, Naon H. Idiopathic fibrosing pancreatitis in a 3-year-old girl: a case report and review of the literature. J Pediatr Surg 2005;40:1335-40.

(395) Bass S, Connon JJ, Ho CS. Biliary tree in cystic fibrosis. Biliary tract abnormalities in cystic fibrosis demonstrated by endoscopic retrograde cholangiography. Gastroenterology 1983;84:1592-6.

(396) Patrick MK, Howman-Giles R, De Silva M, Van Asperen P, Pitkin J, Gaskin KJ. Common bile duct obstruction causing right upper abdominal pain in cystic fibrosis. J Pediatr 1986;108:101-2. 
(397) Waters DL, Dorney SF, Gruca MA, Martin HC, Howman-Giles R, Kan AE, et al. Hepatobiliary disease in cystic fibrosis patients with pancreatic sufficiency. Hepatology 1995;21:963-9.

(398) Zheng E, Burjonrappa S. Pancreatitis because of foregut duplication cyst of the pancreas treated by laparoscopic resection. J Pediatr Surg 2010;45:e1-e3.

(399) Ward HC, Brereton RJ. Pelviureteric junction obstruction and recurrent abdominal pain in childhood. Br J Surg 1989;76:818-9.

(400) Belman AB. Ureteropelvic junction obstruction as a cause for intermittent abdominal pain in children. Pediatrics 1991;88:1066-9.

(401) Mergener K, Weinerth JL, Baillie J. Dietl's crisis: a syndrome of episodic abdominal pain of urologic origin that may present to a gastroenterologist. Am J Gastroenterol 1997;92:2289-91.

(402) Walther PC, Lamm D, Kaplan GW. Pediatric urolithiases: a ten-year review. Pediatrics 1980;65:1068-72.

(403) La Manna A, Polito C, Cioce F, De Maria G, Capacchione A, Rocco CE, et al. Calyceal microlithiasis in children: report on 196 cases. Pediatr Nephrol 1998;12:214-7.

(404) Polito C, La MA, Signoriello G, Marte A. Recurrent abdominal pain in childhood urolithiasis. Pediatrics 2009;124:e1088-e1094.

(405) Polito C, Cioce F, La Manna A, Maiello R, Di Toro R. Renal calyceal microlithiasis: clinical presentation may precede sonographic evidence. Clin Pediatr (Phila) 1999;38:521-4.

(406) Polito C, Cioce F, Signoriello G, La MA. Central/diffuse abdominal perception of urological pain in children. Acta Paediatr 2006;95:82-5.

(407) Skalova S, Konrad M, Kutilek S. Three different causes of hypercalciuria. Klin Padiatr 201 1;223:287-9.

(408) Giannakopoulos $X$, Chambilomatis P, Thirothoulakis M, Seferiadis G. The blind-ending bifid ureter. Int Urol Nephrol 1994;26:161-5.

(409) Gubler C. Intestinal endometriosis. Schweiz Med Wochenschr 1983;113:1970-2.

(410) Minocha A, Davis MS, Wright RA. Small bowel endometriosis masquerading as regional enteritis. Dig Dis Sci 1994;39:1126-33.

(411) Verbeke C, Harle M, Sturm J. Cystic endometriosis of the upper abdominal organs. Report on three cases and review of the literature. Pathol Res Pract 1996;192:300-4.

(412) Khetan N, Torkington J, Watkin A, Jamison MH, Humphreys WV. Endometriosis: presentation to general surgeons. Ann R Coll Surg Engl 1999;81:255-9.

(413) Gershenson DM, del Junco G, Silva EG, Copeland LJ, Wharton JT, Rutledge FN. Immature teratoma of the ovary. Obstet Gynecol 1986;68:624-9.

(414) Imai A, Furui T, Tamaya T. Gynecologic tumors and symptoms in childhood and adolescence; 10-years' experience. Int J Gynaecol Obstet 1994;45:227-34.

(415) Loeffen JL, Wijnen M, Schijf CP, van WP. [Ovarian tumour in a girl with chronic abdominal pain and distension]. Ned Tijdschr Geneeskd 2006;150:677-80.

(416) Quero-Hernandez A, Estrada-Correa R, Tenorio-Rodriguez H, Alvarez-Solis RM. Malignant germ cell ovarian tumors: clinical characteristics, treatment and outcome. Cir Cir 2007;75:81-5.

(417) Yancey LM. Intermittent Torsion of a Normal Ovary in a Child Associated with Use of a Trampoline. J Emerg Med 2011.

(418) Bugenstein $\mathrm{RH}$, Phibbs $\mathrm{CM}$, Jr. Abdominal pain in children caused by linea alba hernias. Pediatrics 1975;56:1073-4.

(419) Greenbaum DS, Greenbaum RB, Joseph JG, Natale JE. Chronic abdominal wall pain. Diagnostic validity and costs. Dig Dis Sci 1994;39:1935-41.

(420) Scheltinga MR, Boelens OB, Tjon A Ten WE, Roumen RM. Surgery for refractory anterior cutaneous nerve entrapment syndrome (ACNES) in children. J Pediatr Surg 2011;46:699-703.

(421) Alexander-Williams J. Do adhesions cause pain? Br Med J (Clin Res Ed) 1987;294:659-60.

(422) Venkataramani A, Behling CA, Lyche KD. Sclerosing mesenteritis: an unusual cause of abdominal pain in an HIV- positive patient. Am J Gastroenterol 1997;92:1059-60. 
(423) Rawashdeh MO, Majeed HA. Familial Mediterranean fever in Arab children: the high prevalence and gene frequency. Eur J Pediatr 1996;155:540-4.

(424) Kavukcu S, Turkmen M, Eroglu Y, Canda T, Yorukoglu K, Igci E, et al. Renal, gastric and thyroidal amyloidosis due to familial Mediterranean fever. Pediatr Nephrol 1997;11:210-2.

(425) Konen O, Rathaus V, Dlugy E, Freud E, Kessler A, Shapiro M, et al. Childhood abdominal cystic lymphangioma. Pediatr Radiol 2002;32:88-94.

(426) Abu-Arafeh I, Russell G. Prevalence and clinical features of abdominal migraine compared with those of migraine headache. Arch Dis Child 1995;72:413-7.

(427) Hamed SA. A migraine variant with abdominal colic and Alice in Wonderland syndrome: a case report and review. BMC Neurol 2010;10:2.

(428) Van Why SK, Boydstun II, Gaudio KM, Siegel NJ. Abdominal symptoms as presentation of hypertensive crisis. Am J Dis Child 1993;147:638-41.

(429) Dahshan A, Donovan K. Isolated superior mesenteric artery thrombosis: a rare cause for recurrent abdominal pain in a child. J Clin Gastroenterol 2002;34:554-6.

(430) Nozaki Y, Mizuguchi M, Momoi MY. A boy with infantile-onset fibromuscular dysplasia showing recurrent cerebrovascular attacks. No To Hattatsu 2003;35:253-8.

(431) Zamani F, Shakeri R, Modiramani O, Malekzadeh R. Abdominal pain as presentation of Takayasu's arteritis in an adolescent male patient. MedGenMed 2006;8:69.

(432) Schweizer P, Berger S, Schweizer M, Schaefer J, Beck O. Arcuate ligament vascular compression syndrome in infants and children. J Pediatr Surg 2005;40:1616-22.

(433) Marcoccia A, Zippi M, Bruni A, Salvatori FM, Badiali D, Donato G, et al. Chronic abdominal pain associated with intermittent compression of the celiac artery. Minerva Gastroenterol Dietol 2007;53:209-13.

(434) Gander S, Mulder DJ, Jones S, Ricketts JD, Soboleski DA, Justinich CJ. Recurrent abdominal pain and weight loss in an adolescent: celiac artery compression syndrome. Can J Gastroenterol 2010;24:91-3.

(435) Fischer GW, Popich GA, Sullivan DE, Mayfield G, Mazat BA, Patterson PH. Diskitis: a prospective diagnostic analysis. Pediatrics 1978;62:543-8.

(436) Bolivar R, Kohl S, Pickering LK. Vertebral osteomyelitis in children: report of four cases. Pediatrics 1978;62:549-53.

(437) Meijers KA, Thompson J, Cats A. (Sub)acute microbial inflammation of the spine: spondylodiskitis. Ned Tijdschr Geneeskd 1982;126:851-6.

(438) van den Ham JA, Beganovic N. Atypical disease aspects in spondylodiskitis. Ned Tijdschr Geneeskd $1985 ; 129: 411-2$.

(439) Walls T, Bate J, Moshal K. Vertebral collapse in an 8-year-old girl. J Paediatr Child Health 2006;42:212-4.

(440) Eeg-Olofsson O, Carlsson E, Jeppsson S. Recurrent abdominal pains as the first symptom of a spinal cord tumor. Acta Paediatr Scand 1981;70:595-7.

(441) Blevens K, Buchino JJ, Fellows R. A child with chronic abdominal pain and leg weakness. J Pediatr 1984;105:329-32.

(442) Robertson PL. Atypical presentations of spinal cord tumors in children. J Child Neurol 1992;7:360-3.

(443) Akiyama H, Tamura K, Takatsuka K, Kondo M. Spinal cord tumor appearing as unusual pain. Spine 1994;19:1410-2.

(444) Zinkin NT, Peppercorn MA. Abdominal epilepsy. Best Pract Res Clin Gastroenterol 2005;19:263-74.

(445) Olmez A, Kose G, Turanli G. Cyclic vomiting with generalized epileptiform discharges responsive to topiramate therapy. Pediatr Neurol 2006;35:348-51.

(446) Alvarez dB, Gomez Reino FJ, Gomez Reino JJ. A long term study of 22 children with brucellar arthritis. Clin Exp Rheumatol 1990;8:609-12.

(447) Lithner F. Could attacks of abdominal pain in cases of acute intermittent porphyria be due to intestinal angina? J Intern Med 2000;247:407-9. 
(448) Miller A, Lees RS, McCluskey MA, Warshaw AL. The natural history and surgical significance of hyperlipemic abdominal crisis. Ann Surg 1979;190:401-8.

(449) Matern D, Seydewitz H, Niederhoff H, Wiebusch H, Brandis M. Dyslipidaemia in a boy with recurrent abdominal pain, hypersalivation and decreased lipoprotein lipase activity. Eur J Pediatr 1996;155:660-4.

(450) Mhanni AA, Prasad C, Rockman-Greenberg C. Ornithine transcarbamylase deficiency presenting as recurrent abdominal pain in childhood. Pediatr Emerg Care 2011;27:850-3.

(451) Marchesoni CL, Roa N, Pardal AM, Neumann P, Caceres G, Martinez P, et al. Misdiagnosis in Fabry disease. J Pediatr 2010;156:828-31.

(452) Slaoui B, Souhail F, Aboussad A, Bougrine M. Recurrent abdominal pain revealing dermatomyositis (letter). Arch Pediatr 1996;3:90-1.

(453) Weinstock LB, Kothari T, Sharma RN, Rosenfeld SI. Recurrent abdominal pain as the sole manifestation of hereditary angioedema in multiple family members. Gastroenterology 1987;93:1116-8.

(454) Shinzato T, Nakamura H, Kuniyoshi T, Higashionna A, Uehara T, Oshiro J, et al. Hereditary angioedema: a case with ascites yet no symptoms in the family. Intern Med 1992;31:633-5.

(455) Talavera A, Larraona JL, Ramos JL, Lopez T, Maraver A, Arias J, et al. Hereditary angioedema: an infrequent cause of abdominal pain with ascites. Am J Gastroenterol 1995;90:471-4.

(456) Shah TJ, Knowles WO, McGeady SJ. Hereditary angioedema with recurrent abdominal pain and ascites. J Allergy Clin Immunol 1995;96:259-61.

(457) Janardhanan D, Nair S, Subramanian TS. Recurrent abdominal pain due to hereditary angioedema. Indian J Pediatr 2007;74:83-4. 
Outline of the thesis 


\section{OUTLINE OF THE THESIS}

In this thesis we set out to find an answer to the question which causes can be found for chronic abdominal pain with nowadays knowledge.

Therefore, consecutive patients with recurrent abdominal pain (RAP, Apley criteria), age 4-16 years, referred to a secondary medical centre were evaluated by a standardized history, physical examination and ancillary tests. After a comprehensive diagnostic work-up, stepwise therapeutic interventions were performed. A diagnosis was considered to be the putative cause of RAP when the patient became pain-free following therapeutic intervention and remained so for at least 6 months.

With these clinical diagnoses we were able to validate alarm symptoms, that are to be used for the Rome criteria for the functional gastrointestinal pain syndromes, and subsequently to validate these Rome criteria.

The Rome III criteria for irritable bowel syndrome (IBS), functional abdominal pain (FAP), functional abdominal pain syndrome (FAPS) and functional dyspepsia (FD) were assigned independently. A 'Rome diagnosis' was made if a patient presented with the symptom cluster of a functional gastrointestinal pain syndrome in the absence of alarm symptoms. The sensitivity and specificity as well as the positive (PPV) and negative predictive value (NPV) of the Rome diagnoses were estimated, using the clinical diagnoses as the reference standard. The role of alarm symptoms with respect to their capacity to differentiate between organic disease and functional causes, was similarly analyzed.

Several diagnoses were described more thoroughly, namely infections with protozoa, carbohydrate malabsorption and (occult) constipation.

To investigate if protozoa could be identified as cause of RAP, in all patients a triple faeces test (TFT) was performed. Standardized history and physical examination were performed, with special reference to pain characteristics and concomitant symptoms. When parasites were detected, patients were treated. Disappearance of RAP after eradication of parasites with a pain-free follow-up period of at least 6 months was considered indicative of a causal relation with RAP. The clinical presentation of patients with protozoan infections as cause of the pain was compared with that of patients with non-causal protozoan infection and without protozoan infection.

To investigate whether malabsorption of lactose and fructose could be considered a valid cause of RAP, hydrogen breath tests were performed with lactose and fructose and patients with an abnormal hydrogen excretion had a dietary intervention. Disappearance of RAP with elimination of the suspected carbohydrate, recurrence with provocation and disappearance with re-elimination, followed by a 6 month pain-free follow-up, was considered indicative of a causal relation with RAP. For definite proof, a double-blinded placebo-controlled (DBPC) provocation was performed.

The role of constipation in RAP was investigated by an intervention with laxative therapy for all patients, after having excluded gastrointestinal infections and food allergy or intolerance as causes of the pain. Constipation was considered to be the cause of RAP when the pain disappeared with laxative treatment for a period of at least 6 months. To investigate if patients diagnosed with constipation could be identified based on history and physical examination, a simple statistical model was build with the variables that showed the strongest association. 

CFM Gijsbers'1, MA Benninga², HA Büller³.

1Department of paediatric gastroenterology, Juliana Children's Hospital/Haga Teaching Hospital, The Hague, 2Department of paediatric gastroenterology Academic Medical Centre, Amsterdam, ${ }^{3}$ Erasmus Medical Centre, Rotterdam, The Netherlands

Acta Paediatrica 2011;100(7):1028-1032

\section{ABSTRACT}

Aim: To investigate the clinical and laboratory findings in children with recurrent abdominal pain (RAP).

Methods: Consecutive patients with RAP (Apley criteria), age 4-16 years, referred to a secondary medical centre were evaluated by a standardized history, physical examination and laboratory tests. The tests encompassed Helicobacter pylori ( $\mathrm{Hp})$, gastrointestinal bacterial infections, protozoa, celiac disease, carbohydrate malabsorption, food intolerance, abdominal ultrasound and plain abdominal X-ray. More investigations were obtained if indicated. Patient characteristics were compared with surgical patients without abdominal pain (control group).

Results: A total of 220 consecutive patients were included ( $92 \mathrm{M}$, mean age 8,8 years [4,1-16,0 years]). In $88 \%$ of the patients abnormalities were found that refer to possible causes. Especially protozoa were present in $33 \%$ of the patients, mostly Dientamoeba fragilis, Yersinia enterocolitica in $12 \%$ and endoscopically proven infection with $\mathrm{Hp}$ in $11 \%$. In $36 \%$ a plain abdominal X-ray raised suspicion of constipation.

Conclusion: In 220 consecutive patients with RAP, referred to secondary care, a standardized work up yielded abnormal results in a high percentage.

The clinical significance of these findings remains to be established.

\section{Introduction}

In 1958 Apley published his pivotal paper on RAP (1). He defined RAP as at least 3 bouts of abdominal pain, severe enough to interfere with daily activities, over a period of at least 3 months. In this school population he found $10,8 \%$ to have RAP, but there was no suspicion of organic disease to explain abdominal pain in these children. A considerable number of children and their families however, showed psychological problems. Apley at that time suggested that emotional disturbances might play an important role in the pathogenesis of abdominal pain. This form of abdominal pain was considered to be 'functional'. In the last decade, experts in the field of paediatric gastroenterology attempted to set criteria for functional gastrointestinal disorders in childhood, including abdominal pain, the Rome criteria. These Rome criteria are based on a complex of symptoms and - importantly - exclusion of organic causes of the pain. There are no guidelines however, as to which organic causes have to be excluded before a functional disorder according to the Rome criteria can be diagnosed.

Attempts to identify somatic causes of RAP are relatively scarce. In the past, somatic causes of RAP were found by Apley in 2 series in 6-8\% (2). More recently, using new techniques, organic abnormalities were found in $25-45 \%$ of children with RAP (3-9).

The prevalence of RAP in children varies from $<1$ to $39 \%$ in population based studies; this difference could be related to different definitions of RAP and differences in the methodologies to assess the diagnosis (10;11). 
We performed a prospective study in children, referred by their general physicians to a secondary care clinic, presenting with RAP to evaluate the characteristics of pain, concomitant symptoms, and results of diagnostic tests. Aim of the study was to assess the percentage of possible organic causes in children with abdominal pain who were worked up with a similar protocol. The ultimate goal is to optimise our approach to children presenting with RAP.

\section{Patients and Methods}

Between May 2002 and May 2004 all consecutive patients (age 4-16 years) with RAP, fulfilling the Apley criteria, who were referred by general practitioners to a non-academic hospital, were included and subsequently evaluated by the first author. After a standardised history and physical examination the following diagnostic tests were performed in all children: a complete blood cell count, ESR, liver and renal function tests, amylase, calcium, phosphate, albumin, total IgE, RAST with a panel of 6 food allergens, total IgA, celiac antibodies (IgA and IgG anti gliadine, IgA anti endomysium, IgA anti tissue transglutaminase); urine protein, glucose, reducing substance and culture. Helicobacter serology, Yersinia serology (immunoblot); faecal culture (Salmonella, Shigella, Campylobacter, Yersinia), faecal tests on Dientamoeba fragilis, Blastocystis hominis and Giardia lamblia (SAF fixative, iron haematoxylin-Kinyoun staining) and Giardia lamblia specific ELISA; examining of an unpreserved stool sample for (oo)cysts and spores of protozoa and faecal Helicobacter pylori antigen (Meridien, later Dako). All patients underwent a lactose hydrogen breath test $\left(\mathrm{LH}_{2} \mathrm{BT}\right)$ and the first 134 patients also had a fructose breath test $\left(\mathrm{FH}_{2} \mathrm{BT}\right)$ with $2 \mathrm{~g}$ lactose or fructose. Abdominal ultrasound and a plain abdominal $\mathrm{X}$ ray were obtained in all patients. Other investigations such as endoscopies, small bowel follow through, $24 \mathrm{~h} \mathrm{pH}$ measurement were only performed if indicated. Patients and/or their parents rated the pain between $0-5$. Zero indicated no pain, whereas 5 indicated severe pain.

The control group consisted of consecutive patients of the paediatric surgical and orthopaedic outpatient clinics without a history of abdominal pain (age 4-16 years). In accordance with the patient group they had the same standard history, but no further physical examination or diagnostic tests were performed. The ethical committee of the hospital approved this study.

\section{Results}

Two hundred twenty consecutive patients were included ( $128 \mathrm{~F}, 92 \mathrm{M})$, of whom 120 Caucasian (55\%). Mean age at presentation was 8,8 years (range 4,1-16,0 years). The control group consisted of $236(115 \mathrm{~F}, 121 \mathrm{M})$ children with a mean age of 9,9 years (range 4,0-16,0), of whom 176 Caucasian (75\%).

\section{History}

Mean age of onset of the pain was 6 years (range "from birth" $-14,9$ years). The mean duration of abdominal pain was 2,6 years (range 3 months -15 years). Forty three (20\%) children had pain for at least 5 years. In table 1 the pain characteristics are presented. Many children $(177 ; 80 \%)$ reported varying severity of pain; in table 1 the maximal score is shown. Hundred eighteen children (54\%) were awakened at night at least once by abdominal pain. Thirty three children (15\%) missed school at least 1 (part of a) day each week. In 8 children pain started after a specific, stressful situation or event. Parents of 51 children mentioned psychosocial problems in the family or at school and the parents of 40 children thought that stress could be the cause of their child's abdominal pain. 
Altogether stress could play a role in 71 children.

Many children had concomitant gastrointestinal complaints as shown in table 2 .

Table 2 also depicts data on past history of the pain group and the control group, whereas table 3 represents the family history in the patient and control group.

\section{Physical examination}

Twenty five patients (11\%) had abdominal distension and 126 children (57\%) had abdominal fullness or a palpable colon. Abdominal tenderness was found in 154 patients (70\%). Rectal digital examination was performed in 215 children (98\%); a full rectum was found in 55 children ( $26 \%$ ). No other abnormalities were found upon rectal digital examination and/or upon physical examination. No gross abnormalities were found with respect to weight or height.

\section{Diagnostic tests}

Table 4 shows the test results of diagnostic tests that refer to specific diagnoses, that could be the cause of the pain. The results of aspecific blood tests, that could serve as alarm signals, are shown in table 5.

Duodenoscopy, with histology, culture of biopsies and urease test, was performed in patients with positive Helicobacter serology or Helicobacter antigen in stool. An infection with Helicobacter pylori was proven endoscopically in 24 patients (11\%).

Celiac antibodies were positive in 1 patient; duodenal biopsies had the typical microscopy of Marsh $3 \mathrm{C}$ and she was consequently diagnosed as celiac disease. IgA deficiency ( $\lg A<0,1 \mathrm{~g} / \mathrm{l})$ was found in 3 patients; they had no $\lg \mathrm{G}$ antigliadin antibodies. Abdominal ultrasound, performed in 213 patients, showed thickening of the bowel wall in 3 patients, 1 of which had ileitis terminalis with Yersinia enterocolitica; 1 had a thickened terminal ileum, that spontaneously normalized; 1 patient had a thickened jejunal loop. Abnormalities of the appendix were seen with ultrasound in 4 patients: 1 had a mucus filled appendix, 2 had a thickened appendix with more or less infiltration of periappendicular fat, 1 was suspected to have a thickened appendix. One patient had a very wide proximal duodenum after operation for a duodenal web as a neonate; she had bilious duodenogastric reflux with severe gastritis.

Aspecific alarm symptoms, the so-called red flags (table 5), were found in 149 patients (68\%). Specific abnormalities, such as urine tract infections, infections with Helicobacter pylori, celiac disease, were found in 194 patients (88\%), with a mean of 1,8 abnormal findings per patient (range 0-5).

\section{Discussion}

Two hundred twenty consecutive patients, referred from general practitioners to a paediatrician in a secondary hospital, were worked up in a similar manner. Based on this standardised work-up 194 patients (88\%) showed at least one abnormality in their results, that could be the cause of the pain. The population described in this study is comparable with patient populations described earlier as to age range and gender $(1 ; 3-5 ; 8 ; 9 ; 12-14)$. The impact of this study lies in the problem of sufficiently excluding organic disease before diagnosing a functional cause according to the Rome criteria.

In accordance with the literature we found a high percentage of patients with longstanding abdominal pain (12 months or more in $69 \%$ ) which potentially could have a great impact on their life; it resulted in a high number of missed days at school (15-18). In adults an increased prevalence of suicidal behaviour is shown in people with chronic abdominal pain syndromes (19). 
All gastrointestinal symptoms occurred much more often in the patients than in the control group. The same is true for extra-intestinal pains, as has been described earlier (1). Only sparse data are available on the relation of infant colics and the existence of RAP later in life, although a relation is suggested in two studies (20;21). In this study abdominal cramps in the first year of life occurred more, but infant colics ("lasting, severe crying, unsoothable", no diary because of retrospective data) occurred less frequently in patients than in the control group. In the families of the patients more gastrointestinal complaints, more headaches and more allergies occurred than in the families of the controls. These data are in accordance with the data of other studies (1).

At physical examination a substantial number of patients had abdominal tenderness, abdominal fullness or a palpable colon. It is noteworthy, that in this unselected group of patients $26 \%$ were found to have a rectal mass upon rectal examination. In the literature only very few publications mention the results of physical examination in children with RAP (3;8;12-14). Most describe abdominal tenderness without guarding in a high percentage. Only in some patients a faecal mass is felt upon abdominal palpation.

The diagnostic tests resulted in numerous abnormal findings, both alarm symptoms like anaemia or an abnormal ESR and results that point to specific diagnoses, like infections or food intolerance. Abnormal tests referring to possible causes of RAP were found in $88 \%$ of the patients. Many of these patients had more than one abnormal test, but many of these abnormal tests refer to diagnoses that are not necessarily the cause of the pain, like infection with Helicobacter pylori, Dientamoeba fragilis, Yersinia enterocolitica or lactose malabsorption. Although fructose malabsorption is thought to cause gastrointestinal symptoms, fructose malabsorption can be found in many normal people without symptoms. The clinical significance of fructose malabsorption is incompletely understood (22). Other abnormal tests indicate gastrointestinal infections like infections with protozoa, which can mimic irritable bowel syndrome, or with Yersinia enterocolitica, which is a potential cause of RAP (23). However, studies as to the prevalence of these microorganisms in children with RAP never have been done. Considerable worldwide differences in the prevalence of protozoa are published; experience of the laboratory in recognizing these parasites is known to play a role in the results as well (24). Surprisingly, alarm symptoms were found in $68 \%$ of the patients. These signs and symptoms are supposed to be warning signals for organic disease (25). Additional work-up is needed to establish the cause of the pain in individual patients and the role and meaning of alarm symptoms in the diagnostic process.

Stress is supposed to be a cause of recurrent abdominal pain. However, the presence of stress in itself is not enough to presume a relationship to the abdominal pain. Guidelines as to the way to establish a causal relationship of RAP with stress are presented by Alfvén (3).

At long term follow up RAP in children seldom appears to be caused by serious organic disease (10;13;16;26-29). This is often considered a justification for only limited diagnostic testing in children without alarm symptoms (30). Currently, children with RAP are often investigated or treated based on the clinical judgement of the individual paediatrician. Generally, review articles and guidelines are not clear about what should be done. The Rome criteria, stating that organic disease should be excluded, leave too much room for under or overtesting of children with RAP. The importance of this study lies in the systematic diagnostic work-up of a large group of non-selected children with RAP. 
The limitations of this study lie in the lack of data as to clinical significance. The finding of positive tests in $88 \%$ of the patients is striking, but should be interpreted carefully. First, because finding an abnormal test is not proof for a causal relationship. Second, the number of tests performed is not very extensive but clearly more than limited and come at a certain cost. Third, the definition of a test and its cut-off value are always a matter of debate, for example Barr score indicating faecal retention. Nevertheless, finding $88 \%$ of children to have a possible cause for their complaints warrants further analysis and studies.

\section{Conclusion}

In 220 consecutive patients with abdominal pain, referred to secondary care, a standardized work up yielded abnormal results in a high percentage. The clinical significance of these findings remains to be established. 
Table 1. Pain characteristics

\begin{tabular}{|c|c|}
\hline Abdominal pain $(n=220)$ & n (\%) \\
\hline \multicolumn{2}{|l|}{ Pain since } \\
\hline 3-6 months & $32(15)$ \\
\hline 6-12 months & $36(16)$ \\
\hline$\geq 12$ months & $152(69)$ \\
\hline Start pain after gastrointestinal infection & $17(8)$ \\
\hline Start pain related to stress & $8(4)$ \\
\hline \multicolumn{2}{|l|}{ Localisation } \\
\hline Umbilicus & $72(33)$ \\
\hline Right upper quadrant & $3(1)$ \\
\hline Epi/hypogastrium & $42(19)$ \\
\hline Upper part & $13(6)$ \\
\hline Right lower quadrant & $5(2)$ \\
\hline Lower part & $35(16)$ \\
\hline Whole belly & $7(3)$ \\
\hline Other & $43(20)$ \\
\hline \multicolumn{2}{|l|}{ Frequency of pain } \\
\hline Daily & $74(34)$ \\
\hline 4- 6 days/week & $71(32)$ \\
\hline 1-3 days/week & $52(24)$ \\
\hline 1-4 days/month & $21(10)$ \\
\hline$<1$ day/month & $2(1)$ \\
\hline \multicolumn{2}{|l|}{ Duration of pain } \\
\hline (Almost) whole day & $37(17)$ \\
\hline 1-several hours & $48(22)$ \\
\hline $15-60$ minutes & $78(35)$ \\
\hline$<15$ minutes & $57(26)$ \\
\hline \multicolumn{2}{|l|}{ Severity of pain (score $1-5$ ) * } \\
\hline 1 & $4(2)$ \\
\hline 2 & $14(6)$ \\
\hline 3 & $53(24)$ \\
\hline 4 & $78(35)$ \\
\hline 5 & $61(28)$ \\
\hline \multicolumn{2}{|l|}{ Pain most prominent } \\
\hline Early morning, before breakfast & $77(35)$ \\
\hline Evening, after dinner & $48(22)$ \\
\hline Night & $27(12)$ \\
\hline After meals & $56(25)$ \\
\hline Before defaecation & $76(35)$ \\
\hline With physical exercise & $87(40)$ \\
\hline Related to menses & 1 \\
\hline Decrease of pain after defaecation & $102(46)$ \\
\hline School non-attendance $\geq 1$ (part of) day/week & $33(15)$ \\
\hline
\end{tabular}

* Pain score 1-5: 1 = very mild pain, 5 = crying or shouting with pain 
Table 2. Gastrointestinal symptoms, other pains and past history

\begin{tabular}{|c|c|c|c|}
\hline & Patients, n (\%) & Controls, n (\%) & p-value * \\
\hline Other gastrointestinal symptoms & $217(99)$ & $114(48)$ & $<0,001$ \\
\hline Loss of appetite & $126(57)$ & $10(4)$ & \\
\hline Early satiety & $106(48)$ & $15(6)$ & \\
\hline Nausea & $123(56)$ & $5(2)$ & \\
\hline Vomiting & $55(25)$ & $5(2)$ & \\
\hline Feeling of fullness & $122(55)$ & $15(6)$ & \\
\hline Regurgitation & $62(28)$ & $5(2)$ & \\
\hline Belching & $47(21)$ & $11(5)$ & \\
\hline Flatulence & $92(42)$ & $32(14)$ & \\
\hline Defaecation $\leq 2 /$ week & $20(9)$ & $8(3)$ & \\
\hline Hard stools (majority of stools) & $41(19)$ & $24(10)$ & \\
\hline $\begin{array}{l}\text { Diarrhea/unformed stools } \\
\text { (majority of stools) }\end{array}$ & $25(11)$ & $14(6)$ & \\
\hline Faecal incontinence & $86(39)$ & $40(17)$ & \\
\hline Rectal blood loss & $21(10)$ & $3(1)$ & \\
\hline Other pains & $143(65)$ & $56(24)$ & $<0,001$ \\
\hline Headaches & $112(51)$ & $30(13)$ & \\
\hline Limb pain & $63(29)$ & $26(11)$ & \\
\hline Arthralgia & $31(14)$ & $8(3)$ & \\
\hline Past history & $113(51)$ & 91 (39) & 0,006 \\
\hline Abdominal cramps & $108(49)$ & $82(35)$ & 0,002 \\
\hline Infant colics & $17(8)$ & $34(15)$ & 0,026 \\
\hline
\end{tabular}

*Chi-square test

Table 3. Family history (1st degree)

\begin{tabular}{|c|c|c|c|}
\hline & Patients, n (\%) & Controls, n (\%) & p-value * \\
\hline Gastrointestinal symptoms & $132(60)$ & $67(28)$ & $<0,001$ \\
\hline IBS-like symptoms & $110(50)$ & $53(22)$ & \\
\hline IBD & $3(1)$ & $2(1)$ & \\
\hline Upper GI symptoms & $55(25)$ & $18(8)$ & \\
\hline Peptic ulcer & $20(9)$ & $7(3)$ & \\
\hline Headaches & $112(51)$ & $77(33)$ & $<0,001$ \\
\hline Migraine & $65(30)$ & $56(24)$ & \\
\hline Non migraine headache & $56(25)$ & $50(21)$ & \\
\hline Allergy & $133(60)$ & $112(47)$ & 0,005 \\
\hline
\end{tabular}

*Chi-square test 
Table 4. Results of diagnostic tests

\begin{tabular}{|c|c|}
\hline Diagnostic tests $(n=220)$ & n (\%) \\
\hline Liver function tests abnormal & 1 \\
\hline Renal function tests abnormal & 0 \\
\hline Hyperamylasaemia $>2 x$ upper limit & 0 \\
\hline Urine amylase $>1500 \mathrm{U} / \mathrm{I}$ & $2(1)$ \\
\hline Urine: protein $>0,15 \mathrm{~g} / \mathrm{l}$ & $14(6)$ \\
\hline Urine: culture positive & $3(1)$ \\
\hline Yersinia immunoblot: IgA positive/weakly pos & $6 / 19(11)$ \\
\hline Faecal culture: Campylobacter jejuni/Yersinia enterocolitica positive & $2 / 1(1)$ \\
\hline Giardia lamblia & $9(4)$ \\
\hline Blastocystis hominis & $28(13)$ \\
\hline Dientamoeba fragilis & $50(23)$ \\
\hline Helicobacter pylori (endoscopically proven) & $24(11)$ \\
\hline Celiac antibodies positive, Marsh $3 \mathrm{C}$ & 1 \\
\hline RAST food allergens positive & $28(13)$ \\
\hline Lactose $\mathrm{H}_{2}$ breath test positive $\left(\Delta \mathrm{H}_{2}>20 \mathrm{ppm}\right)(\mathrm{n}=210)$ & $64(30)$ \\
\hline Fructose $\mathrm{H}_{2}$ breath test positive $\left(\Delta \mathrm{H}_{2}>20 \mathrm{ppm}\right)(\mathrm{n}=121)$ & $92(76)$ \\
\hline \multicolumn{2}{|l|}{ Abdominal ultrasound $(n=213)$} \\
\hline Thickened bowel wall & $3(1)$ \\
\hline Abnormalities appendix & $4(2)$ \\
\hline Prestenotic dilatation duodenum (after duodenal web) & 1 \\
\hline Gallstones & 1 \\
\hline Mesenteric cyst & 1 \\
\hline Splenomegaly & 1 \\
\hline Mesenteric lymph nodes & $27(13)$ \\
\hline Ileocecal lymph nodes & $8(4)$ \\
\hline Plain abdominal X-ray $(n=212)$ : Barr score $\geq 10$ & $76(36)$ \\
\hline
\end{tabular}

Table 5. Red flags

\begin{tabular}{|c|c|}
\hline Red flags & n (\%) \\
\hline Pain at night & $27(12)$ \\
\hline Pain RLQ & $5(2)$ \\
\hline Pain RUQ & $3(1)$ \\
\hline Rectal blood loss & $21(10)$ \\
\hline Arthralgia & $31(14)$ \\
\hline Fever & $26(12)$ \\
\hline Weight loss (by history) & $33(15)$ \\
\hline Family history positive for IBD & $19(9)$ \\
\hline Family history positive for peptic ulcer & $52(24)$ \\
\hline Anemia $(\mathrm{Hb}<7 \mathrm{mmol} / \mathrm{l})$ & $15(7)$ \\
\hline Leucocytosis (>15 x 109/l) & 0 \\
\hline $\mathrm{ESR}>20 \mathrm{~mm} / \mathrm{h}$ & $15(7)$ \\
\hline
\end{tabular}




\section{REFERENCE LIST}

(1) Apley J, Naish N. Recurrent abdominal pains: a field survey of 1,000 school children. Arch Dis Child 1958;33:165-70.

(2) Apley J. The child with abdominal pains. 2 ed. Oxford: Blackwell Scientific; 1975.

(3) Alfven G. One hundred cases of recurrent abdominal pain in children: diagnostic procedures and criteria for a psychosomatic diagnosis. Acta Paediatr 2003;92:43-9.

(4) Croffie JM, Fitzgerald JF, Chong SK. Recurrent abdominal pain in children--a retrospective study of outcome in a group referred to a pediatric gastroenterology practice. Clin Pediatr (Phila) 2000;39:267-74.

(5) El-Matary W, Spray C, Sandhu B. Irritable bowel syndrome: the commonest cause of recurrent abdominal pain in children. Eur J Pediatr 2004;163:584-8.

(6) Hyams JS, Treem WR, Justinich CJ, Davis P, Shoup M, Burke G. Characterization of symptoms in children with recurrent abdominal pain: resemblance to irritable bowel syndrome [see comments]. J Pediatr Gastroenterol Nutr 1995;20:209-14.

(7) Hyams JS, Davis P, Sylvester FA, Zeiter DK, Justinich CJ, Lerer T. Dyspepsia in children and adolescents: a prospective study. J Pediatr Gastroenterol Nutr 2000;30:413-8.

(8) Stordal K, Nygaard EA, Bentsen B. Organic abnormalities in recurrent abdominal pain in children. Acta Paediatr 2001;90:638-42.

(9) van der Meer SB. [Chronic recurrent abdominal pain in school children]. Tijdschr Kindergeneeskd 1993;61:69-75.

(10) Chitkara DK, Rawat DJ, Talley NJ. The epidemiology of childhood recurrent abdominal pain in Western countries: a systematic review. Am J Gastroenterol 2005;100:1868-75.

(11) von Baeyer CL, Walker LS. Children with recurrent abdominal pain: issues in the selection and description of research participants [see comments]. J Dev Behav Pediatr 1999;20:307-13.

(12) Bury RG. A study of 111 children with recurrent abdominal pain. Aust Paediatr J 1987;23:117-9.

(13) Liebman WM. Recurrent abdominal pain in children: a retrospective survey of 119 patients. Clin Pediatr (Phila) 1978;17:149-53.

(14) Stone RT, Barbero GJ. Recurrent abdominal pain in childhood. Pediatrics 1970;45:732-8.

(15) Varni JW, Lane MM, Burwinkle TM, Fontaine EN, Youssef NN, Schwimmer JB, et al. Health-related quality of life in pediatric patients with irritable bowel syndrome: a comparative analysis. J Dev Behav Pediatr 2006;27:451-8.

(16) Walker LS, Garber J, Van Slyke DA, Greene JW. Long-term health outcomes in patients with recurrent abdominal pain. J Pediatr Psychol 1995;20:233-45.

(17) Youssef NN, Murphy TG, Langseder AL, Rosh JR. Quality of life for children with functional abdominal pain: a comparison study of patients' and parents' perceptions. Pediatrics 2006;117:54-9.

(18) Youssef NN, Atienza K, Langseder AL, Strauss RS. Chronic abdominal pain and depressive symptoms: analysis of the national longitudinal study of adolescent health. Clin Gastroenterol Hepatol 2008;6:329-32.

(19) Spiegel B, Schoenfeld P, Naliboff B. Systematic review: the prevalence of suicidal behaviour in patients with chronic abdominal pain and irritable bowel syndrome. Aliment Pharmacol Ther 2007;26:183-93.

(20) Canivet C, Jakobsson I, Hagander B. Infantile colic. Follow-up at four years of age: still more "emotional". Acta Paediatr 2000;89:13-7.

(21) Savino F, Castagno E, Bretto R, Brondello C, Palumeri E, Oggero R. A prospective 10-year study on children who had severe infantile colic. Acta Paediatr Suppl 2005;94:129-32.

(22) Kyaw MH, Mayberry JF. Fructose malabsorption: true condition or a variance from normality. J Clin Gastroenterol 2011;45:16-21.

(23) Stark D, van HS, Marriott D, Ellis J, Harkness J. Irritable bowel syndrome: a review on the role of intestinal protozoa and the importance of their detection and diagnosis. Int J Parasitol 2007;37:11-20. 
(24) Soon GS, Saunders N, Ipp M, Sherman PM, Macarthur C. Community-based case-control study of childhood chronic abdominal pain: role of selected laboratory investigations. J Pediatr Gastroenterol Nutr 2007;44:524-6.

(25) Oberlander TF, Rappaport LA. Recurrent abdominal pain during childhood. Pediatr Rev 1993;14:313-9.

(26) Apley J, Hale B. Children with recurrent abdominal pain: how do they grow up? Br Med J 1973;3:7-9.

(27) Christensen MF, Mortensen O. Long-term prognosis in children with recurrent abdominal pain. Arch Dis Child 1975;50:110-4.

(28) Stickler GB, Murphy DB. Recurrent abdominal pain. Am J Dis Child 1979;133:486-9.

(29) Stordal K, Nygaard EA, Bentsen BS. Recurrent abdominal pain: a five-year follow-up study. Acta Paediatr 2005;94:234-6.

(30) Rasquin A, Di LC, Forbes D, Guiraldes E, Hyams JS, Staiano A, et al. Childhood functional gastrointestinal disorders: child/adolescent. Gastroenterology 2006;130:1527-37. 
Clinical and laboratory findings in 220 children with recurrent abdominal pain 

CFM Gijsbers¹, CMF Kneepkens², JJ Schweizer³, MA Benninga4, HA Büller5.

1Department of paediatric gastroenterology, Juliana Children's Hospital/Haga Teaching Hospital, The Hague, 2Department of paediatric gastroenterology, VU University Medical Centre, Amsterdam, ${ }^{3}$ Department of paediatric gastroenterology, Leiden University Medical Centre, Leiden, ${ }^{4}$ Department of paediatric gastroenterology, Academic Medical Centre, Amsterdam, ${ }^{5}$ Erasmus Medical Centre, Rotterdam, The Netherlands

Acta Paediatrica 2011;100(11):e208-e214

\section{ABSTRACT}

Aim: To establish to what extent somatic causes can be found in children referred to secondary care with recurrent abdominal pain.

Methods: For 2 years all consecutive patients (age 4-16 years) fulfilling Apley criteria, referred to secondary care, were included. After a diagnostic work-up, stepwise therapeutic interventions were performed. A diagnosis was considered to be the cause of the pain when the patient became pain-free following therapeutic intervention and remained so for at least 6 months.

Results: Two hundred twenty children (128 F, 92 M; mean age 8,8 years) were enrolled, 20 were lost to follow-up. Spontaneous recovery was seen in 54 patients, (occult) constipation in 92 patients (of whom 18 also had a somatic cause), gastrointestinal infections in 40, food allergy in 5, miscellaneous disorders in 7, uncertain diagnosis in 13. In 5 patients stress most likely caused the pain. A total of 198 patients became pain-free and remained so during follow-up (mean 18, range 6-60 months).

Conclusion: In 200 children with recurrent abdominal pain somatic causes were found in $26 \%$. Laxative therapy was successful in $46 \%$, resulting in nearly all patients with functional abdominal pain to become pain-free. Eventually, 99\% became pain-free using a therapeutic intervention protocol.

\section{Introduction}

Recurrent abdominal pain (RAP) is a frequent problem in children, leading to considerable morbidity (1). In 1958, Apley defined RAP as at least 3 bouts of abdominal pain, severe enough to affect activities, over a period of at least 3 months (2). Apley found a considerable percentage of patients to have psychological problems, leading to the assumption that RAP is a functional condition and that attempts to diagnose organic conditions would be counterproductive. One decade ago, the Rome criteria were proposed for functional gastrointestinal disorders, including abdominal pain syndromes ${ }^{(3,4)}$. These pain syndromes are based on typical symptom combinations and exclusion of organic causes. However, there are no guidelines as to which diagnostic tests should be performed and which organic causes should be excluded before the pain could be considered functional according to the Rome criteria.

The finding of an organic condition is not enough to presume a relationship to the abdominal pain. Alfvén described criteria for certain diagnoses; however, most authors do not define how they establish a causal relationship (5).

In order to obtain insight into the causative role of organic conditions found in these patients, a study was designed to establish the causes of the pain in children with RAP. 
If the diagnostic work-up pointed to possible organic causes, a stepwise treatment protocol was followed. Success of these therapeutic interventions was followed up during at least 6 months before the organic finding was established as the putative cause.

\section{Methods}

Between May 2002 and May 2004, all consecutive patients (ages 4-16 years) with RAP (Apley criteria), and referred by general practitioners to a secondary centre (CFMG), were included. A standard protocol was developed for history, physical examination and diagnostic work-up, consisting of tests for gastrointestinal infections, celiac disease, food allergy and carbohydrate intolerance. All children underwent a blood cell count, chemistry, urine screening, plain abdominal X-ray and abdominal ultrasound (6). In the first phase, the diagnostic work-up resulted in the establishment of preliminary diagnoses, for instance Helicobacter pylori (Hp) gastritis, or celiac disease, as well as diagnostic clues e.g. carbohydrate malabsorption. In the second phase, criteria for the causal relation of these preliminary diagnoses with the abdominal pain were based on positive results of therapeutic interventions that should persist for at least 6 months (Appendix). Interventions were performed in a fixed order (figure 1). No clinical interpretation or weighing of history or physical findings was performed.

Intervention for Helicobacter pylori infection consisted of triple therapy. Protozoal infections were treated with metronidazole or tinidazole. In case of imidazole intolerance, Dientamoeba fragilis infection was treated with paromomycin and Blastocystis hominis infection with co-trimoxazol. Therapy for Yersinia enterocolitica infection consisted of co-trimoxazol or ciprofloxacin.

Food allergy was considered in patients with either a positive RAST (standard food panel), a history of intolerance or aversion of one or more foods, a (past) history of food allergy or a positive first degree family history of food allergy. If a specific food was suspected, it was eliminated followed by open provocation. The diagnosis of food allergy was made following a positive double-blind placebo-controlled food challenge (DBPCFC). Elimination of lactose and fructose was combined in case both tests were positive. After successful elimination provocation followed with lactose and fructose apart. The diagnosis of lactose or fructose intolerance was made after DBPCFC.

If these therapeutic interventions were not successful, all patients with persistent abdominal pain had a trial with laxatives, a high-fibre diet and toilet training, irrespective of history, physical examination or abdominal X-rays. We defined the children who became pain free with laxative therapy to have (occult) constipation.

The endpoint of this study was the patients being pain free, either spontaneously or by intervention. Success of intervention was defined as a pain free period, as obtained by history from patient/parents, of at least 6 months. When abdominal pain recurred during this follow-up period, tests were repeated as indicated, especially with regard to infections. No pain score was used as an instrument to measure the result of an intervention, because the aim of interventions was absence of pain. Only minor pain for a short time before a bowel movement or incidental minor pain was considered acceptable.

The ethical committee of the hospital approved this study. 
Figure 1. Interventions

Phase 1

Standardized history + physical examination

Diagnostic tests

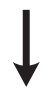

Preliminary diagnoses ${ }^{1}$ / Clues for intervention

Phase 2

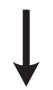

Confirmation/denial of the preliminary diagnosis as the cause of the pain:

\section{Step 1}

Step 2

Step 3

Step 4

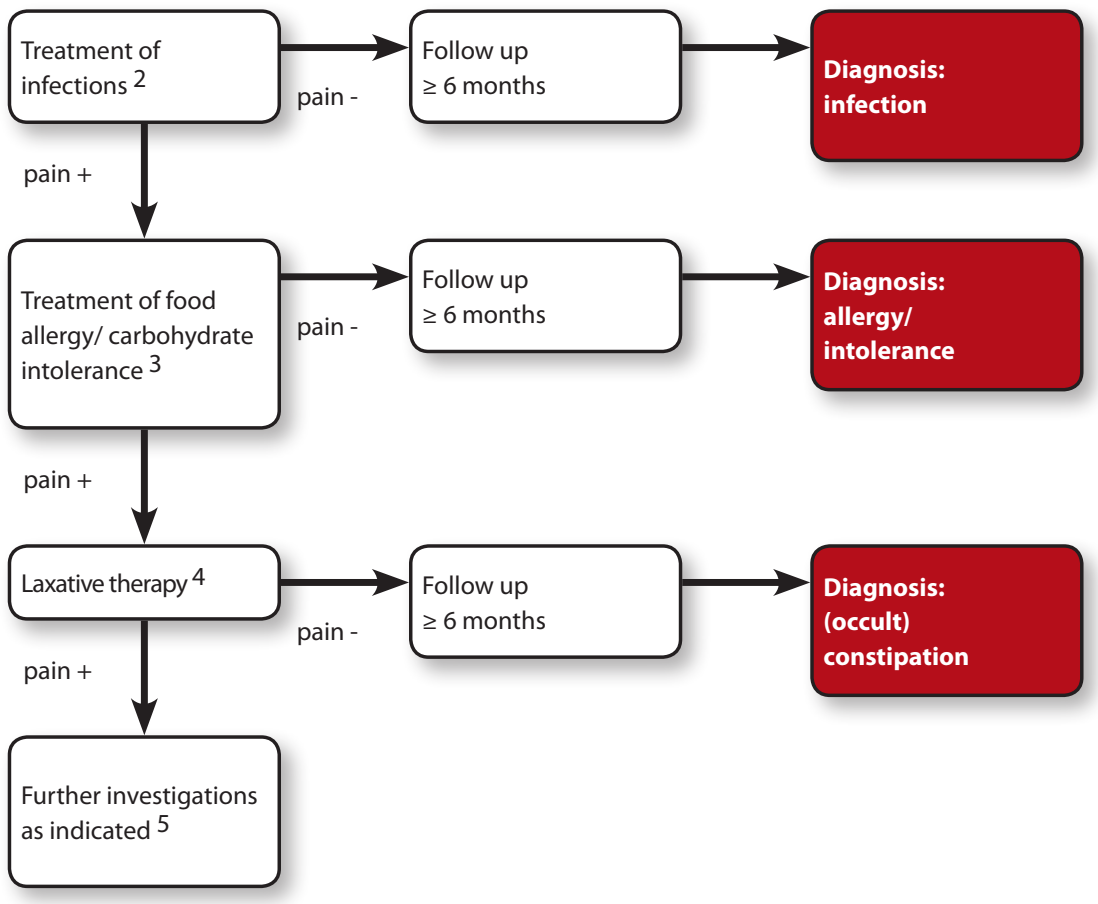

Figure 1, legends

1 Preliminary diagnosis: diagnosis that could be, but not necessarily is the cause of the abdominal pain

2 One by one, in fixed order: urinary tract infection, Helicobacter pylori gastritis, protozoal infection, bacterial intestinal infection

3 Elimination of suspected food and open provocation, if positive followed by DBPC food challenge

4 Irrespective of a history of constipation, findings on physical examination or faecal retention on abdominal $X$-ray

5 When pain persists, as indicated: upper or lower endoscopy, X-ray studies, 24- $h$ pH measurement 


\section{Results}

During a two year period, 220 patients $(128 \mathrm{~F}, 92 \mathrm{M}$; mean age 8,8 years, range 4,1-16,0 years) were enrolled. Twenty patients were lost to follow up.

In the remaining 200 patients, preliminary diagnoses or clues as shown in table 1 were found in 178 patients (89\%), with a mean of 1,8 abnormal findings per patient (range 0-5). Following intervention 139 patients were pain-free, spontaneous recovery was seen in 54 patients en in 5 stress was considered the cause of the pain, resulting in 198 patients (99\%) to become pain free (table 2). The mean follow-up period was 18 months (range 6-60 months).

\section{Spontaneous recovery}

Fifty four children recovered after a mean period of 7 months (range 1 week-3,5 years) without apparent relation to an intervention.

\section{Infections}

Endoscopically confirmed $\mathrm{Hp}$ infection was demonstrated in 22 patients (11\%). Adequate intervention resulted in eradication in all patients as shown by faecal $\mathrm{Hp}$-antigen. Only 5 out of these 22 patients became pain-free and remained so in the follow up period; an additional 4 of these 22 became only pain-free after (occult) constipation (3 patients) or parasitic infection (1 patient) was treated as well.

Parasites were found in 71 patients (36\%). Intervention was performed in 64, resulting in eradication in $58(89 \%)$. According to our definition, the parasitic infection was the cause of RAP in 14 out of these 58 patients; an additional 11 of these 58 also had a second causative condition (occult constipation in 9, other infections in 2).

In 22 patients tests suggested Yersinia enterocolitica infection. Thirteen patients were treated, of whom 4 became pain-free; an additional 4 of these 13 also had a second causative condition (occult constipation in 3 , parasites in 1).

\section{Celiac disease}

One patient diagnosed with celiac disease (Marsh 3C) did not become pain free with a gluten free diet, although both serology and duodenal biopsies normalized. With laxatives the pain disappeared. Celiac disease was considered a coincidental finding and the patient was diagnosed with occult constipation.

\section{Food allergy}

One or more signs that raised the possibility of food allergy were present in 123 patients, with an overlap: a positive RAST was found in 25 patients, 93 patients had an aversion to one or more foods, and 40 felt to be intolerant to one or more foods. As shown in figure 2, 5 patients had a positive DBPCFC: one was allergic for cow's milk, two for soy, one for both, one for gluten.

\section{Carbohydrate malabsorption}

Elimination of carbohydrate was performed arbitrarily if the result of the breath test was $\Delta \mathrm{H}_{2}>30 \mathrm{ppm}$ to prevent unnecessary elimination procedures in children with only marginal elevated hydrogen excretion, often without abdominal pain during/after the test Lactose $\mathrm{H}_{2}$ breath tests were completed in 192 patients. Positive tests $\left(\Delta \mathrm{H}_{2}>30 \mathrm{ppm}\right)$ were found in 52 patients. Lactose elimination was performed in 36 patients, 7 of whom had a positive elimination and open provocation. DBPCFC was performed in 6 patients; all were negative, resulting in no diagnosis of lactose intolerance. 
Fructose $\mathrm{H}_{2}$ breath tests were completed in 112 patients. Positive tests $\left(\Delta \mathrm{H}_{2}>30 \mathrm{ppm}\right)$ were found in 72 patients. Fructose elimination was performed in 47 patients, 12 of whom had a positive elimination and open provocation. DBPCFC was performed in 7 patients; all were negative, resulting in no diagnosis of fructose intolerance.

\section{Functional abdominal pain with successful laxative therapy}

Laxative therapy was started in 113 patients, who in previous therapeutic steps did not become pain free. This resulted in consistent disappearance of abdominal pain in 92 . Out of these 92 patients with functional abdominal pain, who were successfully treated with laxatives, 24 also fulfilled Rome II criteria for functional constipation. In the remaining 68 patients, 24 fulfilled the Rome II criteria for irritable bowel syndrome (IBS), 33 for functional abdominal pain (FAP), 9 for functional dyspepsia (FD) and 2 were unclassifiable. In 5 out of these 68 children, stressful events were apparently related to the symptoms. They were pain-free with laxatives and thus diagnosed with occult constipation, but could discontinue the laxatives only following psychosocial intervention. Of these 5 patients 4 fulfilled the Rome II criteria for IBS, 1 for FAP.

Functional abdominal pain without successful laxative therapy.

In 5 children with FAP laxatives did not alleviate the pain. The pain appeared to be consistently related to stressful situations, e.g. school problems. They became pain free by avoiding stressful situations and/or after psychosocial intervention. Of these 5 patients 3 fulfilled the Rome II criteria for FAP and 2 for FD.

\section{Miscellaneous}

Two patients with RAP underwent appendectomy for (confirmed) acute appendicitis during the protocol. After appendectomy they remained pain free during more than 1 year. In addition, a boy with typical symptoms, underwent elective appendectomy, revealing minor abnormalities on histological examination, after which he remained pain-free.

Two patients had medication-related abdominal pain: a 10 year old girl on fluticason medication became pain-free after discontinuation of this medication; a 12 year old girl, treated with amitriptyline which increased the existing abdominal pain, became much better after discontinuation of medication, but needed laxative treatment to become completely pain-free.

In 13 patients a protocol-based diagnosis could not be established, although the pain disappeared with intervention. 
Table 1. Preliminary diagnoses and diagnostic clues in 200 patients

\begin{tabular}{|c|c|c|c|}
\hline Diagnostic findings & Positive if & $\mathbf{n}$ & $\%$ \\
\hline Urine culture & Positive & 2 & 1 \\
\hline Yersinia immunoblot: $\lg \mathrm{A}$ & Positive/weakly positive & $5 / 16$ & 10,5 \\
\hline \multirow[t]{2}{*}{ Faecal culture } & Yersinia enterocolitica present & 1 & 0,5 \\
\hline & Campylobacter jejuni present & 1 & 0,5 \\
\hline \multirow[t]{4}{*}{ Triple faeces test } & Giardia lamblia present & 8 & 4 \\
\hline & Blastocystis hominis present & 28 & 14 \\
\hline & Dientamoeba fragilis present & 49 & 24,5 \\
\hline & Total number of patients with protozoa & $71^{1}$ & 35,5 \\
\hline Helicobacter pylori gastritis & Endoscopically confirmed & 22 & 11 \\
\hline Celiac antibodies & Positive, histologically confirmed & 1 & 0,5 \\
\hline RAST food allergens & Positive & 25 & 12,5 \\
\hline Lactose $\mathrm{H}_{2}$ breath test $(n=192)$ & Positive $(\Delta \mathrm{H} 2>30 \mathrm{ppm})$ & 52 & 27 \\
\hline Fructose $\mathrm{H}_{2}$ breath test $(\mathrm{n}=112)$ & Positive $(\Delta \mathrm{H} 2>30 \mathrm{ppm})$ & 72 & 64 \\
\hline \multirow[t]{6}{*}{ Abdominal ultrasound $(n=195)$} & Thickened bowel wall & 2 & 1 \\
\hline & Abnormal appendix & 4 & 2 \\
\hline & Mesenteric lymph nodes & 26 & 13 \\
\hline & Ileocecal lymph nodes & 8 & 4 \\
\hline & Various & $3^{2}$ & 1,5 \\
\hline & $\begin{array}{l}\text { Total number of patients with US } \\
\text { abnormalities }\end{array}$ & 37 & 19 \\
\hline Plain abdominal X-ray $(n=194)$ & Barr score $\geq 10$ & 68 & 35 \\
\hline
\end{tabular}

1 Ten patients had 2 parasites, two patients had 3 parasites

2 Gallstone, mesenteric cyst, prestenotic duodenal dilatation (duodenal web in past history)

Table 2. Diagnoses of 200 patients with recurrent abdominal pain

\begin{tabular}{|c|c|c|c|c|c|c|c|c|c|c|}
\hline & $\mathrm{Hp}$ & Paras & Yers & FA & Const & Stress & Various & Spont & No $\mathrm{dx}$ & Unsolved \\
\hline Hp* & 5 & 1 & & & 3 & & & & & \\
\hline Parasites & 1 & 14 & 1 & & 9 & & & & & \\
\hline Yersinia & & 1 & 4 & & 3 & & & & & \\
\hline FA & & & & 3 & 2 & & & & & \\
\hline Const & 3 & 9 & 3 & 2 & 74 & & 1 & & & \\
\hline Stress & & & & & & 5 & & & & \\
\hline Various & & & & & 1 & & 6 & & & \\
\hline Spont & & & & & & & & 54 & & \\
\hline No dx & & & & & & & & & 13 & \\
\hline Unsolved & & & & & & & & & & 2 \\
\hline Total & 9 & 25 & 8 & 5 & 92 & 5 & 7 & 54 & 13 & 2 \\
\hline
\end{tabular}

Explanation: This table gives an overview of single (bold marked cells) and double diagnoses. The lower row gives the totals of every diagnosis $(N=220)$; the numbers in the coloured areas together represent all patients $(N=200)$ and add up to 220; 20 patients have double diagnoses.

*Hp = Helicobacter pylori, paras = parasites, Yers = Yersinia enterocolitica, FA = food allergy,

Const $=$ (occult) constipation, Spont $=$ spontaneous, No $d x=$ no diagnosis 
Figure 2. Food allergy

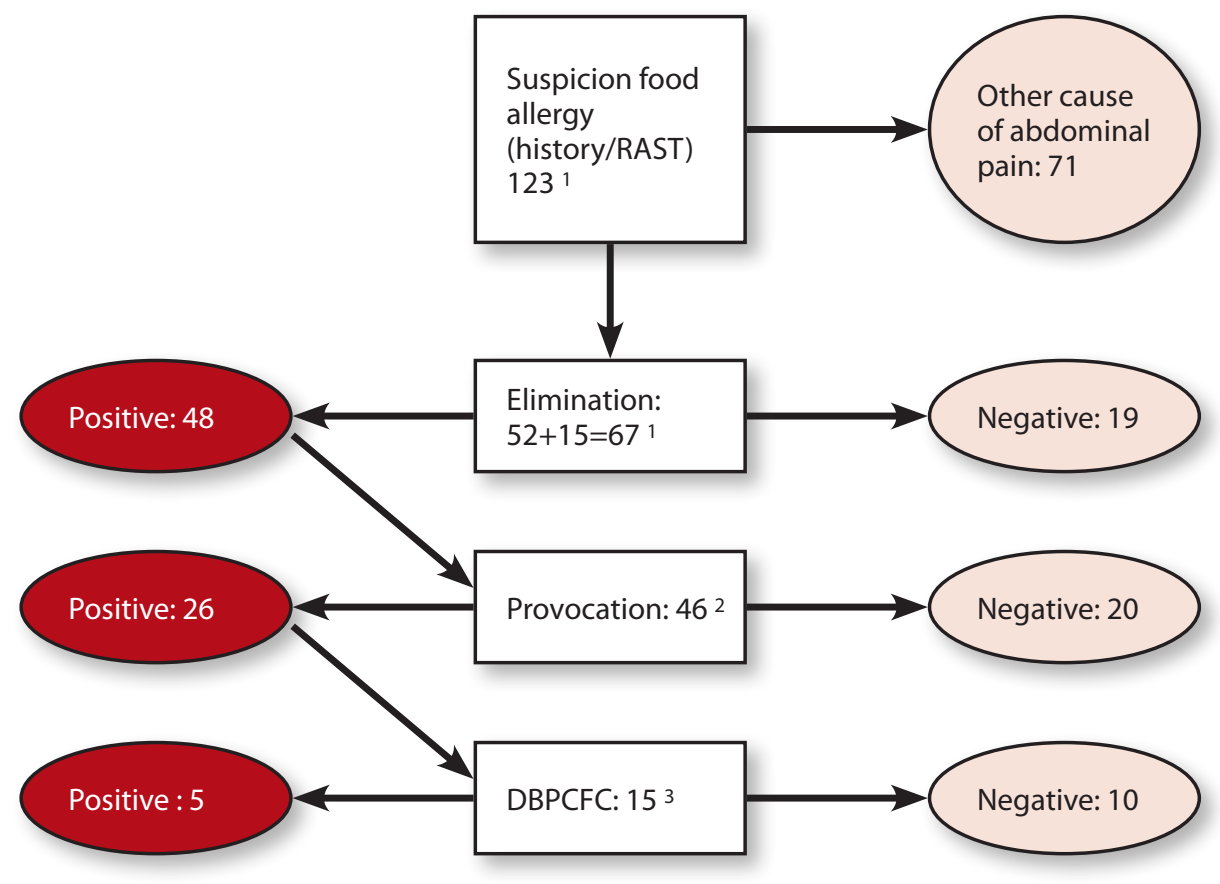

Figure 2, legends

1 Suspicion food allergy by history (aversion or intolerance)/RAST positive: 123; elimination performed in 52 of these. Elimination in an additional 15 patients because of later risen suspicion, food allergy as a baby or food allergy in first degree family.

2 Provocation not performed ( $n=2)$ : provocation was refused.

3 Double blind placebo-controlled food challenge (DBPCFC) not performed ( $n=11$ ): after positive provocation successful reintroduction followed in a later stage $(n=7)$ or DBPCFC was refused $(n=4)$. 


\section{Discussion}

This is the first study to apply a systematic, broad diagnostic approach with stepwise interventions in order to establish putative diagnoses according to preset criteria in patients with RAP. According to our criteria successful therapeutic intervention with a pain-free follow up of at least 6 months was a prerequisite to presume a causal relationship between diagnosis and pain. With these criteria (occult) constipation - usually defined as a functional diagnosis - and a variety of somatic diagnoses were found as causes of RAP in 139 out of 200 patients. They remained pain-free during a mean follow-up period of 18 months. Together with the 54 children who recovered spontaneously and 5 children with stress-related abdominal pain, a total of 198 out of 200 patients (99\%) became pain-free and their diagnoses were confirmed during follow-up according to protocol.

Attempts to identify organic causes of RAP are scarce and are mostly aimed at the evaluation of the yield of certain diagnostic tests. Apley et al described $6-8 \%$ in 2 series of children with RAP to have an organic cause (7). In the 50 years since Apley's conclusions, new techniques have been introduced and new diagnoses are recognised. In the period 19701990 a few studies were performed in children with RAP, using routine blood, urine and faecal tests and more or less extensive X-ray studies. The results showed an organic cause in $0-4 \%$ of the patients $(8-10)$. More recently, organic causes were suggested to be present in $25-45 \%$ of children with RAP $(5,11-16)$.

Gastrointestinal infections can cause recurrent abdominal pain. About one third of patients with IBS are considered to have post infectious IBS, although the causative micro-organism is unknown in most cases (17). In this study attention is paid to the role of $\mathrm{Hp}$, Yersinia enterocolitica and protozoa, which seem to play a role in about $20 \%$ of the patients. Five children had food allergy, with positive DBPCFC. Interestingly, none had a positive RAST. Many children had an abnormal $\mathrm{H}_{2} \mathrm{BT}$ with lactose (27\%) and/or fructose $(64 \%)$. About one third did not need a diagnostic elimination, because they were already pain-free, either spontaneously or by earlier interventions. Of the patients who had a positive diagnostic elimination, only a small number had a positive open provocation. Surprisingly, a DBPCFC was negative in all, indicating that neither lactose nor fructose played a role in RAP. Gomara et al showed a positive result of $81 \%$ with elimination of fructose in 11 patients with a positive $\mathrm{H}_{2} \mathrm{BT}$, but they did not confirm the diagnosis using open provocation or DBPCFC (18). With respect to lactose intolerance conflicting results are reported (19). Importantly, 92 children became pain-free with laxative therapy, of whom 24 (26\%) fulfilled the Rome II criteria of functional constipation; 68 (74\%) were considered to have occult constipation. Our definition of occult constipation implicates that disappearance of symptoms with laxative therapy is the "proof" of this condition. These patients typically fulfil the criteria of functional gastrointestinal pain disorders (Rome II criteria).

No difference was found with respect to the individual functional gastrointestinal pain syndromes: patients who fulfil the criteria of IBS, FAP or FD after exclusion of organic disorders, have a good response with laxatives in nearly all cases. Boccia et al suggested, that $\mathrm{FD}$ in many children results from a constipation-induced cologastric break (20).

Five patients with occult constipation who could stop their laxatives following psychosocial intervention without recurrence of the pain, illustrate the functional character of their pain, but also the observation, that laxatives can make these children pain-free, while awaiting solution of psychosocial problems. 
The strengths of this study lies in the criteria used and the stepwise therapeutic interventions to establish a putative causal relation between findings and abdominal pain. It shows that a broad diagnostic approach yields many putative organic causes, illustrating the difficulty of the phrase in the Rome II criteria, that organic causes 'need to be excluded'. A new finding was that 20 children had more than one putative cause to explain the pain. The limitations lie in the difficulty to establish a causal relationship between an abnormal finding and the abdominal pain with certainty. Disappearance of pain by therapeutic intervention can be coincidental. We chose a 6 -months follow up to restrict the possibility that coincidental or temporary recovery was falsely considered to be the result of therapeutic intervention. The placebo effect of an intervention is a well known cause of decrease of symptoms. Spiller describes the experience from 25 randomized controlled studies; the median placebo response was $47 \%$, range $0-84 \%$. However, this effect starts to disappear after 3 months and is considered to be lost by 6 months (21).

\section{Conclusion}

An approach to RAP with comprehensive diagnostic testing followed by stepwise therapeutic interventions led to disappearance of the pain and a pain-free follow-up period of at least 6 months in $99 \%$ of 200 patients, of whom $27 \%$ spontaneously and $70 \%$ in direct relation to an intervention, while in $2,5 \%$ stress was the cause of the pain. With appropriate investigations in these children, more somatic diagnoses can be found than is often appreciated: in $26 \%$ an organic condition most likely played a causative role. Moreover, patients who fulfil the Rome criteria for functional gastrointestinal pain syndromes frequently appear to be pain-free with laxative therapy. These children, we suggest, have occult constipation. 


\section{APPENDIX. CRITERIA FOR DIAGNOSES}

\section{General}

Based on intervention and follow up a causal relation of a specific disease or condition with abdominal pain is supposed, if the following criteria are fulfilled:

Therapeutic intervention results in elimination of the supposed cause (see below) and disappearance of RAP within an appropriate space of time and RAP does not reappear within a 6 months follow up period or RAP reappears within 6 months, apparently due to the same cause and eliminated in the same way.

\section{Helicobacter pylori gastritis}

Abdominal pain disappears after eradication of hp. Negative faecal test 4-6 weeks after triple therapy.

\section{Protozoal infection}

Abdominal pain disappears after eradication of the parasite.

Negative triple faeces test $\geq 10$ days after therapy.

\section{Yersinia enterocolitica infection}

Abdominal pain disappears after eradication of Yersinia.

Negative Yersinia IgA immunoblot at least 3 months after start of therapy (may take more time).

\section{Celiac disease}

Abdominal pain disappears with a gluten free diet.

Normalization of celiac antibodies (anti-endomysium, ant-tissue transglutaminase) and/or duodenal histology.

\section{Carbohydrate intolerance}

Abdominal pain disappears with elimination of lactose or fructose.

Pain returns with reintroduction of lactose or fructose; this should be repeatable.

Confirmation with double blind placebo controlled provocation.

\section{Food allergy}

Abdominal pain disappears within 5-6 weeks of elimination of offending food from the diet.

Pain returns with reintroduction of the food; this should be repeatable. Reintroduction should comprise a normal daily amount of the offending food; this should be continued during at least 3 days, in case of dubious symptoms to be continued till 7 days. Confirmation with double blind placebo controlled provocation. In case of multiple offending foods, double blind provocation is done with at least one allergen. 
Constipation and occult constipation

Abdominal pain disappears with laxative treatment. Treatment may need to be continued throughout follow-up period. Pain may return upon reduction or discontinuation of treatment, but disappears again with laxative treatment.

Constipation: those children who fulfil the Rome II criteria for functional constipation. Occult constipation: those children who do not fulfil the Rome II criteria for functional constipation, but did show relieve of symptoms with laxative treatment.

\section{Stress-related}

History of consistent relation of abdominal pain with stressful situations or Abdominal pain disappears completely after successful stress relieving intervention and does not recur during follow up.

\section{Spontaneous recovery}

Abdominal pain disappears spontaneously, either before any intervention or in the course of time without assignable causal relation to an intervention.

Pain does not recur during follow up.

No diagnosis

Abdominal pain disappears in relation to an intervention, which excludes the conclusion "spontaneous recovery", but according to protocol causality is insufficiently proven.

Unsolved

Abdominal pain does not disappear, or only temporarily; interventions are not successful.

Drop out

Tests not completed, interventions refused or lost to follow up prior to completion of the 6 months follow up period.

More than one diagnosis

More than one diagnosis is considered possible in case of persistent considerable relief of pain with an intervention, followed by persistent complete disappearance of pain with another intervention. 


\section{REFERENCE LIST}

1. Varni JW, Lane MM, Burwinkle TM, Fontaine EN, Youssef NN, Schwimmer JB et al. Health-related quality of life in pediatric patients with irritable bowel syndrome: a comparative analysis. J Dev Behav Pediatr. 2006;27:451-458.

2. Apley J, Naish N. Recurrent abdominal pains: a field survey of 1,000 school children. Arch Dis Child. 1958;33:165-170.

3. Rasquin-Weber A, Hyman PE, Cucchiara S, Fleisher DR, Hyams JS, Milla PJ et al. Childhood functional gastrointestinal disorders. Gut. 1999;45 Suppl 2:I160-II68.

4. Rasquin A, Di LC, Forbes D, Guiraldes E, Hyams JS, Staiano A et al. Childhood functional gastrointestinal disorders: child/adolescent. Gastroenterology. 2006;130:1527-1537.

5. Alfven G. One hundred cases of recurrent abdominal pain in children: diagnostic procedures and criteria for a psychosomatic diagnosis. Acta Paediatr. 2003;92:43-49.

6. Gijsbers CFM, Benninga MA, Buller HA. Clinical and laboratory findings in 220 children with recurrent abdominal pain. Acta Paediatr. 2011.

7. Apley J. The child with abdominal pains. 2 ed. Oxford: Blackwell Scientific; 1975.

8. Stone RT, Barbero GJ. Recurrent abdominal pain in childhood. Pediatrics. 1970;45:732-738.

9. Liebman WM. Recurrent abdominal pain in children: a retrospective survey of 119 patients. Clin Pediatr (Phila). 1978;17:149-153.

10. Bury RG. A study of 111 children with recurrent abdominal pain. Aust Paediatr J. 1987;23:117-119.

11. van der Meer SB. [Chronic recurrent abdominal pain in school children]. Tijdschr Kindergeneeskd. 1993;61:69-75.

12. Hyams JS, Treem WR, Justinich CJ, Davis P, Shoup M, Burke G. Characterization of symptoms in children with recurrent abdominal pain: resemblance to irritable bowel syndrome [see comments]. J Pediatr Gastroenterol Nutr. 1995;20:209-214.

13. Hyams JS, Davis P, Sylvester FA, Zeiter DK, Justinich CJ, Lerer T. Dyspepsia in children and adolescents: a prospective study. J Pediatr Gastroenterol Nutr. 2000;30:413-418.

14. Croffie JM, Fitzgerald JF, Chong SK. Recurrent abdominal pain in children--a retrospective study of outcome in a group referred to a pediatric gastroenterology practice. Clin Pediatr (Phila). 2000;39:267274.

15. Stordal K, Nygaard EA, Bentsen B. Organic abnormalities in recurrent abdominal pain in children. Acta Paediatr. 2001;90:638-642.

16. El-Matary W, Spray C, Sandhu B. Irritable bowel syndrome: the commonest cause of recurrent abdominal pain in children. Eur J Pediatr. 2004;163:584-588.

17. Spiller R, Garsed K. Postinfectious irritable bowel syndrome. Gastroenterology. 2009;136:1979-1988.

18. Gomara RE, Halata MS, Newman LJ, Bostwick HE, Berezin SH, Cukaj L et al. Fructose intolerance in children presenting with abdominal pain. J Pediatr Gastroenterol Nutr. 2008;47:303-308.

19. Savaiano DA, Boushey CJ, McCabe GP. Lactose intolerance symptoms assessed by meta-analysis: a grain of truth that leads to exaggeration. J Nutr. 2006;136:1107-1113.

20. Boccia G, Buonavolonta R, Coccorullo P, Manguso F, Fuiano L, Staiano A. Dyspeptic symptoms in children: the result of a constipation-induced cologastric brake? Clin Gastroenterol Hepatol. 2008;6:556-560.

21. Spiller RC. Problems and challenges in the design of irritable bowel syndrome clinical trials: experience from published trials. Am J Med. 1999;107:91S-97S. 
Recurrent abdominal pain in 200 children: somatic causes and diagnostic criteria 

Carolien FM Gijsbers, MD1, Marc A Benninga, MD PhD22, Joachim J Schweizer, MD PhD³, CM Frank Kneepkens, MD PhD4, Yvonne Vergouwe, MD PhD5, Hans A Büller, MD PhD5.

1Juliana Children's Hospital/Haga Teaching Hospital, The Hague, 2Emma Children's Hospital/ Academic Medical Centre, Amsterdam, 3Willem-Alexander Children's Hospital/Leiden University Medical Centre, Leiden, 4 VU University Medical Centre, Amsterdam, ${ }^{5}$ Erasmus Medical Centre, Rotterdam, The Netherlands

Submitted

\section{ABSTRACT}

Aims

1) To validate the Rome III criteria as to their capacity to differentiate between organic and functional causes of abdominal pain, and 2) to assess the role of alarm symptoms with respect to their capacity to differentiate between organic disease and functional causes of abdominal pain

\section{Methods}

During 2 years all patients (age 4-16 years) fulfilling Apley criteria of abdominal pain, referred to a secondary centre, were included. A "clinical diagnosis" was based on protocolized diagnostic evaluation and a therapeutic intervention protocol with 6 month follow up. Alarm symptoms were registered. The Rome III criteria for irritable bowel syndrome (IBS), functional abdominal pain (FAP), functional abdominal pain syndrome (FAPS) and functional dyspepsia (FD) were assigned independently.

\section{Results}

Two hundred patients were evaluated and diagnosed with an organic (17\%), functional (39,5\%), combined organic and functional (9\%), or other (34,5\%) "clinical diagnosis".

Alarm symptoms were found in $57,5 \%$ (65\% of patients with functional and $56 \%$ with organic diagnoses). Evaluation for Rome symptom clusters revealed symptoms of IBS in $27 \%$, FD in $15 \%$, FAP $28 \%$, FAPS $14,5 \%$ and no pain syndrome in $15,5 \%$ of the patients. 'Rome diagnoses', based on symptom clusters and absence of alarm symptoms, predicted functional clinical diagnosis with a PPV of $34-71 \%$ and a sensitivity of $32-35 \%$.

\section{Conclusion}

The Rome III criteria for abdominal pain are not specific enough to rule out an organic cause of abdominal pain. The presence of alarm symptoms does not differentiate between organic and functional abdominal pain.

\section{Introduction}

In 1958 Apley published his landmark paper on recurrent abdominal pain (RAP) in children (1). RAP, defined as "at least 3 bouts of pain, severe enough to affect the daily activities, over a period of not less than 3 months", was found in $108(10,8 \%)$ of 1000 schoolchildren. No organic diagnoses were suspected in these 108 children (no ancillary investigations were performed), and Apley concluded that RAP could mainly be attributed to psychological factors. Alarm symptoms were advocated to be used as indicators of organic disease. 
Several versions of these so-called "red flags" were published, addressing Crohn's disease, peptic ulcer and urinary tract disease (2).

In the 1980's the Manning criteria for irritable bowel syndrome (IBS) in adults were developed to obtain a positive diagnosis of IBS without the need of diagnostic tests (3). These criteria were followed by the expert-based Rome criteria, first published in the early 1990's, providing criteria for functional gastrointestinal disorders (FGIDs) in adults and children (4;5) (table 1). The Rome criteria were meant to structure the area of functional symptoms by classification, leading to more homogeneous patient groups, which could be helpful for patient care and could form the basis of research on pathophysiological mechanisms as well as clinical research. The Rome Working Teams pointed out that validation of the diagnostic criteria is needed, because they were adopted by consensus rather than by data analysis (4-6). Therefore we set out 1) to validate the Rome III criteria as to their capacity to differentiate between organic and functional causes of abdominal pain, and 2) to assess the role of alarm symptoms with respect to their capacity to differentiate between organic disease and functional causes of abdominal pain.

Table 1. Rome III diagnostic criteria for functional gastrointestinal pain syndromes*

\begin{tabular}{|c|c|}
\hline \multicolumn{2}{|c|}{ Rome III criteria: irritable bowel syndrome (IBS) } \\
\hline \multicolumn{2}{|c|}{ Must include all of the following: } \\
\hline \multirow[t]{2}{*}{1.} & Abdominal discomfort (an uncomfortable sensation not described as pain) or pain associated with \\
\hline & 2 or more of the following at least $25 \%$ of the time: \\
\hline a. & Improved with defaecation \\
\hline b. & Onset associated with a change in frequency of stool \\
\hline c. & Onset associated with a change in form (appearance) of stool; and \\
\hline 2. & $\begin{array}{l}\text { No evidence of an inflammatory, anatomic, metabolic or neoplastic process that explains the } \\
\text { subject's symptoms. }\end{array}$ \\
\hline
\end{tabular}

\begin{tabular}{|c|c|}
\hline \multicolumn{2}{|c|}{ Rome III criteria: functional dyspepsia (FD) } \\
\hline \multicolumn{2}{|c|}{ Must include all of the following: } \\
\hline 1. & Persistent or recurrent pain or discomfort centred in the upper abdomen (above the umbilicus) \\
\hline 2. & $\begin{array}{l}\text { Not relieved by defaecation or associated with the onset of a change in stool frequency or stool } \\
\text { form (ie. not IBS) }\end{array}$ \\
\hline 3. & $\begin{array}{l}\text { No evidence of an inflammatory, anatomic, metabolic or neoplastic process that explains the } \\
\text { subject's symptoms }\end{array}$ \\
\hline
\end{tabular}

\begin{tabular}{|c|c|}
\hline \multicolumn{2}{|c|}{ Rome III criteria: functional abdominal pain (FAP) } \\
\hline \multicolumn{2}{|c|}{ Must include all of the following: } \\
\hline 1. & Episodic or continuous abdominal pain \\
\hline 2. & Insufficient criteria for other FGIDs \\
\hline 3. & $\begin{array}{l}\text { No evidence of an inflammatory, anatomic, metabolic or neoplastic process that explains the } \\
\text { subject's symptoms }\end{array}$ \\
\hline
\end{tabular}

\begin{tabular}{l}
\hline \begin{tabular}{l} 
Rome III criteria: functional abdominal pain syndrome (FAPS) \\
\hline Must include childhood functional abdominal pain at least $25 \%$ of the time and 1 or more of the following: \\
\hline $1 . \quad$ Some loss of daily functioning \\
\hline $2 . \quad$ Additional somatic symptoms such as headache, limb pain, or difficult sleeping \\
\hline
\end{tabular}
\end{tabular}

*Criteria fulfilled at least once per week for at least 2 months before diagnosis

Rasquin, A et al. Gastroenterology 2006;130:1527-1537 


\section{Patients and Methods}

Between May 2002 and May 2004, all consecutive patients (age 4-16 years) fulfilling the Apley criteria of RAP and referred by general practitioners to a secondary centre (CFMG), were included. The patients were prospectively evaluated and diagnosed in two independent ways.

Firstly, they were evaluated in a standardized way as described previously (7). History and physical examination were followed by a diagnostic work-up, resulting in the establishment of preliminary diagnoses, e.g. Helicobacter pylori ( $\mathrm{Hp}$ ) gastritis, and diagnostic clues e.g. carbohydrate malabsorption. A causal relation of these preliminary diagnoses with the abdominal pain was only assumed, when the pain disappeared following adequate therapeutic intervention and the child remained symptom-free during a follow-up period of at least 6 months $(7 ; 8)$. When these therapeutic interventions were not successful, patients with persistent abdominal pain had a trial with laxatives. According to our definition, children were considered to have (occult) constipation when they became pain free with laxative therapy and remained so during a follow-up period of at least 6 months. This definition includes both children fulfilling the Rome criteria for functional constipation as well as children not fulfilling these criteria who are diagnosed with 'occult constipation', as described earlier (8). In case of persistent pain after a trial with laxatives, other investigations were performed as indicated. The resulting 'clinical diagnoses' were independently reviewed by two pediatric gastroenterologists (CMFK, JJS) and subsequently categorized as 'organic', 'functional', 'both organic and functional' and 'other'. Secondly, a fourth pediatric gastroenterologist (MAB) independently categorized the symptom clusters of the patients according to the Rome III criteria as 'IBS', 'functional dyspepsia (FD),',functional abdominal pain (FAP)', 'functional abdominal pain syndrome (FAPS)' or 'no Rome pain syndrome'. Nocturnal pain, localization in right upper or right lower quadrant, rectal blood loss, fever (by history), weight loss (by history), family history of inflammatory bowel disease or celiac disease or (first degree family) peptic ulcer, hemoglobin concentration $<7,0 \mathrm{mmol} / \mathrm{l}$ and ESR $>20 \mathrm{~mm}$ were considered alarm symptoms. Alarm symptoms were provided by the parents without verification with diaries or otherwise. As indicated by the Rome criteria, a 'Rome diagnosis' was made if a patient presented with the symptom cluster of a functional gastrointestinal pain syndrome in the absence of alarm symptoms.

After the two above mentioned diagnostic categorizations, it was concluded which patients with Rome symptoms, who were initially withheld a Rome diagnosis because of alarm symptoms, could finally be given a Rome diagnosis after having excluded organic disease definitively (figure).

\section{Statistical analysis}

To validate the Rome III criteria ('Rome diagnoses', based on symptom clusters and absence of alarm symptoms) as to their capacity to differentiate between organic and functional causes of abdominal pain, descriptive statistics were performed, using SPSS statistics 17.0 (IBM, New York, USA). The sensitivity and specificity as well as the positive (PPV) and negative predictive value (NPV) of the Rome diagnoses were estimated, using the clinical diagnoses as the reference standard.

The role of alarm symptoms with respect to their capacity to differentiate between organic disease and functional causes, was similarly analyzed. 
Figure. Validation procedure

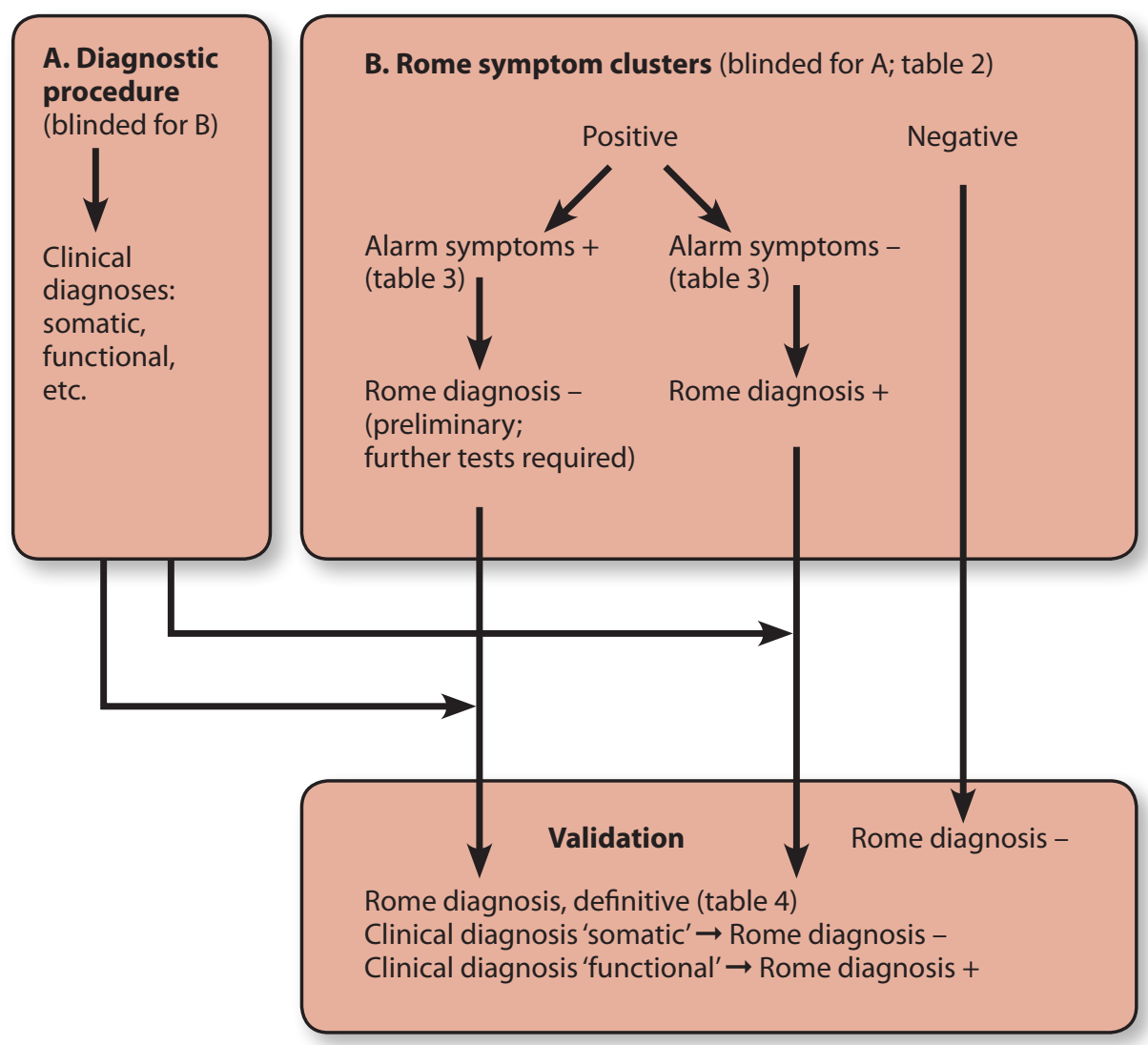

Figure legends

Procedure A: performed by CFMG and independently reviewed by CMFK and JJS.

Procedure B: Rome symptom clusters were assigned by MAB. Alarm symptoms as mentioned by patients were used to make a Rome diagnosis (if no alarm symptoms) or to deny - for the moment - a Rome diagnosis.

As the next step, the reliability of the Rome diagnoses (Rome symptom clusters present, no alarm symptoms) in recognizing a functional disorder was estimated, using the clinical diagnoses as the reference standard (table 41). In the same way, with the clinical diagnoses as the reference standard, the clinical diagnostic procedure was used as the 'further tests required' for the definitive establishing of the Rome diagnoses in patients with alarm symptoms (table 42,3) 


\section{Results}

Two hundred twenty patients entered the study protocol, of whom 20 were lost to follow up. Of the 200 remaining patients ( 113 girls, 87 boys, mean age 8,8 [range 4,1-16,0] years), table 2 shows the finally obtained 'clinical diagnoses' after 6 months of follow-up. Organic causes were found in 34 patients (17\%), functional causes in 79 (39,5\%), both organic and functional cause in 18 (9\%); a rest group of 69 patients $(34,5 \%)$ consisted of patients who recovered spontaneously (54), patients with no certain diagnosis (13) and two unresolved cases. In the functional group all but 5 patients became pain-free with laxative therapy and were considered to have (occult) constipation; in 5 patients the pain was stress-related. In this table also the symptom clusters at presentation, according to the Rome III criteria, were shown in relation with the clinical diagnoses.

One or more alarm symptoms were found in 115 (57,5\%) patients (table 3). Alarm symptoms were found in $56 \%$ of patients with organic disease, in $65 \%$ of patients with a functional diagnosis, in $50 \%$ of patients with both organic and functional disease and in $52 \%$ of the other patients.

Table 4 shows the 'Rome diagnoses', based on symptom clusters at presentation and absence of alarm symptoms: 54 patients presented with the symptom cluster of IBS, 30 with symptoms of FD, 56 with symptoms of FAP and 29 with symptoms of FAPS (table 2); after exclusion of patients with alarm symptoms 17 patients were diagnosed with IBS, 10 with FD, 34 with FAP and 12 with FAPS. Table 4 shows the Rome diagnoses as related to functional and organic clinical diagnoses. As can be seen, patients presented with roughly the same distribution of Rome diagnoses in the clinical diagnosis groups, IBS being present in around $30 \%$ of patients with organic and functional causes, FAP in around $45-50 \%$ of them and FD in a lower percentage.

The sensitivity of the Rome criteria to detect a functional disorder, based on symptom clusters and absence of alarm symptoms, was $32 \%$, the specificity $60 \%$. The PPV of a Rome diagnosis was $34 \%$ to diagnose a functional disorder. The NPV of a Rome diagnosis was $58 \%$. In this estimation the group 'other' was not considered to be functional. If we assume that the group 'other' mainly consists of patients with a functional cause and therefore is added to the functional group, the sensitivity of the Rome criteria to detect a functional disorder is $35 \%$, the specificity $60 \%$, the PPV $71 \%$ and the NPV $24 \%$.

After both diagnostic categorizations, the clinical diagnoses made clear, which patients finally had an organic and which patients had a functional diagnosis. Table 4 shows 46 patients who had "no Rome diagnosis", because of having alarm symptoms, but eventually had a functional diagnosis. If we assume that the group 'other' mainly consists of patients with a functional cause and therefore is taken together with the functional group, in total 77 patients (38,5\%) finally had a Rome diagnosis. 
Table 2. Children with abdominal pain due to various causes ('clinical diagnoses') and their presentation with the symptom cluster of irritable bowel syndrome (IBS), functional dyspepsia (FD), functional abdominal pain (FAP) or functional abdominal pain syndrome (FAPS).

\begin{tabular}{|c|c|c|c|c|c|c|}
\hline \multirow[t]{3}{*}{ Clinical diagnoses } & \multicolumn{6}{|c|}{ Rome III pain symptom clusters } \\
\hline & IBS & FD & FAP & FAPS & $\begin{array}{c}\text { no Rome pain } \\
\text { diagnosis }\end{array}$ & Total \\
\hline & $\mathrm{n}(\% *)$ & $\mathrm{n}(\% *)$ & $\mathrm{n}\left(\%^{*}\right)$ & $\mathrm{n}(\% *)$ & $\mathrm{n}\left(\%{ }^{*}\right)$ & $\mathrm{n}(\% *)$ \\
\hline \multicolumn{7}{|l|}{ ORGANIC } \\
\hline Helicobacter pylori (Hp) & 1 & 1 & 1 & & 2 & 5 \\
\hline $\mathrm{Hp}+$ parasites & & & & & 1 & 1 \\
\hline Parasites & 4 & 1 & 5 & & 4 & 14 \\
\hline Parasites + Yersinia & & & 1 & & & 1 \\
\hline Yersinia enterocolitica & 2 & & 1 & & 1 & 4 \\
\hline Lactose intolerance & & & & & & 0 \\
\hline Fructose intolerance & & & & & & 0 \\
\hline Food allergy & & 1 & 1 & 1 & & 3 \\
\hline $\begin{array}{l}\text { Recovered with } \\
\text { appendectomy }\end{array}$ & 1 & & & 1 & 1 & 3 \\
\hline Mesenteric cyst & & & & & 1 & 1 \\
\hline Gallstones & & & & 1 & & 1 \\
\hline Side-effect medication & 1 & & & & & 1 \\
\hline Subtotal organic causes & $9(26,5)$ & $3(8,8)$ & $9(26,5)$ & $3(8,8)$ & $10(29,4)$ & $34(100)$ \\
\hline \multicolumn{7}{|l|}{ FUNCTIONAL } \\
\hline (Occult) constipation & 22 & 10 & 20 & 9 & 8 & 69 \\
\hline $\begin{array}{l}\text { (Occult) constipation, } \\
\text { stress related }\end{array}$ & 4 & & 1 & & & 5 \\
\hline Stress related & & 2 & 3 & & & 5 \\
\hline Subtotal functional causes & $26(32,9)$ & $12(15,2)$ & $24(30,4)$ & $9(11,4)$ & $8(10,1)$ & $79(100)$ \\
\hline \multicolumn{7}{|c|}{ COMBINATION ORGANIC AND FUNCTIONAL } \\
\hline $\mathrm{Hp}+$ constipation & 2 & & & & 1 & 3 \\
\hline Parasites + constipation & 3 & 1 & 3 & 2 & & 9 \\
\hline Yersinia + constipation & & & 2 & 1 & & 3 \\
\hline Food allergy + constipation & & & & 1 & 1 & 2 \\
\hline $\begin{array}{l}\text { Constipation + side-effect } \\
\text { medication }\end{array}$ & & 1 & & & & 1 \\
\hline $\begin{array}{l}\text { Subtotal organic and } \\
\text { functional causes }\end{array}$ & $5(27,8)$ & $2(11,1)$ & $5(27,8)$ & $4(22,2)$ & $2(11,1)$ & $18(100)$ \\
\hline \multicolumn{7}{|l|}{ OTHER } \\
\hline 1. Spontaneous recovery & 12 & 11 & 16 & 7 & 8 & 54 \\
\hline 2. No certain diagnosis & 2 & 2 & 2 & 5 & 2 & 13 \\
\hline 3. Unsolved & & & & 1 & 1 & 2 \\
\hline Subtotal other & $14(20,3)$ & $13(18,8)$ & $18(26,1)$ & $13(18,8)$ & $11(15,9)$ & $69(100)$ \\
\hline TOTAL & $54(27)$ & $30(15)$ & $56(28)$ & $29(14,5)$ & $31(15,5)$ & $200(100)$ \\
\hline
\end{tabular}

* percentage of subtotal clinical diagnostic group 
Table 3. Number of patients with alarm symptoms

\begin{tabular}{|c|c|c|c|c|c|c|c|c|c|c|c|}
\hline \multirow{2}{*}{ Clinical diagnoses } & \multicolumn{2}{|c|}{ Alarm symptoms } & \multirow[b]{2}{*}{$\begin{array}{c}\text { rectal } \\
\text { blood } \\
(>1 x)\end{array}$} & \multirow[b]{2}{*}{$\begin{array}{c}\text { fever } \\
\text { (history) }\end{array}$} & \multirow[b]{2}{*}{$\begin{array}{l}\text { weight } \\
\text { loss } \\
\text { (history) }\end{array}$} & \multirow[b]{2}{*}{ fam IBD } & \multirow[b]{2}{*}{$\begin{array}{c}\text { fam } \\
\text { celiac } \\
\text { disease }\end{array}$} & \multirow[b]{2}{*}{$\begin{array}{c}{ }^{*} \text { fam } \\
\text { peptic } \\
\text { ulcer }\end{array}$} & \\
\hline & $\begin{array}{c}\text { pain } \\
\text { at night }\end{array}$ & $\begin{array}{c}\text { pain } \\
\text { RUQ/ } \\
\text { RLQ }\end{array}$ & & & & & & & $\mathrm{Hb}<7$ & $\begin{array}{c}\text { ESR } \\
>20 \mathrm{~mm}\end{array}$ & Total** \\
\hline \multicolumn{12}{|l|}{ ORGANIC $(n=34)$} \\
\hline infections (25) & 3 & 2 & 1 & 3 & 4 & 3 & 1 & 3 & 1 & 3 & 15 \\
\hline \multicolumn{12}{|l|}{ food allergy (3) } \\
\hline miscellaneous (6) & 1 & & 1 & 1 & 2 & & & 1 & & & 4 \\
\hline \multicolumn{12}{|l|}{ FUNCTIONAL $(n=79)$} \\
\hline $\begin{array}{l}\text { (occult) } \\
\text { constipation (69) }\end{array}$ & 6 & 2 & 6 & 14 & 12 & 8 & 1 & 5 & 5 & 5 & 44 \\
\hline \multicolumn{12}{|l|}{ (occult) } \\
\hline $\begin{array}{l}\text { constipation, } \\
\text { stress-related (5) }\end{array}$ & & & 2 & & 1 & & & & 1 & & 4 \\
\hline stress-related (5) & 1 & & 1 & & & & & & & 1 & 3 \\
\hline \multicolumn{12}{|c|}{ ORGANIC AND FUNCTIONAL $(n=18)$} \\
\hline $\begin{array}{l}\text { infection + } \\
\text { constipation (15) }\end{array}$ & 3 & & & & 1 & & & 1 & 2 & 1 & 7 \\
\hline $\begin{array}{l}\text { food allergy + } \\
\text { constipation (2) }\end{array}$ & 1 & & 1 & & & & & & & & 1 \\
\hline $\begin{array}{l}\text { miscellaneous + } \\
\text { constipation (1) }\end{array}$ & & & & & 1 & & & 1 & & & 1 \\
\hline \multicolumn{12}{|l|}{ OTHER (n=69) } \\
\hline $\begin{array}{l}\text { spontaneous } \\
\text { recovery (54) }\end{array}$ & 7 & 1 & 5 & 3 & 7 & 7 & 3 & 4 & 3 & 2 & 30 \\
\hline $\begin{array}{l}\text { no certain } \\
\text { diagnosis (13) }\end{array}$ & & 1 & & 2 & 2 & 1 & & 1 & 1 & & 5 \\
\hline unsolved (2) & & & & & & & & 1 & & & 1 \\
\hline TOTAL & 22 & 6 & 17 & 23 & 30 & 19 & 5 & 17 & 13 & 12 & 115 \\
\hline
\end{tabular}

$R \cup Q=$ right upper quadrant, $R L Q=$ right lower quadrant, fam = family history,

$I B D=$ inflammatory bowel disease, $\mathrm{Hb}=$ Hemoglobin $(\mathrm{mmol} / \mathrm{l}), \mathrm{ESR}=$ erythrocyte sedimentation rate

* Family history peptic ulcer disease: first degree family members only

**Patients can have $>1$ alarm symptom 
Table 4. Rome diagnoses of functional gastrointestinal pain syndromes in patients with organic or functional diagnosis

\begin{tabular}{|c|c|c|c|c|c|c|}
\hline \multicolumn{2}{|c|}{ Rome diagnosis } & \multicolumn{5}{|c|}{ Classification clinical diagnoses } \\
\hline & & $\begin{array}{l}\text { Functional } \\
\text { (constipation, } \\
\text { stress) }\end{array}$ & $\begin{array}{l}\text { Organic } \\
\text { (infections, food } \\
\text { allergy, etc) }\end{array}$ & $\begin{array}{l}\text { Organic and } \\
\text { functional } \\
\text { (organic and } \\
\text { constipation) }\end{array}$ & $\begin{array}{l}\text { Other } \\
\text { (spontaneous } \\
\text { recovery, } \\
\text { no diagnosis, } \\
\text { unresolved) }\end{array}$ & Total \\
\hline \multirow{5}{*}{$\begin{array}{l}\text { Rome pain } \\
\text { diagnosis } \\
\text { established } 1\end{array}$} & $I B S, n(\%)$ & $8(32)$ & $3(25)$ & $3(33)$ & $3(11)$ & $17(23)$ \\
\hline & $F D, n(\%)$ & $4(16)$ & $1(8)$ & $1(11)$ & $4(15)$ & $10(14)$ \\
\hline & $F A P, n(\%)$ & $12(48)$ & $6(50)$ & $3(33)$ & $13(48)$ & $34(47)$ \\
\hline & FAPS, $n(\%)$ & $1(4)$ & $2(17)$ & $2(22)$ & $7(26)$ & $12(16)$ \\
\hline & Subtotal, n(\%) & $25(100)$ & $12(100)$ & $9(100)$ & $27(100)$ & $73(100)$ \\
\hline \multicolumn{2}{|c|}{ No Rome pain diagnosis 2} & 46 & 12 & 7 & 31 & $96 *$ \\
\hline \multicolumn{2}{|c|}{ No Rome pain diagnosis 3} & 8 & 10 & 2 & 11 & 31 \\
\hline \multicolumn{2}{|c|}{ TOTAL } & 79 & 34 & 18 & 69 & 200 \\
\hline
\end{tabular}

Legends:

1 Rome diagnosis established: a functional gastrointestinal pain syndrome according to Rome III criteria: symptom cluster of one of the functional gastrointestinal pain-syndromes (irritable bowel syndrome (IBS), functional dyspepsia (FD), functional abdominal pain (FAP), functional abdominal pain syndrome (FAPS)) present, no alarm symptoms.

2,3 No Rome pain diagnosis: no diagnosis of a functional pain syndrome according to Rome III criteria: 2 symptom cluster of one of the functional gastrointestinal pain syndromes (IBS, FD, FAP, FAPS) present, but alarm symptoms are present* or 3 no symptoms of one of the functional gastrointestinal pain syndromes are present.

Alarm symptoms (at least one): nocturnal pain, pain in right upper quadrant or right lower quadrant, rectal blood loss (more than once), fever (by history), weight loss (by history), family history of peptic ulcer disease in first degree family or family history of inflammatory bowel disease or celiac disease, $\mathrm{Hb}<7 \mathrm{mmol} / \mathrm{l}, \mathrm{ESR}>20 \mathrm{~mm}$.

*Preliminary result, based on Rome symptom clusters but presence of alarm symptoms, in these 96 patients; definitive diagnoses result from the clinical diagnoses.

\section{Discussion}

This is the first study to validate the Rome criteria for the functional pain syndromes as to their capacity to differentiate between organic and functional causes of abdominal pain in children. It is also the first study to assess the significance of alarm symptoms in children with abdominal pain. This study is based on a diagnostic process that includes therapeutic intervention and requires a 6 month pain-free follow up as a prerequisite for a "clinical diagnosis"."Rome diagnoses" were made independently by assigning the criteria for the Rome pain syndromes while excluding patients with alarm symptoms. The main finding is, that the Rome criteria are not able to differentiate between organic and functional causes of abdominal pain. In addition, we found alarm symptoms suggesting organic causes of RAP in the same percentage in patients with a functional clinical diagnosis as in patients with an organic clinical diagnosis, implicating insufficient capacity to differentiate between organic disease and functional causes of abdominal pain.

In 1990 Talley et al evaluated the validity of the Manning criteria for the discrimination of IBS patients from healthy controls, from patients with other gastrointestinal diseases and from patients with non-ulcer dyspepsia. Sensitivity and specificity of the Manning score 
with respect to differentiation of IBS from organic disease were $58 \%$ and $74 \%$, respectively (9). It is noteworthy that the process of validation of the Rome criteria is complicated by the requirement of exclusion of organic disease as a prerequisite for a functional diagnosis. The capacity of the Rome criteria to recognize functional disease versus organic disease is by definition $100 \%$, when exclusion of organic disease is included as a requirement for a Rome diagnosis. The consequence for clinicians is, that organic diseases have to be excluded. The problem lies in the difficulty of how to exclude organic disease. The Rome Working Team gives the advice to diagnose IBS when symptoms meet the IBS criteria, in the presence of a normal physical examination and growth curve with the absence of alarm symptoms; for FAP and FD comparable advices are given $(4 ; 10)$.

Alarm symptoms are considered a reason for more extensive clinical investigations (2;4;10). In this study we found $57,5 \%$ of the patients presenting with one or more alarm symptoms. However, they are even more frequent in patients with functional disorders than in patients with organic disease. Although alarm symptoms are important for the recognition of more severe conditions such as Crohn's disease, they are not helpful in the diagnostic process of RAP. Remarkably, the individual alarm symptoms all showed roughly the same distribution in the various clinical diagnosis groups. Rectal blood loss is not unusual in children with constipation; in most patients they were probably caused by fissures. Other alarm symptoms in children with a functional diagnosis are more difficult to understand. In a study on the frequency of Rome III pain diagnoses in children with abdominal pain, Helgeland et al found $7 \%$ to have alarm symptoms ${ }^{(11)}$. This suggests that clear definition of alarm symptoms is needed.

Based on symptom clusters and absence of alarm symptoms, Rome pain diagnoses were assigned, independent of the diagnostic process of the clinical diagnoses (table 4). Only 73 patients (36,5\%) had a Rome pain diagnosis due to the high number of patients with alarm symptoms (57,5\%). However, many patients who met the criteria of a Rome diagnosis appeared to have an organic cause of the pain when investigated more thoroughly: of 73 patients with a Rome diagnosis, 21 (29\%) had an organic disease, as well as an unknown number of patients in the group 'other'. Of 79 patients with a functional RAP diagnosis only 25 had a Rome diagnosis at first sight (sensitivity $32 \%$ ). Another 46 patients had alarm symptoms, but after finishing the diagnostic process appeared to have no organic cause (table 4). Eight patients finally had a functional diagnosis as well, but had no symptoms of a Rome pain syndrome.

The low sensitivity of the Rome criteria is inherent to the Rome procedure as well as the high prevalence of alarm symptoms: patients with alarm symptoms need to be investigated for organic disease before a Rome diagnosis can be made. Because alarm symptoms appear to be at least as frequent in functional as in organic disorders, many patients with alarm symptoms end up to have a functional cause of their pain and therefore in the end can be given a Rome pain diagnosis.

The PPV and NPV of the Rome diagnoses to predict a functional clinical diagnosis show wide ranges as a consequence of the high prevalence of spontaneous recovery, which most likely is related to functional causes; unknown or missed infections however are possible causes as well. Considering the group 'other' as functional, therefore, leads to overestimation of the prevalence of functional disease, while considering the group 'other' as nonfunctional will underestimate the prevalence of functional causes. The importance of the Rome symptoms in combination with the absence of alarm symptoms lies in the ability to diagnose a functional disorder with sufficient certainty, without the need of further investigations. 
The PPV indicates the reliability of this approach. Organic disease would be missed (1-PPV) in 21 of 73 patients (29\%) with a Rome diagnosis (table 4). Helgeland et al found 8/152 children $(5,3 \%)$ with organic diagnoses that would have been missed had the investigations been limited to medical history, clinical examination and stool examination for blood (11).

This study provides no evidence that differentiation between the functional pain syndromes makes any difference with respect to therapy or outcome. For clinical use, the added value of the Rome classification is limited. This is reflected in the use of the Rome criteria in children with abdominal pain by only $39 \%$ of members of NASPGHAN (13).

With respect to research, the gain of the Rome classification for functional gastrointestinal pain syndromes lies in the more restricted symptom clusters as opposite to the broad Apley criteria. More uniformity of presentation presumably is a better basis for research, especially with respect to pathophysiology. However, diagnostic disagreement with respect to Rome classification is a recognized problem, in view of the considerable interobserver- and intraobserver variability and the limited diagnostic agreement between physicians, parents and children, with respect to both Rome II and III criteria (14-17). Recently, several authors disputed the clinical utility of the Rome criteria because of insufficient differentiation between functional and organic disease and insufficient help with identification of individualized therapeutic strategies that are based on etiologic mechanisms (18;19).

The strength of this study lies in the way of establishing the diagnoses, based on preset criteria including therapeutic intervention to establish a causal relation in every patient, as a basis for validation of the Rome criteria for the functional pain syndromes, and the independent scoring of the Rome criteria.

The limitations lie firstly in the difficulty to prove causal relationships with certainty. We chose a follow-up of at least 6 months to restrict the possibility that temporary or coincidental recovery was falsely considered to be the cause of the pain and to restrict placebo effects (8;20). A second limitation is the number of patients without organic or functional clinical diagnosis according to the protocol; the category 'other', which includes the patients who spontaneously recovered, undoubtedly contains patients with functional disease, but possibly some patients with organic disease as well. However, regardless of how the groups are analyzed, PPV, NPV, sensitivity and specificity, with values consistently below $75 \%$, are unacceptably low for clinical use.

\section{Conclusion}

The clinical symptom-based Rome III criteria are not specific enough to rule out an organic cause of abdominal pain. The presence of alarm symptoms does not differentiate between organic and functional abdominal pain. 


\section{REFERENCE LIST}

(1) Apley J, Naish N. Recurrent abdominal pains: a field survey of 1,000 school children. sArch Dis Child 1958;33:165-70.

(2) Oberlander TF, Rappaport LA. Recurrent abdominal pain during childhood. Pediatr Rev 1993;14:313-9.

(3) Manning AP, Thompson WG, Heaton KW, et al. Towards positive diagnosis of the irritable bowel. Br Med J 1978;2:653-4

(4) Rasquin A, Di Lorenzo C, Forbes D, et al. Childhood functional gastrointestinal disorders: child/ adolescent. Gastroenterology 2006;130:1527-37.

(5) Hyman PE, Milla PJ, Benninga MA, et al. Childhood functional gastrointestinal disorders: neonate/ toddler. Gastroenterology 2006;130:1519-26.

(6) Thompson WG. The road to Rome. Gut 1999;45 Suppl 2:I180.

(7) Gijsbers CFM, Benninga MA, Buller HA. Clinical and laboratory findings in 220 children with recurrent abdominal pain. Acta Paediatr 2011;100:1028-32.

(8) Gijsbers CFM, Kneepkens CMF, Schweizer JJ, et al. Recurrent abdominal pain in 200 children: somatic causes and diagnostic criteria. Acta Paediatr 2011;100:e208-e214.

(9) Talley NJ, Phillips SF, Melton LJ, et al. Diagnostic value of the Manning criteria in irritable bowel syndrome. Gut 1990;31:77-81.

(10) Rasquin-Weber A, Hyman PE, Cucchiara S, et al. Childhood functional gastrointestinal disorders. Gut 1999;45 Suppl 2:1160-II68.

(11) Helgeland H, Flagstad G, Grotta J, et al. Diagnosing pediatric functional abdominal pain in children (4-15 years old) according to the Rome III Criteria: results from a Norwegian prospective study. J Pediatr Gastroenterol Nutr 2009;49:309-15.

(12) Baber KF, Anderson J, Puzanovova M, et al. Rome II versus Rome III classification of functional gastrointestinal disorders in pediatric chronic abdominal pain. J Pediatr Gastroenterol Nutr 2008;47:299-302.

(13) Schurman JV, Hunter HL, Friesen CA. Conceptualization and treatment of chronic abdominal pain in pediatric gastroenterology practice. J Pediatr Gastroenterol Nutr 2010;50:32-7.

(14) Saps M, Di Lorenzo C. Interobserver and intraobserver reliability of the Rome II criteria in children. Am J Gastroenterol 2005;100:2079-82.

(15) Schurman JV, Friesen CA, Danda CE, et al. Diagnosing functional abdominal pain with the Rome II criteria: parent, child, and clinician agreement. J Pediatr Gastroenterol Nutr 2005;41:291-5.

(16) Chogle A, Dhroove G, Sztainberg M, et al. How reliable are the Rome III criteria for the assessment of functional gastrointestinal disorders in children? Am J Gastroenterol 2010;105:2697-701.

(17) Czyzewski DI, Lane MM, Weidler EM, et al. The interpretation of Rome III criteria and method of assessment affect the irritable bowel syndrome classification of children. Aliment Pharmacol Ther 2011;33:403-11.

(18) Camilleri M. Do the Symptom-Based, Rome Criteria of Irritable Bowel Syndrome Lead to Better Diagnosis and Treatment Outcomes? The Con Argument. Clin Gastroenterol Hepatol 2009;8:129.

(19) Quigley EM. The 'con' case. The Rome process and functional gastrointestinal disorders: the barbarians are at the gate! Neurogastroenterol Motil 2007;19:793-7.

(20) Spiller RC. Problems and challenges in the design of irritable bowel syndrome clinical trials: experience from published trials. Am J Med 1999;107:91S-7S. 


\section{Protozoa as causes of recurrent abdominal pain in children}


Carolien FM Gijsbers, MD1, Joachim J Schweizer, MD PhD22, Hans A Büller, MD PhD².

1Juliana Children's Hospital/Haga Teaching Hospital, department of paediatric gastroenterology, The Hague, 2Willem-Alexander Children's Hospital/Leiden University Medical Centre, department of paediatric gastroenterology, Leiden, 3Sophia Children's Hospital/Erasmus Medical Centre, Rotterdam, The Netherlands

Submitted

\section{ABSTRACT}

Giardia lamblia, Dientamoeba fragilis and Blastocystis hominis have been implied in the pathophysiology of gastrointestinal symptoms ${ }^{(1-3)}$. Only scarce information is available on the role of protozoa in chronic abdominal pain in children.

\section{Aim}

To investigate if protozoa can be identified as cause of recurrent abdominal pain, and if protozoan infections can be recognized by a specific clinical presentation.

\section{Methods}

In a two-year period all consecutive patients (age 4-16 years) fulfilling the Apley criteria of recurrent abdominal pain, referred to secondary care, were prospectively evaluated for protozoa (Giardia lamblia [Gl], Dientamoeba fragilis [Df], Blastocystis hominis [Bh]) as part of a protocolized diagnostic workup and treated if positive. Re-examination of faeces followed at least 10 days after the end of treatment. Disappearance of pain with eradication and a pain free follow up of at least 6 months was considered indicative of a causal relation with RAP. The predictive value of the characteristics of the pain for protozoan infections was calculated.

\section{Results}

Two hundred and twenty consecutive patients (128 F, $92 \mathrm{M}$, mean age 8,8 [range 4,1-16,0] years) were included. Stool samples were received from 215 patients; 73 (34\%) carried parasites, 10 of whom had 2 parasites, 2 had 3 parasites. Eight patients had spontaneous resolution of pain, 65 were treated. Twenty five (11\%) were pain free after eradication (21 had Df, 8 had Bh, 4 had Gl), of whom 11 had another infection (2) or constipation (9) as a second diagnosis for the pain. Five had recurrence of infection with Df and were again pain free with eradication. Patients with a protozoan infection as the cause of their pain did not show remarkable differences with respect to their clinical presentation when compared with patients with an asymptomatic protozoan infection and patients without protozoa.

\section{Conclusion}

Protozoa can be found in $11 \%$ of children with recurrent abdominal pain as the cause of the pain. Patients with protozoan infections as the cause of abdominal pain did not show a characteristic presentation when compared with patients with other causes of abdominal pain. 


\section{Introduction}

Recurrent abdominal pain (RAP) has been found in $10-15 \%$ of children at school age. Psychological factors are supposed to play an important role. Recently attention has been given to protozoan gastrointestinal infections, especially to the role of Dientamoeba fragilis (Df) and Blastocystis hominis (Bh) in patients with abdominal pain and other gastrointestinal symptoms (1-4). Although $\mathrm{Bh}$ has been described for the first time as early as 1911 and Df in 1918, it is only since the last decades that some information has come to light about the role of these protozoa. Especially presentation with the symptom complex of irritable bowel syndrome (IBS) has been described (1;5).

\section{Aim}

To investigate the causal relationship between protozoan infections and RAP, as part of a comprehensive study on RAP $(6 ; 7)$, and to investigate if protozoan infections can be recognised by a characteristic clinical presentation of abdominal pain.

\section{Methods}

Between May 2002 and May 2004 all consecutive children, age 4 -16 years, with RAP according to the Apley criteria (abdominal pain since at least 3 months; at least 3 bouts of pain, severe enough to interfere with daily activities) ${ }^{(8)}$, who were referred by their general practitioner to one of the authors (CG), were prospectively evaluated for protozoan infections (Giardia lamblia [Gl], Dientamoeba fragilis, Blastocystis hominis). Standardized history and physical examination were performed as described earlier (6), with special reference to pain characteristics and concomitant symptoms (table 2). In all children faecal testing for parasites was performed according to the specific triple feces test (TFT) protocol as described earlier by Van Gool et al (9). When parasites were detected, patients were treated with metronidazole $(20 \mathrm{mg} / \mathrm{kg} /$ day for $\mathrm{Gl}, 35-50 \mathrm{mg} / \mathrm{kg} /$ day for Df and Bh) for 10 days. Some children, because of intolerance or refusal of metronidazole, were treated with tinidazole (two dosages of $75 \mathrm{mg} / \mathrm{kg}$ 1 week apart) or, in case of Df, paromomycin (25-35 mg/kg/day for 7 days), in case of Bh, co-trimoxazol $36 \mathrm{mg} / \mathrm{kg} /$ day for 7 days. At least 10 days after the end of treatment, examination of faeces was repeated.

Disappearance of RAP after eradication of parasites with a pain-free follow-up period of at least 6 months was considered indicative of a causal relation with RAP as described earlier (7).

\section{Statistical analysis}

Statistical analysis was performed using SPSS version 17.0 to investigate the characteristics of abdominal pain in patients with protozoan infections and their predictive value with respect to protozoan infections as the cause of the pain.

\section{Results}

Two hundred and twenty consecutive patients were included. Stool samples were obtained from 215 patients ( $125 \mathrm{~F}, 90 \mathrm{M}$, mean age 8,8 [range 4,1-16,0] years), 73 (34\%) carried parasites. Out of 73, 10 of them had two and 2 had three species of protozoa (table 1). These infections were found in 50 of 120 patients (42\%) of Western European descent, in 5 of 18 patients (28\%) of half-Western European descent and in 18 of 82 patients (22\%) of non-Western European descent $(p=0.003$ for the difference between Western European and non-Western European descent). All three protozoa were more frequent in patients of Western European descent. 
Eight of 73 patients had spontaneous resolution of abdominal pain (TFT was not repeated). The remaining 65 patients were treated as described.

Eradication was confirmed in 60 out of 65 patients (88\%). In 9 patients 2 or more courses of therapy were necessary. One patient still had a positive TFT after therapy, but received no further therapy because of resolution of abdominal pain. Four patients failed to bring a control stool sample and they were considered lost to follow-up. Following eradication, resolution of abdominal pain was confirmed in 25 out of 73 infected patients (34\%). In 14/25 the pain disappeared after eradication of the parasites; in 11 the pain was considerably reduced after eradication of the parasites, but complete resolution of the pain was only achieved after treatment of Helicobacter pylori infection (1 patient), Yersinia enterocolitica infection (1 patient), or constipation (9 patients) (7).

Five patients who had an infection with Df as the most likely cause of abdominal pain, had recurrence of abdominal pain; they had again an infection with Df and were again immediately pain free after eradication of the parasite.

Table 2 shows the characteristics of patients with a parasite as the cause of their pain, compared with those with an asymptomatic parasitic infection and those without parasites. No remarkable differences are observed with respect to age of the patients, duration of pain, localization of pain and other characteristics. The numbers of the patients in the group 'protozoa as cause of the pain' are too small to allow adequate statistics; however, differences between the groups are obviously too small to be clinically relevant.

Table 1. Parasitic infections and their relation with abdominal pain

\begin{tabular}{|c|c|c|c|c|c|c|c|}
\hline Parasites & $\begin{array}{l}\text { Number } \\
\text { of pts }\end{array}$ & No therapy & Eradication & $\begin{array}{l}\text { Resolution } \\
\text { of pain not } \\
\text { related to } \\
\text { eradication }\end{array}$ & $\begin{array}{l}\text { Resolution of } \\
\text { pain related } \\
\text { to eradication } \\
(\% *)\end{array}$ & $\begin{array}{c}\text { No } \\
\text { eradication } \\
\text { with therapy }\end{array}$ & $\begin{array}{l}\text { No faecal } \\
\text { control ** }\end{array}$ \\
\hline $\begin{array}{l}\text { Dientamoeba } \\
\text { fragilis (df) }\end{array}$ & 38 & 2 & 33 & 19 & $14(37)$ & $1 * * *$ & 2 \\
\hline $\begin{array}{l}\text { Blastocystis } \\
\text { hominis (bh) }\end{array}$ & 17 & 3 & 12 & 10 & $2(18)$ & & 2 \\
\hline $\begin{array}{l}\text { Giardia } \\
\text { lamblia (gl) }\end{array}$ & 6 & 1 & 5 & 3 & $2(33)$ & & \\
\hline$d f+b h$ & 9 & 2 & 7 & 2 & $5(56)$ & & \\
\hline$d f+g l$ & 1 & & 1 & & $1(100)$ & & \\
\hline$d f+b h+g l$ & 2 & & 2 & 1 & $1(50)$ & & \\
\hline Total & 73 & 8 & 60 & 35 & $25(34)$ & 1 & 4 \\
\hline
\end{tabular}

* percentage of infected patients

** 1patient with df: pain free after therapy, during 13 months follow up, refused faecal control; 4 patients: pain not related to parasites

*** pain not related to parasites 
Table 2. Characteristics of patient groups

\begin{tabular}{|c|c|c|c|c|c|c|c|}
\hline & & $\begin{array}{r}\text { Protozoa } \\
\text { pa }\end{array}$ & of the & $\begin{array}{r}\text { Protozo } \\
\mathbf{n}\end{array}$ & Isative & $\begin{array}{l}\text { Abdom } \\
\text { parasite }\end{array}$ & $\begin{array}{l}\text { n, no } \\
\text {; n (\%) }\end{array}$ \\
\hline Age, mean (yr) & & & & & & & \\
\hline Duration of pa & in, mean (yr) & & & & & & \\
\hline & & $\mathbf{n}$ & $\%$ & $\mathbf{n}$ & $\%$ & $\mathbf{n}$ & $\%$ \\
\hline Start pain after & r Gl infection & 4 & 16 & 2 & 5 & 10 & 7 \\
\hline Localization & upper abdomen & 7 & 28 & 10 & 23 & 38 & 27 \\
\hline of pain & mid abdomen & 9 & 36 & 16 & 37 & 49 & 35 \\
\hline & lower abdomen & 5 & 20 & 9 & 21 & 23 & 16 \\
\hline & whole abdomen & 1 & 4 & 3 & 7 & 2 & 1 \\
\hline & various & 3 & 12 & 5 & 12 & 30 & 21 \\
\hline Frequency of & $\leq 4$ days/months & 4 & 16 & 3 & 7 & 13 & 9 \\
\hline pain & 1-3 days/week & 3 & 12 & 11 & 26 & 35 & 25 \\
\hline & 4-6 days/week & 11 & 44 & 12 & 28 & 46 & 32 \\
\hline & every day & 7 & 28 & 17 & 40 & 48 & 34 \\
\hline Duration of & $<15 \min$ & 4 & 16 & 9 & 21 & 41 & 29 \\
\hline pain episodes & $15-60 \mathrm{~min}$ & 15 & 60 & 14 & 33 & 48 & 34 \\
\hline & 1-some hours & 4 & 16 & 10 & 23 & 31 & 22 \\
\hline & \pm whole day & 2 & 8 & 10 & 23 & 22 & 16 \\
\hline Constipation ( & Rome II criteria) $(n=192)$ & 5 & 20 & $8 / 41^{*}$ & 20 & $33 / 126$ & 26 \\
\hline Diarrhoea (unf & ormed stools) & 7 & 28 & 23 & 54 & 57 & 40 \\
\hline Mucus with stc & ools ( $n=207)$ & $5 / 24$ & 21 & 9 & 21 & $28 / 140$ & 20 \\
\hline Blood with sto & ols $(n=209)$ & $1 / 24$ & 4 & 3 & 7 & 17 & 12 \\
\hline Flatulence & & 13 & 52 & 24 & 56 & 51 & 36 \\
\hline Bloating $(n=20$ & & 15 & 60 & $30 / 40$ & 75 & $74 / 135$ & 55 \\
\hline IBS presentatic & $n(n=192)$ & 10 & 40 & 11 & 27 & 36 & 29 \\
\hline Anorexia $(n=2$ & & $8 / 24$ & 33 & 32 & 74 & 79 & 55 \\
\hline Early satiety ( $\mathrm{n}$ & $=204)$ & $8 / 24$ & 33 & $28 / 42$ & 67 & $65 / 138$ & 47 \\
\hline Nausea $(n=208$ & & 16 & 64 & 26 & 61 & $77 / 140$ & 55 \\
\hline Vomiting & & 3 & 12 & 11 & 26 & 38 & 27 \\
\hline Awake at nigh & t, regularly & 2 & 8 & 3 & 7 & 20 & 14 \\
\hline Missed school & at least $1 x /$ week $(n=208)$ & 2 & 8 & 9 & 22 & 20 & 14 \\
\hline Eosinophils $>0$ & $0,4 \times 109 / 1(n=196)$ & $10 / 24$ & 42 & $9 / 42$ & 21 & $21 / 130$ & 16 \\
\hline
\end{tabular}

Total number of patients: 210

Constipation (Rome II): $\leq 2 x /$ week and/or hard stools

* 8 out of 41 patients 


\section{Discussion}

We performed a prospective cohort study to evaluate the possible relationship between RAP and protozoan infections in children. The main findings were that protozoa were present in approximately $30 \%$ of all patients, and were supposed to be causative in about $30 \%$ of infected patients. Considering the whole group of 220 patients, we found $25(11 \%)$ to be due to parasites. We could not identify symptoms or signs at presentations that predicted parasitical infection as cause of the RAP.

Pathogenicity of intestinal parasites is mainly based on microbiologically initiated studies (1-3). In these studies, patients with gastrointestinal complaints who tested positive for faecal protozoa were treated; after eradication of the parasites the symptoms disappeared in a high percentage, varying from $82-100 \%$ (2-4) especially with respect to Gl and Df, leading to the opinion that these protozoa can be considered pathogens. However, prospective double-blind, placebo-controlled studies are not available, except for one recent study on $\mathrm{Bh}{ }^{(10)}$. A limitation of these studies is, that hardly any study describes the time relation between eradication of the parasite and disappearance of the pain.

Gl has been accepted as a pathogen. Diarrhea may have an acute onset, but may last for years and may be continuous or intermittent. Abdominal pain may be present, independent of the presence of diarrhea. Flatulence, anorexia, nausea, vomiting, weight loss and general malaise are reported as symptoms of a Gl infection. Chronic Gl infection can present as irritable bowel syndrome (IBS) ${ }^{(1 ; 3)}$ or dyspepsia (11;12). Grazioli et al (12) found $\mathrm{Gl}$ in $6,5 \%$ of patients diagnosed with IBS. At least $50 \%$ of people spontaneously clear $\mathrm{Gl}$ without symptoms ${ }^{(1)}$.

Nowadays, Df is accepted as a pathogen, although its exact role in disease is still subject of discussion (13). The duration of disease varies from 2 weeks to years ${ }^{(1)}$. Reported symptoms of an infection with Df are acute or chronic and include abdominal pain, diarrhoea and looseness of stools, flatulence, anorexia, nausea, vomiting, weight loss

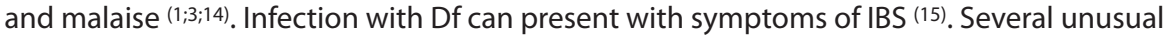
presentations are reported (16-19).

Vandenberg et al (3) found abdominal pain in a high percentage of patients with Df or Gl infection; all reported a clinical cure after eradication of their parasites. Stark et al (2) found abdominal pain or discomfort in a high percentage of patients with Df; symptoms disappeared in $94 \%$ after eradication of the parasite. Bosman et al (4) in a retrospective study found $82 \%$ of 33 patients with Df and gastrointestinal complaints to have considerably less or no complaints after eradication of Df.

Pathogenicity of Bh is subject of more discussion. Symptoms attributed to Bh include abdominal pain, cramps or discomfort, diarrhea and nausea (1). Bh has been found in considerable numbers as sole identified potential pathogen in patients with gastrointestinal symptoms; their symptoms disappeared with eradication. A role of $\mathrm{Bh}$ as a cause of IBS like symptoms is suggested, but is still controversial: several clinical and epidemiological studies implicate Bh as a pathogen, but others consider it to be a commensal ${ }^{(1 ; 20)}$. Windsor et al (13) commented not to overlook Df in these patients, because Df could be the cause of the symptoms, but is more difficult to detect. In a recent double blind placebo controlled study 37 children with RAP as their only complaint and $\mathrm{Bh}$ as the only pathological finding were treated with trimethoprim / sulfamethoxazol (TMP/SMX) or placebo. Eradication was $35 \%$ in the TMP/SMX group and $29 \%$ in the placebo 
group. Decrease of the pain score was comparable in both groups and independent of the detection of $\mathrm{Bh}$ at the end of treatment ${ }^{(10)}$.

Df and $\mathrm{Gl}$ have a worldwide distribution; Bh is suggested to be more frequent in developing countries (2;3;20). We found protozoa more often in patients of Western European descent than in patients of non-Western European descent.

The characteristics of the patients, including pain, in the different patient groups showed no remarkable differences. We conclude that clinical presentation does not indicate, which patients should be tested for parasites.

We found a causal relationship between RAP and protozoan infection in 25/73 patients, whereas in the remaining patients the abdominal pain appeared not to be related to the parasites.

Our results suggest that Df can be associated with RAP. Our observations in 5 patients with reinfection with $\mathrm{Df}$ can be seen as a confirmation of the causal relation.

Only two of 25 patients with abdominal pain caused by protozoan infections had Bh only; all other patients had Df, Gl or a combination. This number is too small to conclude, that Bh infection can cause RAP on its own, the more because Df can easily be overlooked by the presence of $\mathrm{Bh}$ in a stool sample (13).

It is of interest, that 11 of 25 patients with a causative protozoan infection had a second diagnosis (7): there was a lasting, remarkable reduction of their pain by eradication of the parasite, but sometimes pain was still present; after a second intervention, laxative therapy in most, the pain totally disappeared.

The percentage of infected patients in our study is $34 \%$, and is comparable to other studies $(2 ; 3)$. Success of eradication on complaints (34\%) is lower than found in these studies $(82-100 \%(2-4))$. This difference is probably explained by selection bias because TFT in these studies is performed because of acute gastrointestinal complaints as opposed to the recurrent abdominal pain in our study. Moreover, our strict criteria for a causal relation of protozoan infection and RAP could play a role. In total, $11 \%$ of patients with RAP has a protozoan infection as the cause of the pain (21-23).

The limitation lies in the difficulty to diagnose parasitic disease with certainty as the cause of the pain. We chose a follow-up of at least 6 months to restrict the possibility that parasites were falsely considered to be the cause of the pain (24). However, these data need confirmation from other studies in order to acquire more certainty about the effects of protozoan infections.

The strengths of this prospective study lie in the diagnostic procedure based on therapeutic intervention and a pain-free follow-up and in the comparison of pain characteristics in patients diagnosed with and without parasites as the cause of the pain.

\section{Conclusion}

Protozoa can be found in $11 \%$ of children with RAP as the cause of the pain, according to our criteria. Patients with protozoan infections as the cause of RAP did not show a characteristic presentation when compared with patients with other causes of abdominal pain. 


\section{REFERENCE LIST}

(1) Stark D, van HS, Marriott D, Ellis J, Harkness J. Irritable bowel syndrome: a review on the role of intestinal protozoa and the importance of their detection and diagnosis. Int J Parasitol 2007;37:11-20.

(2) Stark D, Barratt J, Roberts T, Marriott D, Harkness J, Ellis J. A review of the clinical presentation of dientamoebiasis. Am JTrop Med Hyg 2010;82:614-9.

(3) Vandenberg O, Peek R, Souayah H, Dediste A, Buset M, Scheen R, et al. Clinical and microbiological features of dientamoebiasis in patients suspected of suffering from a parasitic gastrointestinal illness: a comparison of Dientamoeba fragilis and Giardia lamblia infections. Int J Infect Dis 2006;10:255-61.

(4) Bosman DK, Benninga MA, van de BP, Kooijman GC, van Gool T. Dientamoeba fragilis: possibly an important cause of persistent abdominal pain in children. Ned Tijdschr Geneeskd 2004;148:575-9.

(5) Yakoob J, Jafri W, Beg MA, Abbas Z, Naz S, Islam M, et al. Blastocystis hominis and Dientamoeba fragilis in patients fulfilling irritable bowel syndrome criteria. Parasitol Res 2010;107:679-84.

(6) Gijsbers CFM, Benninga MA, Büller HA. Clinical and laboratory findings in 220 children with recurrent abdominal pain. Acta Paediatr 2011;100:1028-32.

(7) Gijsbers CFM, Kneepkens CMF, Schweizer JJ, Benninga MA, Büller HA. Recurrent abdominal pain in 200 children: somatic causes and diagnostic criteria. Acta Paediatr 2011;100:e208-e214.

(8) Apley J, Naish N. Recurrent abdominal pains: a field survey of 1,000 school children. Arch Dis Child 1958;33:165-70.

(9) van Gool T, Weijts R, Lommerse E, MankTG. Triple Faeces Test: an effective tool for detection of intestinal parasites in routine clinical practice. Eur J Clin Microbiol Infect Dis 2003;22:284-90.

(10) Heyland K, Friedt M, Buehr P, Braegger CP. No advantage for antibiotic treatment over placebo in Blastocystis hominis-positive children with recurrent abdominal pain. J Pediatr Gastroenterol Nutr 2012;54:677-9.

(11) Yakoob J, Jafri W, Abid S, Jafri N, Hamid S, Shah HA, et al. Giardiasis in patients with dyspeptic symptoms. World J Gastroenterol 2005;11:6667-70.

(12) Grazioli B, Matera G, Laratta C, Schipani G, Guarnieri G, Spiniello E, et al. Giardia lamblia infection in patients with irritable bowel syndrome and dyspepsia: a prospective study. World J Gastroenterol 2006;12:1941-4.

(13) Windsor JJ, Macfarlane L. Irritable bowel syndrome: the need to exclude Dientamoeba fragilis. Am JTrop Med Hyg 2005;72:501-2.

(14) Yang J, Scholten T. Dientamoeba fragilis: a review with notes on its epidemiology, pathogenicity, mode of transmission, and diagnosis. Am J Trop Med Hyg 1977;26:16-22.

(15) Borody TJ, Warren EF, Wettstein A, Robertson G, Recabarren P, Fontela A, et al. Eradication of dientamoeba fragilis can resolve IBS-like symptoms. J Gastroenterol Hepatol 2002;17:A103.

(16) Shein R, Gelb A. Colitis due to Dientamoeba fragilis. Am J Gastroenterol 1983;78:634-6.

(17) Cerva L, Schrottenbaum M, Kliment V. Intestinal parasites: a study of human appendices. Folia Parasitol (Praha) 1991;38:5-9.

(18) Schwartz MD, Nelson ME. Dientamoeba fragilis infection presenting to the emergency department as acute appendicitis. J Emerg Med 2003;25:17-21.

(19) Ito R, Sakagami J, Kataoka K, Nakamura H, Motoyoshi T, Takada R, et al. Chronic diarrhea and protein-losing gastroenteropathy caused by Dientamoeba fragilis. J Gastroenterol 2004;39:1117-9.

(20) Stenzel DJ, Boreham PF. Blastocystis hominis revisited. Clin Microbiol Rev 1996;9:563-84.

(21) Alfven $G$. One hundred cases of recurrent abdominal pain in children: diagnostic procedures and criteria for a psychosomatic diagnosis. Acta Paediatr 2003;92:43-9.

(22) Kokkonen J, Haapalahti M, Tikkanen S, Karttunen R, Savilahti E. Gastrointestinal complaints and diagnosis in children: a population-based study. Acta Paediatr 2004;93:880-6.

(23) Rasquin A, Di Lorenzo C, Forbes D, Guiraldes E, Hyams JS, Staiano A, et al. Childhood functional gastrointestinal disorders: child/adolescent. Gastroenterology 2006;130:1527-37.

(24) Spiller RC. Problems and challenges in the design of irritable bowel syndrome clinical trials: experience from published trials. Am J Med 1999;107:91S-7S. 

CFM Gijsbers'1, CMF Kneepkens², HA Büller³.

1Juliana Children's Hospital/Haga Teaching Hospital, The Hague, 2VU University Medical

Centre, Amsterdam, ${ }^{3}$ Erasmus Medical Centre, Rotterdam, The Netherlands

Acta Paediatrica 2012;101(9):e411-e415

\section{ABSTRACT}

Aim

To investigate malabsorption of lactose and fructose as causes of recurrent abdominal pain (RAP).

\section{Methods}

In 220 children (128 girls, mean age 8,8 [4,1-16,0] years) with RAP, hydrogen breath tests $\left(\mathrm{H}_{2} \mathrm{BT}\right.$; abnormal if $\left.\Delta \mathrm{H}_{2}>30 \mathrm{ppm}\right)$ were performed with lactose and fructose. Disappearance of RAP with elimination, recurrence with provocation and disappearance with re-elimination, followed by a 6 month pain-free follow-up, was considered indicative of a causal relation with RAP. For definite proof, a double-blinded placebo-controlled (DBPC) provocation was performed.

\section{Results}

Malabsorption of lactose was found in 57 of 210, of fructose in 79 of 121 patients. Pain disappeared upon elimination in $24 / 38$ patients with lactose malabsorption, and in 32/49 with fructose malabsorption. Open provocation with lactose and fructose was positive in $7 / 23$ and $13 / 31$ patients. DBPC provocation in $6 / 7$ and $8 / 13$ patients was negative in all. However, several children continued to report abdominal symptoms upon intake of milk or fructose.

\section{Conclusion}

Lactose intolerance nor fructose intolerance could be established as causes of RAP, according to preset criteria including elimination, open provocation and DBPC provocation. However, in clinical practice persistent feeling of intolerance in some patients should be taken seriously and could warrant extended elimination with repeated challenges.

\section{Introduction}

Carbohydrate malabsorption is considered one of the possible causes of RAP (1-4). Malabsorbed carbohydrate is fermented by the colonic microbiota, which may result in symptoms of carbohydrate intolerance, including abdominal pain, bloating, borborygmi, flatulence and diarrhoea (5).

Lactose malabsorption caused by hypolactasia is found in about $70 \%$ of the adult world population, especially in those of non-Western European descent ${ }^{(6)}$. Yet, only a small percentage of them is intolerant of dietary lactose $(7 ; 8)$. The same holds true for fructose malabsorption, which is found in the majority of children and many adults but causes symptoms only in a small percentage (9).

Why lactose and fructose are causing problems in some people, but not in others, is insufficiently elucidated (9-14). Although lactose intolerance has been recognised 
as a cause of irritable bowel-like symptoms, the causal relationship between abdominal pain and lactose malabsorption remains a matter of much discussion $(5 ; 15)$. The aim of our study, therefore, was to investigate whether malabsorption of lactose and fructose can be considered a valid cause of RAP.

\section{Methods}

Two hundred and twenty consecutive patients (128 F, $92 \mathrm{M}$, mean age 8,8 [range 4,1-16,0] years; 120 of Western European descent, 18 half-Western European and 82 non-Western European) referred by general practitioners to one of the authors (CG) because of RAP, fulfilling Apley's criteria, were evaluated prospectively for lactose malabsorption and intolerance as part of a more comprehensive study on the causes of RAP in a secondary medical centre, comprising extensive clinical evaluation with therapeutic interventions as indicated ${ }^{(16 ; 17)}$. The first 134 consecutive patients (74 F, $\left.60 \mathrm{M}\right)$ were also evaluated for fructose malabsorption and intolerance.

Hydrogen breath tests $\left(\mathrm{H}_{2} \mathrm{BT}\right)$ were performed with a $16,7 \%(50 \mathrm{~g} / 300 \mathrm{ml})$ solution of lactose or fructose, $2 \mathrm{~g} / \mathrm{kg}$, with a maximum of $50 \mathrm{~g}$. An increase over baseline of breath hydrogen excretion $\left(\Delta \mathrm{H}_{2}\right)$ of $\leq 20 \mathrm{ppm}$ was considered normal, $\Delta \mathrm{H}_{2} 21-30 \mathrm{ppm}$ was considered an equivocal result. Adverse reactions were recorded.

Elimination of carbohydrate was performed in patients with an abnormal $\mathrm{H}_{2} \mathrm{BT}\left(\Delta \mathrm{H}_{2}>30\right.$ $\mathrm{ppm})$. This threshold was arbitrarily chosen to prevent unnecessary elimination procedures in children with probably irrelevant hydrogen excretion. No elimination was performed in children in whom the abdominal pain already had been resolved. Positive elimination of lactose or fructose from the diet was followed by open provocation at home, reintroducing a normal milk and fructose containing diet. Patients with abnormal $\mathrm{H}_{2} \mathrm{BT}$ for both lactose and fructose were advised to eliminate both lactose and fructose, followed by provocation with lactose and fructose one by one.

Disappearance of abdominal pain with elimination, recurrence with provocation and disappearance with re-elimination, followed by a pain-free period of at least 6 months with diet, was considered indicative of a causal relation with RAP.

Open provocation procedures are considered insufficiently reliable. For a definite proof of intolerance, a double-blind placebo-controlled (DBPC) provocation was performed. For the DBPC provocation the patients received two containers with $25 \mathrm{~g}$ lactose or fructose and two with glucose in amounts that resulted in the same sweetness, numbered 1 through 4 in a randomised way. The hospital pharmacist provided the containers with carbohydrates and the randomisation. The patients were asked to consume the content of 1 container in 1 day, mixed with fluid. When they had symptoms, they were asked to postpone the consumption of the next dose until symptoms had disappeared. Two children followed an extended procedure, with four consecutive days of lactose or fructose and four with glucose in random order. Two other children, with additional suspicion of cow's milk allergy, had cow's milk or placebo processed in pancakes, cookies or mashed potatoes at their choices. In the verum challenge, they received $500 \mathrm{ml}$ of milk ( $25 \mathrm{~g}$ of lactose) per day for 3 consecutive days. Randomisation was performed by the dietician.

\section{Results}

Lactose breath tests were successfully performed in 210 of 220 patients, eight patients did not show up for the test and two refused to drink the lactose solution. Results of breath tests are shown in table 1, results of elimination and provocation in figure 1. Fructose breath tests were successfully performed in 121 of 134 patients, 9 patients did not show 
up and 4 refused to drink the fructose solution. Results of breath tests are shown in table 2 , results of elimination and provocation are shown in figure 2 .

Nineteen patients with abnormal $\mathrm{H}_{2} \mathrm{BT}$ s to lactose and 30 patients with abnormal fructose tests did not proceed to elimination diets because their abdominal pain already had been resolved and remained so during the 6-month follow up period. One patient with positive open provocation to lactose and five patients with positive open provocation to fructose refused DBPC provocation. All children resumed normal feeding except for 4 of the 6 children with (negative) DBPC lactose provocation: two consumed restricted amounts of milk, one complained of borborygmi after drinking milk and one reported faecal soiling after drinking milk for more than one week. One child successfully eliminates milk in case of incidental abdominal pain.

Table 1. Symptoms during/after lactose $\mathrm{H}_{2} B T$

\begin{tabular}{|c|c|c|c|c|}
\hline \multirow[t]{2}{*}{ Result $\mathrm{H}_{2} \mathrm{BT}(\mathrm{n}=210)$} & \multicolumn{4}{|c|}{ Symptoms during/after $\mathrm{H}_{2} \mathrm{BT}$ in 210 patients, $\mathrm{n}(\%)$} \\
\hline & Abdominal pain & Diarrhoea & Nausea & Vomiting \\
\hline$\Delta \mathrm{H}_{2} \leq 30 \mathrm{ppm}(\mathrm{n}=153)$ & $38(25)$ & $7(5)$ & $20(13)$ & $1(1)$ \\
\hline$\Delta \mathrm{H}_{2}>30 \mathrm{ppm}(\mathrm{n}=57)$ & $33(58)$ & $17(30)$ & $12(21)$ & $4(7)$ \\
\hline
\end{tabular}

Table 2. Symptoms during/after fructose $\mathrm{H}_{2} B T$

\begin{tabular}{|c|c|c|c|c|}
\hline \multirow[t]{2}{*}{ Result $\mathrm{H}_{2} \mathrm{BT}(\mathrm{n}=121)$} & \multicolumn{3}{|c|}{ Symptoms during/after $\mathrm{H}_{2} \mathrm{BT}$ in 121 patients, $\mathrm{n}(\%)$} & \\
\hline & Abdominal pain & Diarrhoea & Nausea & Vomiting \\
\hline$\Delta \mathrm{H}_{2} \leq 30 \mathrm{ppm}(\mathrm{n}=42)$ & $20(48)$ & $9(21)$ & $15(36)$ & $4(10)$ \\
\hline$\Delta \mathrm{H}_{2}>30 \mathrm{ppm}(\mathrm{n}=79)$ & 55 (70) & $25(32)$ & 27 (34) & $2(3)$ \\
\hline
\end{tabular}

Figure 1. Testing of lactose intolerance

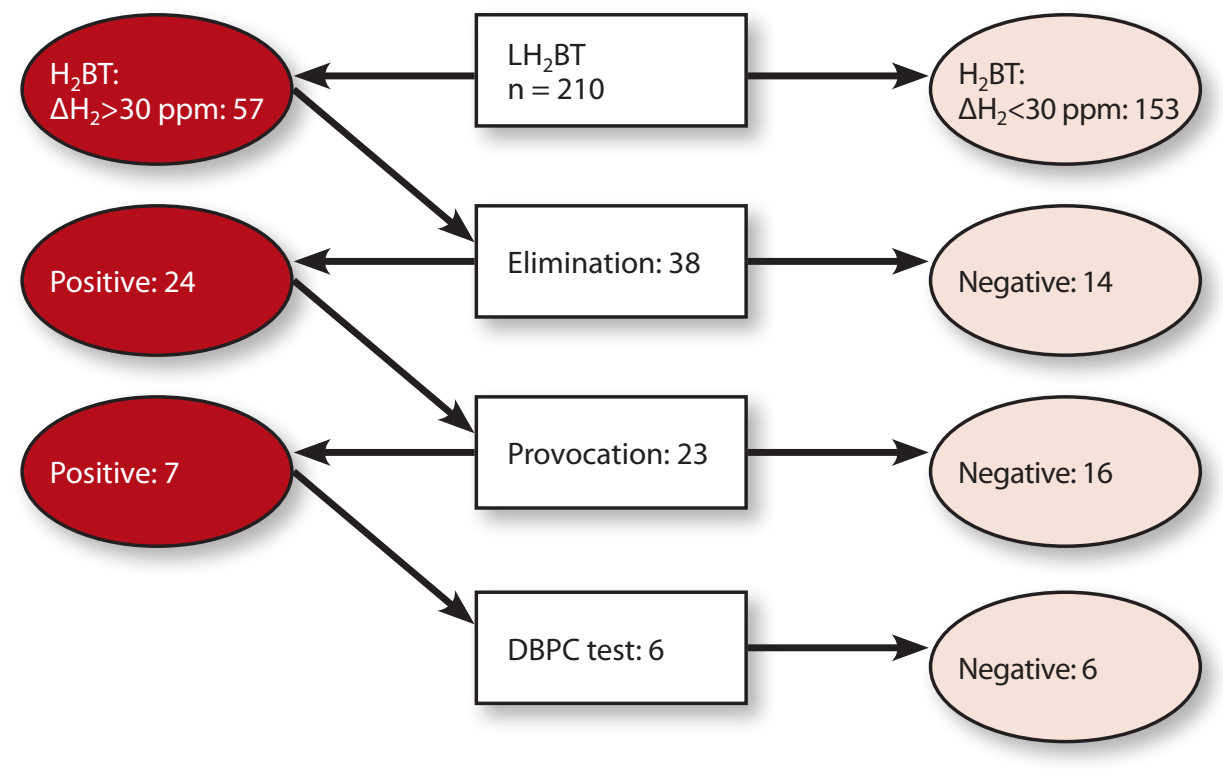


Figure 2. Testing of fructose intolerance

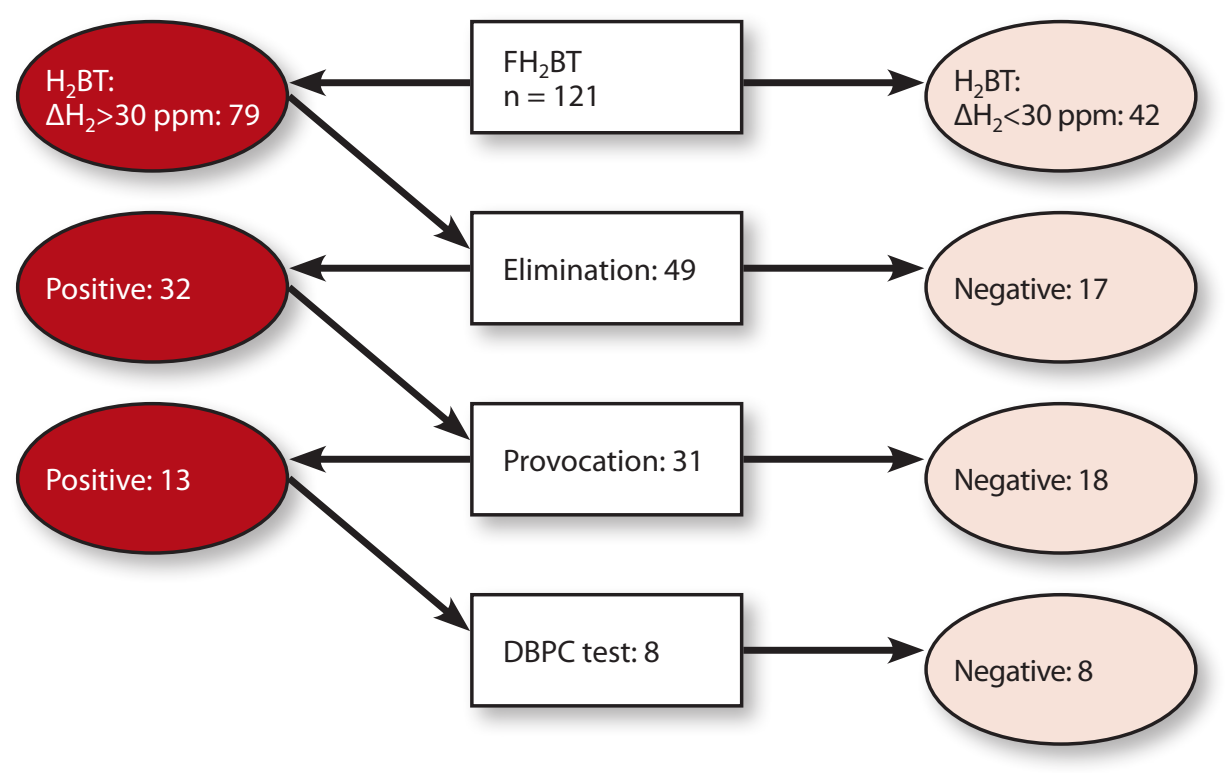

\section{Discussion}

In a cohort of 220 patients with RAP intolerance to lactose or fructose, according to preset criteria including DBPC provocation, could not be established. Despite negative DBPC provocation, however, some children persisted in complaining of abdominal symptoms when using milk or fructose containing food and were pain-free by elimination.

In many papers on lactose intolerance it is concluded that most - but not all - patients with lactose malabsorption tolerate some amounts of milk (3;7;8). Other studies emphasize that a certain percentage of patients complain of abdominal pain, bloating or diarrhoea in case of malabsorption of lactose (1;2;;;18). Böhmer et al (19) in a study on irritable bowel syndrome (IBS) and lactose malabsorption in adults showed more frequent lactose malabsorption in IBS patients than in healthy controls. Decrease of symptoms with a lactose-restricted diet in patients with IBS and lactose malabsorption has been shown

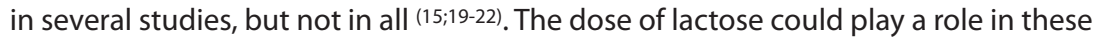
different results ${ }^{(15)}$. Literature on fructose has shown the same discrepancies $(9 ; 23)$.

Many children had abdominal pain during $\mathrm{H}_{2} \mathrm{BT}$, although they had a normal test result (table 1 and 2). This could be the patients usual abdominal pain, that was not necessarily caused by the tested carbohydrate. In addition, the test situation and the expectation of the patient as to the consequence of the sugar load could be experienced as stressful, resulting in abdominal pain. Moreover, the $\mathrm{H}_{2} \mathrm{BT}$ is supposed to be falsely negative in some patients, for instance because of $\mathrm{H}_{2}$ consuming or non $\mathrm{H}_{2}$ producing colonic microbiota or the recent use of antibiotics (24;25); diarrhoea and abdominal cramps in these cases are assumed to be caused by lactose metabolites in the colon.

We found negative DBPC tests in all patients investigated. However, only $10 \%$ of our patients with $\Delta \mathrm{H}_{2}>30$ ppm eventually had a DBPC test, 6 patients with lactose 
malabsorption and 8 patients with fructose malabsorption, and several of these patients continued to complain of abdominal symptoms from milk or fructose containing food. It has to be realised that there is no fixed relationship between carbohydrate malabsorption and intolerance. Vonk et al suggested, that the degree of lactose digestion in adults with genetically determined low lactase activity is determined by residual lactase activity and by the time available for hydrolysis (orocaecal transit time). Other, still incompletely understood, host-specific factors were supposed to be responsible for intolerance $(13 ; 14)$. Moreover, adaptation of intestinal microbiota with increase of bacterial $\beta$-galactosidase activity is recognised as a cause of reduction of the symptoms of lactose intolerance (10-12).

With respect to fructose, adding glucose or galactose in same amount to the fructose load leads to a normal result of a fructose $\mathrm{H}_{2}$-breath test (26). This effect is also found for amino acids by Hoekstra et al (27). Facilitation of fructose absorption by glucose or galactose is considered to be caused by adaptation of the transporter GLUT2 by other hexoses (28).

In addition, distension of the bowel seems to be an important factor in the origin of the pain, as has been found in patients with irritable bowel syndrome (29). Faecal retention and retention of gas from carbohydrate malabsorption can reinforce each other and therefore variation in the severity of faecal retention could play a role in the inconsistency of abdominal pain in patients with carbohydrate malabsorption.

The complexity of these factors could lead to inter- and intraindividual variation in the clinical effect of a lactose or fructose load in malabsorbing patients.

It is noteworthy, that all 14 children with a negative DBPC provocation had a positive open provocation. This positive result could be explained by the expectations of the patient about the open provocation. Another explanation could be that the lactose (fructose) load in the DBPC provocation was not high enough to elicit symptoms, which is in agreement with some studies (7;8). However, intra individual variation in the above suggested host-specific factors like faecal flora and transit time and also faecal retention and other still unknown factors possibly plays a role in this seemingly inconsistent phenomenon.

The importance of this study lies in the strict criteria for the diagnosis of lactose (fructose) intolerance. However, at the same time this seems to be the limitation of the study. Moreover the load to be used for a reliable DBPC provocation is difficult to establish because of the well-known differences in intolerance.

A gold standard for the diagnosis lactose (fructose) intolerance does not exist, neither for lactose (fructose) malabsorption. For lactose malabsorption the gold standard probably is best approximated by the $13 \mathrm{C}$ lactose/ $2 \mathrm{H}$ glucose test, described by Vonk et al (30). However, this test is a research tool, not suitable for daily practice. For lactose (fructose) intolerance the method used in this study, relying on consistency of symptoms, probably is not the accurate way to exclude the diagnosis of carbohydrate intolerance. These uncertainties warrant further studies, designed to establish the role of factors that could influence the consequences of a carbohydrate load in patients with carbohydrate malabsorption. Especially faecal retention is suggested as a potential factor that could play a role, which could challenge the validity of a DBPC provocation in the diagnosis of carbohydrate intolerance. 


\section{Conclusion}

In 220 children with RAP lactose intolerance nor fructose intolerance could be established as a cause of the pain, according to preset criteria including elimination, open provocation and DBPC provocation. However, in clinical practice persistent feeling of intolerance in some patients should be taken seriously; this could warrant extended elimination, but repeated challenges are required. 


\section{REFERENCE LIST}

(1) Ceriani R, Zuccato E, Fontana M, Zuin G, Ferrari L, Principi N, et al. Lactose malabsorption and recurrent abdominal pain in Italian children. J Pediatr Gastroenterol Nutr 1988;7:852-7.

(2) Gremse DA, Greer AS, Vacik J, DiPalma JA. Abdominal pain associated with lactose ingestion in children with lactose intolerance. Clin Pediatr (Phila) 2003;42:341-5.

(3) Wald A, Chandra R, Fisher SE, Gartner JC, Zitelli B. Lactose malabsorption in recurrent abdominal pain of childhood. J Pediatr 1982;100:65-8.

(4) Webster RB, DiPalma JA, Gremse DA. Lactose maldigestion and recurrent abdominal pain in children. Dig Dis Sci 1995;40:1506-10.

(5) Shaw AD, Davies GJ. Lactose intolerance: problems in diagnosis and treatment. J Clin Gastroenterol 1999;28:208-16.

(6) Lomer MC, Parkes GC, Sanderson JD. Review article: lactose intolerance in clinical practice--myths and realities. Aliment Pharmacol Ther 2008;27:93-103.

(7) Lisker R, Aguilar L, Zavala C. Intestinal lactase deficiency and milk drinking capacity in the adult. Am J Clin Nutr 1978;31:1499-503.

(8) Newcomer AD, McGill DB, Thomas PJ, Hofmann AF. Tolerance to lactose among lactase-deficient American Indians. Gastroenterology 1978;74:44-6.

(9) Kyaw MH, Mayberry JF. Fructose malabsorption: true condition or a variance from normality. J Clin Gastroenterol 2011;45:16-21.

(10) Johnson AO, Semenya JG, Buchowski MS, Enwonwu CO, Scrimshaw NS. Adaptation of lactose maldigesters to continued milk intakes. Am J Clin Nutr 1993;58:879-81.

(11) Hertzler SR, Savaiano DA, Levitt MD. Faecal hydrogen production and consumption measurements. Response to daily lactose ingestion by lactose maldigesters. Dig Dis Sci 1997;42:348-53.

(12) Briet F, Pochart P, Marteau P, Flourie B, Arrigoni E, Rambaud JC. Improved clinical tolerance to chronic lactose ingestion in subjects with lactose intolerance: a placebo effect? Gut 1997;41:632-5.

(13) Vonk RJ, Priebe MG, Koetse HA, Stellaard F, Lenoir-Wijnkoop I, Antoine JM, et al. Lactose intolerance: analysis of underlying factors. Eur J Clin Invest 2003;33:70-5.

(14) He T, Venema K, Priebe MG, Welling GW, Brummer RJ, Vonk RJ. The role of colonic metabolism in lactose intolerance. Eur J Clin Invest 2008;38:541-7.

(15) Savaiano DA, Boushey CJ, McCabe GP. Lactose intolerance symptoms assessed by meta-analysis: a grain of truth that leads to exaggeration. J Nutr 2006;136:1107-13.

(16) Gijsbers CFM, Benninga MA, Büller HA. Clinical and laboratory findings in 220 children with recurrent abdominal pain. Acta Paediatr 2011;100:1028-32.

(17) Gijsbers CFM, Kneepkens CMF, Schweizer JJ, Benninga MA, Büller HA. Recurrent abdominal pain in 200 children: somatic causes and diagnostic criteria. Acta Paediatr 2011;100:e208-e214.

(18) Lisker R, Aguilar L. Double blind study of milk lactose intolerance. Gastroenterology 1978;74:1283-5.

(19) Böhmer CJ, Tuynman HA. The clinical relevance of lactose malabsorption in irritable bowel syndrome. Eur J Gastroenterol Hepatol 1996;8:1013-6.

(20) Tolliver BA, Jackson MS, Jackson KL, Barnett ED, Chastang JF, DiPalma JA. Does lactose maldigestion really play a role in the irritable bowel? J Clin Gastroenterol 1996;23:15-7.

(21) Vesa TH, Seppo LM, Marteau PR, Sahi T, Korpela R. Role of irritable bowel syndrome in subjective lactose intolerance. Am J Clin Nutr 1998;67:710-5.

(22) Turnbull GK. Lactose intolerance and irritable bowel syndrome. Nutrition 2000;16:665-6.

(23) Symons P, Jones MP, Kellow JE. Symptom provocation in irritable bowel syndrome. Effects of differing doses of fructose-sorbitol. Scand J Gastroenterol 1992;27:940-4.

(24) Vernia P, Di Camillo M, Marinaro V, Caprilli R. Effect of predominant methanogenic flora on the outcome of lactose breath test in irritable bowel syndrome patients. Eur J Clin Nutr 2003;57:1116-9. 
(25) Vernia P, Di Camillo M, Foglietta T, Avallone VE, De Carolis A. Diagnosis of lactose intolerance and the "nocebo" effect: the role of negative expectations. Dig Liver Dis 2010;42:616-9.

(26) Kneepkens CM, Vonk RJ, Fernandes J. Incomplete intestinal absorption of fructose. Arch Dis Child 1984;59:735-8.

(27) Hoekstra JH, van den Aker JH. Facilitating effect of amino acids on fructose and sorbitol absorption in children. J Pediatr Gastroenterol Nutr 1996;23:118-24.

(28) Gibson PR, Newnham E, Barrett JS, Shepherd SJ, Muir JG. Review article: fructose malabsorption and the bigger picture. Aliment Pharmacol Ther 2007;25:349-63.

(29) Quigley EM. From comic relief to real understanding; how intestinal gas causes symptoms. Gut 2003;52:1659-61.

(30) Vonk RJ, Stellaard F, Priebe MG, Koetse HA, Hagedoorn RE, De Bruijn S, et al. The 13C/2H-glucose test for determination of small intestinal lactase activity. Eur J Clin Invest 2001;31:226-33. 
Lactose and fructose malabsorption in children with recurrent abdominal pain: results of double-blinded testing 

CFM Gijsbers'1, CMF Kneepkens², Y. Vergouwe³, HA Büller³.

1Juliana Children's Hospital/Haga Teaching Hospital, The Hague, 2VU University Medical Centre, Amsterdam, ${ }^{3}$ Erasmus Medical Centre, Rotterdam, The Netherlands

Submitted

\section{ABSTRACT}

\section{Introduction}

Recurrent abdominal pain (RAP) is a frequently occurring problem in children.

It is supposed to be generally a functional problem, which should be treated with reassurance and life style advice. However, in clinical practice many children with RAP appear to become pain-free with laxatives.

\section{Aim}

The first aim of the study was to establish the role of (occult) constipation in RAP. The second aim was to investigate if patients diagnosed with (occult) constipation could be identified based on history and physical examination.

\section{Methods}

During 2 years all consecutive patients (age 4-16 years) fulfilling Apley criteria of RAP, referred to a secondary centre, were included. After exclusion of gastrointestinal infections and food allergy / intolerance as causes of the pain, laxative therapy was advised for all children in whom the abdominal pain persisted. (Occult) constipation was defined as 'abdominal pain disappearing with laxative treatment and not reappearing within a 6 month follow up period'. This definition includes children who fulfil the Rome criteria for functional constipation as well as children who do not fulfil these criteria; the latter are diagnosed with 'occult constipation'. Laxative therapy consisted of laxatives, mostly macrogol, dietary advice and toilet training.

\section{Results}

Two hundred children (113 F, 87 M; mean age 8.8 years) were evaluated. Disappearance of the pain, with laxative therapy, for at least 6 months was found in 92 patients (46\%), of whom 18 already had persistent considerable relief of pain when treated for a somatic cause, but experienced complete relief only after laxative measures; they were considered to have two diagnoses. Using multivariate analysis, a simple model could be developed with cystitis in past history, early satiety and flatulence as predictors for (occult) constipation. The risk of (occult) constipation ranged from $31 \%$ (18/58) if no predictor was present to $100 \%(4 / 4)$ if all three were present.

\section{Conclusion}

Laxatives played a pivotal role in the recovery of patients with RAP. We were able to develop a simple model to identify patients at high risk of having (occult) constipation, who might benefit from laxative treatment. 


\section{Introduction}

Recurrent abdominal pain (RAP) as defined by Apley (1) is found in 10-15\% of 4-16 year old children, with considerable morbidity. RAP often has a great impact on the lifes of the child and his family and frequently causes much anxiety (2). In most patients, RAP is considered a functional problem. Conventional therapy, consisting of reassurance and advice on lifestyle and feeding habits, has only limited success (2).

In the 1990's the first Rome criteria ("Rome I criteria") for functional gastrointestinal disorders (FGIDs), including functional abdominal pain and functional constipation, were published in order to attain more uniform patient groups as a basis for research, followed by specific criteria for children in the second version of the Rome criteria ("Rome II criteria"). This has resulted in an enormous increase in research, which until now, however, did not lead to satisfactory advice for therapy.

Constipation is considered by some clinicians to be a cause of abdominal pain in many patients, even without the presence of typical symptoms of functional constipation as described in the Rome criteria (3), but studies with respect to constipation and laxative therapy in relation to abdominal pain are scarce ${ }^{(4-7)}$.

Because of the impression from a clinical point of view that many children with RAP become pain-free with laxatives (4), we performed a study - as part of a more comprehensive study on somatic causes of RAP $(8,9)$ - on the effect of laxatives in children with RAP.

\section{Aim}

The first aim of the study was to establish the role of (occult) constipation in RAP. The second aim was to investigate if patients diagnosed with (occult) constipation could be identified based on history and physical examination.

\section{Methods}

From May 2002 until May 2004, all consecutive patients (ages 4.0-16.0 years) referred by general practitioners to a secondary centre (CFMG) with RAP (Apley criteria: abdominal pain for at least 3 months; at least 3 bouts of pain, severe enough to interfere with daily activities) as the main presenting symptom, were included in the study. They were evaluated in a standardized way as described previously, resulting in the establishment of preliminary diagnoses and diagnostic clues, such as protozoan infection, celiac disease and lactose intolerance ${ }^{(8 ; 9)}$. Subsequently, a causal relation with the abdominal pain was based on the disappearance of the pain with a specific therapeutic intervention and the child remaining pain-free during a follow-up period of at least 6 months. In order to avoid bias in case of more than one diagnostic clue, interventions were performed in a fixed order, without clinical interpretation or weighing of history or physical findings. As the first step, the gastrointestinal infections and food allergy / intolerance, respectively, were treated. As the second step, in every patient with persistent symptoms following these interventions, a trial with laxatives was performed, combined with dietary advice and toilet training, irrespective of history, physical examination or the outcome of plain abdominal X-ray (9). Oral macrogol 4000 (polyethylene glycol 4000) was prescribed in a daily dose of $1 \mathrm{~g} / \mathrm{kg}$ (maximum $40 \mathrm{~g}$ ), the parents being told to adjust the dose according to the resulting defaecation pattern. They could give a double dose for some days as a "mini lavage" if they preferred fast result. Some patients used other laxatives, especially lactulose or lactitol, as to their preference, with the same instructions. Frequent telephone contacts were used to support the parents with respect to laxative dosage. In case of therapy-resistant constipation, lavage of the colon was performed with polyethylene glycol-electrolyte solution. 


\section{Definitions}

According to the preset criteria for this study, (occult) constipation was considered to be the cause of RAP when the pain disappeared with laxative treatment for a period of at least 6 months (Table 1). Treatment may need to be continued or restarted throughout the follow-up period. Constipation was diagnosed in those children who fulfilled the Rome II criteria for functional constipation (table $2{ }^{(3)}$ ) occult constipation was diagnosed in children who did not fulfil the Rome II criteria for functional constipation, but had relieve of their symptoms with laxative treatment.

Rome II criteria for functional constipation were used because Rome III criteria were not yet published at the time of inclusion of patients.

\section{Statistical analysis}

Logistic regression analysis was used to estimate univariate odds ratios (OR) for 18 variables possibly associated with (occult) constipation. We combined the three variables that showed the strongest association with (occult) constipation in a simple model. Each included variable was assigned an equal weight (a score of one). The total score was related to the observed proportion of (occult) constipation.

Table 1. Criteria for diagnosis

General
Based on intervention and follow-up, a causal relation of a specific disease or condition with abdominal pain
is supposed, if the following criteria are fulfilled:
Therapeutic intervention results in elimination of the supposed cause (see below) and
disappearance of RAP within an appropriate space of time and
RAP does not reappear within a 6 months follow-up period or
RAP reappears within 6 months, apparently due to the same cause and eliminated in the same way
Constipation and occult constipation
Abdominal pain disappears with (laxative measures leading to) production of more faeces than before,
regardless the kind of the measures.
Treatment may need to be continued throughout follow-up period.
Pain may return upon reduction or discontinuation of treatment, but disappears again with laxative
treatment.
Constipation: those children who fulfil the Rome II criteria for functional constipation
Occult constipation: those children who do not fulfil the Rome Il criteria for functional constipation,
but show relieve of symptoms with laxative treatment.

Table 2. Rome Il criteria

Functional constipation:

Scybalous, pebble-like, hard stools for a majority of stools, or

Firm stools $\leq 2 \mathrm{x}$ per week; and

No evidence of structural, endocrine or metabolic disease 


\section{Results}

Two hundred twenty children were enrolled, of whom 20 were lost to follow-up, leaving 200 patients ( 113 girls, 87 boys; mean age 8.8 [range 4.1-16.0] years, median age 8.8 years) for analysis. Laxative therapy was advised to 111 patients and was successful in 92 patients (83\%; 59 girls, 33 boys), patients being pain-free with therapy. In 14 patients laxatives were not successful and in 5 patients no conclusion was possible because they performed the therapeutic measures insufficiently. Of the 14 patients in whom laxative therapy was not successful, 6 patients had a somatic diagnosis, 3 were considered to have stress-related abdominal pain, 2 recovered spontaneously and 3 had no certain diagnosis or had their pain unresolved.

Eighteen of the 92 patients who were successfully treated, resulting in persistent considerable relief of pain with intervention for gastrointestinal infection (15 patients) or food allergy ( 2 patients) or after discontinuation of medication (1 patient; amitriptyline), but were not completely pain-free, only had complete relief of pain after additional treatment with laxatives; they were considered to have two diagnoses.

These 92 patients were pain-free with laxative therapy for at least 6 months and therefore, according to our definition, were considered to have constipation or occult constipation as the cause of the abdominal pain. Most children needed 20-30 grams of macrogol per day, but there was considerable variation in the time (up to 4 weeks) and laxative doses (up to $70 \mathrm{~g}$ per day) needed to obtain success. The mean follow up period of the patients with (occult) constipation was 16 (range 6-48) months.

Of the 92 children who were successfully treated with laxatives including a 6 month follow up, 24 (26\%) fulfilled Rome II criteria for functional constipation and therefore were considered to have functional constipation. The other 68 children (74\%), who were pain-free with laxatives but did not fulfil Rome II criteria for functional constipation, by definition were considered to have occult constipation.

Nine children had a somatic diagnosis for the abdominal pain; they became pain-free without laxative treatment, although they fulfilled the Rome II criteria for functional constipation. 
Table 3 Prevalence of symptoms and Odds ratio

\begin{tabular}{|c|c|c|c|c|c|c|c|c|}
\hline \multirow{4}{*}{ Symptoms } & \multicolumn{8}{|c|}{ Diagnostic group } \\
\hline & \multicolumn{2}{|c|}{$\begin{array}{l}\text { (Occult) } \\
\text { constipation1 }(n=92)\end{array}$} & \multicolumn{2}{|c|}{$\begin{array}{l}\text { Somatic disease } \\
(n=34)\end{array}$} & \multirow[t]{2}{*}{$\begin{array}{l}\text { Other } 2 \\
(n=74)\end{array}$} & & \multirow{2}{*}{\multicolumn{2}{|c|}{$\begin{array}{l}\text { Odds ratio } 3 \\
\text { (Occ) constipation vs } \\
\text { somatic and other }\end{array}$}} \\
\hline & & \multirow[b]{2}{*}{$\%$} & \multirow[b]{2}{*}{$\mathbf{n}$} & \multirow[b]{2}{*}{$\%$} & & & & \\
\hline & $\mathbf{n}$ & & & & $\mathbf{n}$ & $\%$ & \multirow{2}{*}{$\begin{array}{c}\text { OR } \\
1.083\end{array}$} & $\mathrm{Cl} 95 \%$ \\
\hline Pain at awakening & $37 / 92$ & 40 & $13 / 33$ & 39 & $28 / 74$ & 38 & & $.612-1.916$ \\
\hline Pain with/after meals & $25 / 92$ & 27 & $11 / 33$ & 33 & $17 / 74$ & 23 & 1.053 & $.561-1.977$ \\
\hline $\begin{array}{l}\text { Pain with physical } \\
\text { exercise }\end{array}$ & $37 / 92$ & 40 & $14 / 34$ & 41 & $25 / 74$ & 34 & 1.190 & $.671-2.110$ \\
\hline $\begin{array}{l}\text { More pain before } \\
\text { defaecation }\end{array}$ & $34 / 91$ & 37 & $13 / 33$ & 39 & $20 / 74$ & 27 & 1.338 & $.741-2.414$ \\
\hline $\begin{array}{l}\text { Pain relieved by } \\
\text { defaecation }\end{array}$ & $43 / 88$ & 49 & $19 / 33$ & 58 & $29 / 73$ & 40 & 1.155 & $.655-2.035$ \\
\hline $\begin{array}{l}\text { Frequently small } \\
\text { amounts of faeces }\end{array}$ & $9 / 92$ & 10 & $7 / 34$ & 21 & $10 / 74$ & 14 & .580 & $.245-1.373$ \\
\hline $\begin{array}{l}\text { Varying consistency } \\
\text { of stool }\end{array}$ & $29 / 92$ & 32 & $6 / 34$ & 18 & $18 / 74$ & 24 & 1.611 & $.856-3.031$ \\
\hline $\begin{array}{l}\text { Change in frequency } \\
\text { at onset of pain }\end{array}$ & $22 / 87$ & 25 & $10 / 32$ & 31 & $17 / 71$ & 23 & .953 & $.496-1.831$ \\
\hline $\begin{array}{l}\text { Change in consistency } \\
\text { at onset of pain }\end{array}$ & $35 / 88$ & 40 & $12 / 34$ & 35 & $16 / 72$ & 22 & 1.840 & $1.002-3.376$ \\
\hline Flatulence & $44 / 92$ & 48 & $15 / 34$ & 44 & $20 / 74$ & 27 & 1.912 & $1.077-3.395$ \\
\hline Mucus & $19 / 90$ & 21 & $9 / 34$ & 26 & $9 / 73$ & 12 & 1.323 & $.647-2.708$ \\
\hline $\begin{array}{l}\text { Feeling of incomplete } \\
\text { evacuation }\end{array}$ & $64 / 92$ & 70 & $18 / 33$ & 55 & $42 / 74$ & 57 & 1.790 & $.997-3.216$ \\
\hline Anorexia & $52 / 92$ & 57 & $18 / 33$ & 55 & $42 / 74$ & 57 & 1.018 & $.581-1.786$ \\
\hline Early satiety & $55 / 88$ & 63 & $10 / 33$ & 30 & $34 / 74$ & 46 & 2.386 & $1.338-4.255$ \\
\hline $\begin{array}{l}\text { Feeling of abdominal } \\
\text { fullness }\end{array}$ & $57 / 88$ & 65 & $20 / 32$ & 63 & $32 / 70$ & 46 & 1.768 & $.985-3.173$ \\
\hline Cystitis in past history & $15 / 91$ & 16 & $4 / 34$ & 12 & $3 / 74$ & 4 & 2.848 & $1.107-7.328$ \\
\hline Abdominal distension & $10 / 92$ & 11 & $5 / 34$ & 15 & $9 / 74$ & 12 & .819 & $.345-1.942$ \\
\hline $\begin{array}{l}\text { Abdominal/rectal } \\
\text { faecal mass }\end{array}$ & $65 / 92$ & 71 & $29 / 34$ & 85 & $40 / 74$ & 54 & 1.361 & $.750-2.470$ \\
\hline 1 Occult constipation in & ng patier & boths & natic dise & 1010 & constipat & & & \\
\hline 2 Other: spontaneous $r$ & $r y(54), u$ & n diagr & sis (13), st & ), un & ved abdor & pam & & \\
\hline $\begin{array}{l}3 \text { Odds ratio (OR) and } 9 \\
\text { constipation, versus o }\end{array}$ & $\begin{array}{l}\text { onfidence } \\
\text { patients }\end{array}$ & al (Cl 95 & ): (occult) & tipati & cluding $p$ & & natic cau & id (occult) \\
\hline
\end{tabular}

Table 4 Numbers of patients having up to three symptoms 1

\begin{tabular}{|c|c|c|c|c|c|}
\hline $\begin{array}{l}\text { No of symptoms per patient } \\
\text { ("3-symptom score") }\end{array}$ & 0 & 1 & 2 & 3 & Total \\
\hline $\begin{array}{l}\text { Patients with (occult) constipation } \\
(\mathrm{n}=92)\end{array}$ & 18 & 38 & 32 & 4 & 92 \\
\hline Other $(n=108)$ & 40 & 50 & 18 & 0 & 108 \\
\hline Positive predictive value (PPV) 2 & $31.0 \%$ & $43.2 \%$ & $64.0 \%$ & $100.0 \%$ & $46.0 \%$ \\
\hline
\end{tabular}

1 Symptoms: cystitis (past history), early satiety, flatulence

2 PPV of 3-symptom score to predict (occult) constipation 
Table 3 shows the univariate association of the patient characteristics with (occult) constipation. Cystitis (past history), early satiety, flatulence, change in consistency at onset of pain, the sensation of incomplete evacuation and the sensation of abdominal fullness were clearly more common in patients with (occult) constipation than in patients without constipation. The three strongest symptoms, i.e. cystitis (past history), early satiety and flatulence, were combined in a model, resulting in a scoring system. Table 4 shows the link between the scores and (occult) constipation. Higher scores were related to higher risks of (occult) constipation: $31 \%$ of patients with a score of 0 had (occult) constipation compared to $100 \%(4 / 4)$ of the patients with a score of 3.

\section{Discussion}

The present study is part of a comprehensive project aiming at finding definite diagnoses for RAP in a large group of children. In this study, resolution of abdominal pain was obtained in 198 (99\%) of 200 patients (9). In 92 of these patients (46\%) a diagnosis of functional or occult constipation was made, according to preset criteria. It is of importance to realize that a diagnosis of functional constipation according to the Rome criteria does not guarantee a causal relation with the abdominal pain: as in other diagnoses that potentially can cause RAP, such as celiac disease or parasites, the causal relation has to be made plausible by therapeutic intervention and a pain-free follow up period. Faecal retention in (part of) the colon with subsequent bowel distension with or without visceral hypersensitivity could very well explain why laxatives were successful in these RAP patients.

Clinical studies investigating occult constipation in relation with abdominal pain are very scarce. Eidlitz-Markus et al (5) found 29 of 68 (43\%) patients with RAP to have'occult constipation', which was defined as 'no complaints or symptoms of constipation, but hard stools on rectal examination or distended large intestines at plain abdominal X-ray'. Boccia et al (7) found functional constipation in $67 \%$ of patients with functional dyspepsia (both according to Rome II criteria); symptoms of both functional constipation and functional dyspepsia diminished significantly with laxatives in these patients, as did the gastric emptying time. The functional dyspepsia was supposed to be the result of a constipationinduced cologastric break.

Keuzenkamp-Jansen et al (4) retrospectively investigated clinical symptoms and outcome of treatment in 244 children diagnosed with constipation as assessed by plain abdominal $\mathrm{X}$-ray. Of these children 75 presented with hard stools and infrequent defaecation, while 77 had abdominal pain as the presenting symptom. There were no differences between the two groups with respect to laxative dose needed or efficacy and duration of treatment, the only difference being the delay until the diagnosis of constipation - with long patient's delays in case of overt constipation and long doctor's delays in case of abdominal pain (4). It is noteworthy, that in this study, a considerable discrepancy is found between the clinical diagnosis of (occult) constipation as the cause of RAP, based on successful laxative therapy (92 patients), and functional constipation as defined by the Rome II criteria (24/92, 26\%). The Rome criteria are primarily designed as the starting point of research, for which sharp definitions are necessary. In clinical practice, however, accepting broader criteria for laxative therapy leads to recovery in a higher percentage of children with abdominal pain. In this study Rome II criteria for functional constipation were used because Rome III criteria were not yet published at the time of inclusion of patients. The Rome III criteria for functional constipation (for children with a developmental age of at least 4 years) combine the criteria of functional constipation and functional faecal retention of 'Rome II', however with several adjustments. It is to be expected, that this new design implicates considerable change in the number of patients to be categorized with 'functional constipation'. However, 
in this study this makes no difference for the total number of patients to be diagnosed with (occult) constipation, because this is based only on the result of laxative therapy.

While patients with functional constipation can be identified by symptoms according to the Rome criteria, no symptoms are recognised so far that point to occult constipation. Therefore we sought to identify all patients with constipation, functional and occult, based on history or physical examination. Eighteen gastrointestinal or related variables, other than the symptoms of the Rome II criteria and the later Rome III criteria of functional constipation, were analysed as to their relation with (occult) constipation. Univariate analysis showed that several of these symptoms were clearly more frequent in patients with (occult) constipation than in other patients (table 3). Combining the 3 most strongly related symptoms in a model indicated the patients with low and high risk of having (occult) constipation (table 4); patients with two or three of these symptoms should have laxative therapy to confirm (or deny) a definite diagnosis of (occult) constipation as the cause of abdominal pain. Separate analysis on functional and occult constipation did not show significant differences. Patients diagnosed with constipation but lacking Rome symptoms for functional constipation, are considered to have occult constipation. This is the first exploratory study on risk factors for (occult) constipation. These results may serve as input for further research.

The strength of this study is the systematic way in which all children referred to secondary care with RAP - after having excluded gastrointestinal infections and food allergy or intolerance - were treated with laxatives and, if successful, were diagnosed with (occult) constipation according to preset criteria.

The limitations lie in the placebo effect and spontaneous recovery that is known to play a role in a certain percentage of patients with RAP. In a meta-analysis, Krogsbøll et al found average relative contributions of spontaneous improvement and of placebo to the effect of active treatment of $24 \%$ and $20 \%$, respectively ${ }^{(10)}$. Spiller reported that placebo effects last for approximately 12 weeks before they start to recede and are supposed to disappear in about 6 months ${ }^{(11)}$. We diminished the placebo effect as much as possible by requiring a follow-up period of at least 6 months.

\section{Conclusion}

Disappearance of RAP with laxative therapy for at least 6 months was found in about half of the patients. They were considered to have (occult) constipation as cause of the pain. Many of these did not fulfil the criteria for functional constipation: they were considered to have 'occult constipation'.

We propose a first model to identify patients at presentation to be at high risk of having (occult) constipation, who might benefit from laxative treatment. 


\section{REFERENCE LIST}

1. Apley J, Naish N. Recurrent abdominal pains: a field survey of 1,000 school children. Arch Dis Child. 1958;33:165-170.

2. Gieteling MJ, Bierma-Zeinstra SM, Passchier J, Berger MY. Prognosis of chronic or recurrent abdominal pain in children. J Pediatr Gastroenterol Nutr. 2008;47:316-326.

3. Rasquin-Weber A, Hyman PE, Cucchiara S, Fleisher DR, Hyams JS, Milla PJ et al. Childhood functional gastrointestinal disorders. Gut. 1999;45 Suppl 2:I160-I168.

4. Keuzenkamp-Jansen CW, Fijnvandraat CJ, Kneepkens CM, Douwes AC. Diagnostic dilemmas and results of treatment for chronic constipation. Arch Dis Child. 1996;75:36-41.

5. Eidlitz-Markus T, Mimouni M, Zeharia A, Nussinovitch M, Amir J. Occult constipation: a common cause of recurrent abdominal pain in childhood. Isr Med Assoc J. 2004;6:677-680.

6. Wilschanski M, Branski D. Recurrent abdominal pain in children: is constipation an issue? Isr Med Assoc J. 2004;6:697-698.

7. Boccia G, Buonavolonta R, Coccorullo P, Manguso F, Fuiano L, Staiano A. Dyspeptic symptoms in children: the result of a constipation-induced cologastric brake? Clin Gastroenterol Hepatol. 2008;6:556-560.

8. Gijsbers CFM, Benninga MA, Büller HA. Clinical and laboratory findings in 220 children with recurrent abdominal pain. Acta Paediatr. 2011;100:1028-1032.

9. Gijsbers CFM, Kneepkens CMF, Schweizer JJ, Benninga MA, Büller HA. Recurrent abdominal pain in 200 children: somatic causes and diagnostic criteria. Acta Paediatr. 2011;100:e208-e214.

10. Krogsbøll LT, Hróbjartsson A, Gøtzsche PC. Spontaneous improvement in randomised clinical trials: meta-analysis of three-armed trials comparing no treatment, placebo and active intervention. BMC Med Res Methodol. 2009;9:1-10.

11. Spiller RC. Problems and challenges in the design of irritable bowel syndrome clinical trials: experience from published trials. Am J Med. 1999;107:91S-97S. 
Occult constipation: faecal retention as a cause of recurrent abdominal pain in children 


\section{Summary and discussion}




\section{INTRODUCTION}

Since the publication of John Apley in 1958, it is assumed that recurrent abdominal pain (RAP) in children mostly is of functional origin. Since then, several new possible causes of abdominal pain have been recognized, such as atypical presentation of celiac disease, gastro-esophageal reflux, infections with Helicobacter pylori or Dientamoeba fragilis, and the eosinophilic gastrointestinal diseases. Remarkably, these new potential causes of abdominal pain were reported in the literature without consequence for the diagnostic approach of RAP, according to many review-papers.

Functional abdominal pain has been defined as pain for which no organic cause can be found. However, nobody knows which organic diseases have to be looked for. Moreover, there can not be any doubt that in the next 50 years new diseases will be found to cause abdominal pain, as has happened in the last 50 year. This definition of functional abdominal pain, therefore, describes a rest group in stead of defining an entity. Functional abdominal pain is also thought of as pain due to disordered function, as opposed to an anatomic or inflammatory disorder. In the light of the findings in basic medical science with respect to functional gastrointestinal disorders, it has to be questioned how these 'functional' disorders are related to microscopic or molecular (organic) findings as is formulated by Douglas Drossman in an editorial in Gastroenterology in 2003, entitled 'The Organification of Functional Gastrointestinal Disorders'.

Functional abdominal pain has been related to stress, varying kinds of stress like sexual abuse, bullying and learning problems being reported. Although many doctors feel that a causal relation of stress and abdominal pain is plausible in many of their patients, a direct causal relation of RAP and emotional problems has not clearly been shown, as is formulated in a report of a committee of NASPGHAN in 2005. Moreover, stress is part of normal life, for which people are provided with an adrenergic system and coping mechanisms. All people, including children, experience stress, some more than others, varying from sexual abuse to the usual fight for pecking order at school. Therefore, the mere finding of stress in a patient should not lead to the assumption that stress is the cause of the pain. Some consider functional abdominal pain as a way for patients to make clear to their bystanders that they have a psychological problem. Solving the abdominal pain will lead to another somatic symptom to express their needs. However, this is a kind of psychopathology, which cannot be considered responsible for the abdominal pain in all children.

\section{CHAPTER 3 AND 4}

A study on the causes of RAP in children was performed to answer the question which causes of abdominal pain can be found with nowadays' knowledge as to differential diagnosis and diagnostic techniques. Chapter 3 and 4 together describe this study. In chapter 3, a description of the population and the diagnostic findings are presented. In a two year period all consecutive patients (age 4-16 years) with RAP, fulfilling the Apley criteria (at least 3 bouts of pain, severe enough to affect the daily activities, over a period of not less than 3 months), who were referred by general practitioners to a non-academic hospital, were included and subsequently evaluated. A total of 220 consecutive patients were included ( $92 \mathrm{M}, 128 \mathrm{~F}$, mean age 8.8 years [4-16 years]) and evaluated by a standardized history, physical examination and ancillary diagnostic work-up. Mean age at onset of the pain was 6 years (range "from birth" - 15 years). The mean duration of abdominal pain was 2.6 years (range 3 months - 15 years); $20 \%$ of the patients had pain for at least 5 years. One hundred eighteen children (54\%) were awakened at night at least 
once by abdominal pain; in $12 \%$ of the patients awakening at night with pain was part of the usual pattern. Thirty three children (15\%) missed school at least one (part of a) day each week. The diagnostic work-up resulted in the establishment of preliminary diagnoses, for instance Helicobacter pylori $(\mathrm{Hp})$ gastritis or celiac disease (which were both endoscopically confirmed), as well as diagnostic clues e.g. carbohydrate malabsorption. In $88 \%$ of the patients abnormalities were found that referred to possible causes of the pain, with a mean of 1,8 per patient (range $0-5$ ).

In chapter 4 the clinical significance of these findings was evaluated. For this purpose, criteria for the causal relation of the abnormal findings and the abdominal pain were formulated, based on positive results of therapeutic interventions that should persist for at least 6 months. The endpoint of the study was the patients being pain free, either spontaneously or by intervention. Interventions were performed in a fixed order. No clinical interpretation or weighing of history or physical findings was performed. Success of intervention was defined as a pain free period, as obtained by history from patient or parents, of at least 6 months. When abdominal pain recurred during this follow-up period, tests or interventions were repeated as indicated. Recurrence of the same disorder and again disappearance of pain upon the same intervention was considered a confirmation of the initial diagnosis.

No pain score was used as an instrument to measure the result of an intervention, because the aim of interventions was absence of pain.

The diagnoses of all patients were independently reviewed by two clinicians; in case of different conclusions discussion took place until agreement was achieved.

Twenty of 220 patients were lost to follow-up. In the remaining 200 patients this approach led to disappearance of the pain and a pain free follow-up period of at least 6 months (mean follow-up 18 months) in 198 patients (99\%), with 54 (27\%) becoming pain free spontaneously and $139(70 \%)$ in direct relation to an intervention (organic causes 34 , (occult) constipation 74, combination of organic cause and (occult) constipation 18, uncertain diagnosis 13 ), while in 5 (2.5\%) stress was diagnosed as the cause of the pain. In conclusion, with appropriate investigations in children with RAP, more somatic diagnoses can be found than is often appreciated: in 52 patients (26\%) an organic condition (with or without combination with (occult) constipation) most likely was causative. Ninety two patients (46\%) with (occult) constipation ( with or without combination with an organic cause) were pain free with laxative therapy.

Only 2 patients did not become pain free.

A limitation of the study is the difficulty to establish a causal relationship between an abnormal finding and the abdominal pain with certainty. Disappearance of pain by therapeutic intervention can be coincidental or a placebo effect. The placebo effect of an intervention is a well known cause of decrease of symptoms. Spiller described the experience from 25 randomized controlled studies; the median placebo response was $47 \%$, range $0-84 \%$. However, this effect starts to disappear after 3 months and is considered to be lost by 6 months. We chose a 6 month follow-up to restrict the possibility that a placebo effect or coincidental temporary recovery were falsely considered to be the result of therapeutic intervention. 
The diagnoses found in this cohort of patients can be classified as gastrointestinal infections, food intolerances, and other.

\section{Gastrointestinal infections}

Gastrointestinal infections were considered to be the cause of the pain in many patients. This concerned protozoa, Helicobacter pylori, and Yersinia enterocolitica. Knowledge of these infections is limited.

\section{Protozoa}

Protozoan infections are described in chapter 6.

\section{Helicobacter pylori $(\mathrm{Hp})$}

The advice in the recent guideline of ESPGHAN and NASPGHAN (2011) not to 'test and treat' for $\mathrm{Hp}$ in children with RAP seems to be based on insufficient studies to permit a definitive opinion: some case-control studies and one controlled trial with considerable methodological drawbacks did not point to a role of Hp in RAP; however, in some (uncontrolled) studies a 6 month to 2 year pain free follow-up has been found after therapy. Studies on the role of $\mathrm{Hp}$ in abdominal pain should take into account that only a small percentage of the patients with RAP is to be expected to have an infection with $\mathrm{Hp}$. Moreover, of the infected patients, only a certain percentage is expected to be pain free with eradication of $\mathrm{Hp}$; the rest is carrier of $\mathrm{Hp}$ without having symptoms. In our study, 22 of 200 patients had endoscopically confirmed Hp infection. Only 5 of 22 infected patients were pain free with eradication of $\mathrm{Hp}, 4$ other infected patients had a double diagnosis of $\mathrm{Hp}$ with constipation (3 patients) or parasites (1 patient). Studies that overlook this kind of nuances will not be able to recognize the true relations of $\mathrm{Hp}$ and RAP, if present at all. Our study is too small as well, with respect to $\mathrm{Hp}$.

Better studies are needed to discover the place of $\mathrm{Hp}$ in RAP including upper abdominal pain.

\section{Yersinia enterocolitica}

Yersinia enterocolitica characteristically has a tendency to chronicity with relapses, being persistent in lymph nodes and lymphoid tissue in the bowel wall, especially in older children. Abdominal pain is a major complaint in these cases, often more pronounced than diarrhoea. No systematic study on the presence of Yersinia enterocolitica in children with RAP has been performed. We performed serology (immunoblot) in all patients and treated patients who were positive, according to our protocol. Twenty two patients were considered positive for Yersinia, 13 were treated, 4 of whom became pain free and another 4 were considered to have Yersinia and a second causative diagnosis. However, Yersinia serology is rather complicated and information is lacking as to the usual rate of disappearance of the pain, which in our study took about 4-6 weeks after the antibiotic course. Moreover, it takes several months before the IgA antibodies disappear after eradication of the microorganism. Therefore, systematic studies should be performed to learn more about the relation between Yersinia enterocolitica and RAP.

\section{Food intolerances}

The food intolerances, that were investigated in our study concerned lactose intolerance, fructose intolerance, celiac disease and food allergy. 


\section{Lactose and fructose intolerance}

Lactose and fructose intolerance are described in chapter 7.

\section{Celiac disease}

Celiac disease can present with abdominal pain. However, according to the literature, celiac disease has not been found more often in children with abdominal pain than in healthy controls. In our study, we found one patient with endoscopically proven celiac disease. She did not become pain free with a gluten free diet, although both serology and duodenal biopsies normalized. The pain disappeared with laxatives. Celiac disease was considered a coincidental finding and the patient was diagnosed with occult constipation.

\section{Food allergy}

Food allergy can only be diagnosed with certainty by elimination and double blind provocation. Because gastrointestinal food allergies are often non-lgE-mediated, blood tests for specific lgE and skin prick tests do not help to find the possibly causative antigen and - after elimination of the suspected food - it can take several weeks for the symptoms to disappear and - upon provocation - many hours to several days to reappear.

The consequence is that suspicion of a food allergy must rise from history (association of symptoms with specific food or aversion of specific food) and can easily be overlooked. Moreover, the way to a diagnosis of food allergy is rather long and complicated; a double blind provocation is not as easy to perform as in IgE-mediated allergies.

In our study, we asked the patients for association of abdominal pain with ingestion of specific food, food aversions, food allergy in past history and in family history. In case of suspicion of food allergy, the suspected food was eliminated for five to six weeks, followed by open provocation. When open provocation was positive, double blind test was performed. Moreover, as in all diagnoses in this study, the patients should be pain free during the follow-up period of at least 6 months.

In our study, specific IgE for a panel of food allergens was performed in all patients. Of the patients with a positive test, no one had food allergy. We found 5 patients to be allergic to one or more foods. All were negative for specific lgE; they were suspected because of history. Two of these patients also had (occult) constipation; intervention for constipation only was insufficient effective, elimination of the offending food was insufficient as well; only intervention for both constipation and food allergy made them pain free.

Although the procedure to diagnose food allergy is difficult, for both the patient and the doctor, the result is very important for the patient. Patients with RAP should be questioned as to the possibility of food allergy. However, when an elimination - provocation procedure is considered, patients should be well informed about the procedure, including the possibility that the result of the procedure is negative.

Repeated attempts at reintroduction of the offending food can show if the allergy disappears over time.

\section{Other diagnoses \\ Appendicopathy}

Many case reports have been published with respect to chronic appendicitis and several other kinds of appendicopathy.

In our study, three patients became pain free with appendectomy. Two of these participants in our study came to the Emergency Room because of acute abdominal pain and had an appendectomy because of suspected acute appendicitis; immediately 
after appendectomy they were pain free and remained pain free during follow-up. Histology of both showed acute inflammation and faecal material in the appendix. A third patient was operated because of chronic abdominal pain in the right lower quadrant. He was operated in a 'quiet period' of his pain; however, the pathologist found some acute inflammation. He was also pain free, shortly after operation. We conclude that - after exclusion of other causes of pain in the right lower quadrant by means of proper evaluation including ileocolonoscopy - appendectomy can be indicated in patients with consistent pain in the right lower quadrant.

\section{Adverse effect of drugs}

It is of note that in one of two patients who had abdominal pain as adverse effect of drugs, amitriptyline was the offending drug, although this drug is a tricyclic antidepressant that is often used in patients with abdominal pain

\section{CHAPTER 5}

In the eighties, the Manning criteria for irritable bowel syndrome (IBS) in adults were developed in order to obtain a positive diagnosis of IBS without the need of diagnostic tests. With the expert-based Rome criteria, first published in the early nineties, a method was provided to diagnose various functional gastrointestinal disorders (FGIDs) including IBS in adults, followed by the Rome II and III revisions in 1999 and 2006; the latter two also included criteria for children. The Rome criteria were meant to structure the area of functional symptoms by classification, leading to more homogeneous patient groups. The resulting Rome diagnoses, based on clusters of symptoms and exclusion of organic disease, were meant to be the basis of research on pathophysiological mechanisms as well as clinical research, in addition to their use for patient care. In practice, Rome diagnoses are advised to be based on symptom clusters and absence of alarm symptoms. The Rome Working Teams pointed out that validation of the diagnostic criteria was needed, because they were arrived at by consensus rather than by data analysis or evidence.

With the data obtained in our study, resulting in clinical diagnoses of patients with RAP, validation of the Rome criteria for the pain syndromes has been realised.

Alarm symptoms which should raise suspicion of organic disease, were used in relation with abdominal pain since about 20 years; however, their validity has never been evaluated. Validation was realised in this study together with the process of validation of the Rome criteria.

Both these validation processes are described in chapter 5 .

For the purpose of validation of Rome criteria, a clinician independently categorized the symptom clusters of the patients according to the Rome III criteria as 'irritable bowel syndrome (IBS),', functional abdominal pain (FAP),' 'functional abdominal pain syndrome (FAPS),' 'functional dyspepsia (FD)' or 'no Rome pain syndrome'.

Nocturnal pain, localization in the right upper or right lower quadrant, rectal blood loss, fever (by history), weight loss (by history), family history of inflammatory bowel disease or celiac disease or (first degree family) peptic ulcer, hemoglobin concentration $<7,0 \mathrm{mmol} / \mathrm{l}$ and $\mathrm{ESR}>20 \mathrm{~mm}$ were considered alarm symptoms. One or more of these were present in 115 of the 200 patients (58\%).

Alarm symptoms appeared to be present in $56 \%$ of patients with an organic cause, and in $65 \%$ of patients with a functional cause (constipation, occult constipation or 'stress') of RAP and therefore do not differentiate between organic and functional disease. 
The lack of specificity of alarm symptoms can be explained by the character of the symptoms and the organic diseases that were diagnosed: the alarm symptoms are especially addressed to inflammatory bowel disease. However, this is a very rare diagnosis in patients with abdominal pain at presentation. Organic diseases diagnosed in this study are infections, especially with protozoa, food allergy and some other diagnoses, all of which are not typically accompanied by these alarm symptoms. Moreover, nocturnal pain and location of the pain in right upper or right lower quadrant appear to be often present in patients with functional disease.

Sensitivity, specificity and positive and negative predictive values of the Rome criteria (Rome diagnoses defined as Rome symptom clusters without alarm symptoms) as to their capacity to differentiate between organic and functional clinical diagnoses, were low (roughly between $30 \%$ and $70 \%$ ). Therefore, the Rome criteria must be considered to be not specific enough to rule out an organic cause of abdominal pain at presentation. The clinical diagnoses do not have specific presentations, resulting in presentation with seemingly random Rome symptom clusters.

We conclude that the presence of one or more alarm symptoms does not differentiate between organic and functional disease. Moreover, this study provides no evidence that differentiation between the functional pain syndromes makes any difference with respect to therapy or outcome. For clinical use, the added value of the Rome classification is limited.

Parasitic infections, carbohydrate intolerance and constipation were described as capita selecta in this study, in chapter 6, 7 and 8.

\section{CHAPTER 6}

Chapter 6 describes the role of protozoa in chronic abdominal pain. Aim of this part of the study was to investigate if protozoa can be identified as cause of RAP, and if protozoan infections can be recognized by a specific clinical presentation.

All patients were evaluated for protozoa (Giardia lamblia [Gl], Dientamoeba fragilis [Df], Blastocystis hominis [Bh]) by means of a triple faeces test (TFT) and treated if positive. Re-examination of faeces followed at least 10 days after the end of treatment.

Disappearance of pain with eradication and a pain free follow-up of at least 6 months was considered indicative of a causal relation with RAP. The predictive value of the characteristics of the pain in protozoan infections was calculated.

Stool samples were received from 215 patients; 73 (34\%) carried parasites, 10 of whom had 2 parasites, 2 had 3 parasites. Eight patients had spontaneous resolution of pain, 65 were treated. Twenty five (11\%) were pain free after eradication ( 21 had Df, 8 had Bh, 4 had Gl), of whom 11 had a second diagnosis for the pain, either another infection (2) or constipation (9). Five had recurrence of infection with Df and were again pain free with eradication. Patients with a protozoan infection as the cause of their pain did not show remarkable differences with respect to their clinical presentation when compared to patients with an asymptomatic protozoan infection and patients without protozoa. In conclusion, we found protozoa to be present in about one third of our patients with RAP and to play a role as cause of the pain in one third of the infected patients, altogether in about $10 \%$ of the total patient group. Because of lack of specific symptoms, the patients with a protozoan infection cannot be recognised at presentation.

We found a remarkably high percentage of all patients who were presented to secondary care with chronic abdominal pain to be infected with a protozoon. However, we do not 
know the prevalence of these protozoa in the general population in our country or region. A double-blinded placebo-controlled trial should be performed to confirm these data; in the statistics of such a trial the percentage of asymptomatic carriers should be taken into account.

\section{CHAPTER 7}

Chapter 7 describes the role of incomplete absorption of carbohydrates in chronic abdominal pain. Aim of this part of the study was to investigate whether malabsorption of lactose and fructose can be considered a valid cause of RAP. Hydrogen breath tests $\left(\mathrm{H}_{2} \mathrm{BT}\right.$; abnormal if $\left.\Delta \mathrm{H}_{2}>30 \mathrm{ppm}\right)$ were performed with lactose and fructose.

Disappearance of RAP with elimination, recurrence with provocation and disappearance with re-elimination, followed by a 6 month pain-free follow-up, was considered indicative of a causal relation with RAP. For definite proof, a double-blinded placebo-controlled (DBPC) provocation was performed. Malabsorption of lactose was found in 57 / 210 (27\%), of fructose in $79 / 121$ (65\%) patients. Elimination and open provocation with lactose and fructose were positive in 7 and 13 patients respectively. DBPC provocation - in 6/7 and $8 / 13$ patients - was negative in all. However, several children continued to report abdominal symptoms upon intake of milk or fructose.

We concluded, that neither lactose intolerance nor fructose intolerance could be established as causes of RAP, according to our preset criteria. However, in clinical practice persistent feeling of intolerance in some patients should be taken seriously and could warrant extended elimination with repeated challenges.

A gold standard for the diagnosis lactose (fructose) intolerance does not exist, neither for lactose (fructose) malabsorption. There is no fixed relationship between carbohydrate malabsorption and intolerance. Vonk et al. suggested that the degree of lactose digestion in adults with genetically determined low lactase activity is determined by residual lactase activity and by the time available for hydrolysis (orocoecal transit time). Other host-specific factors, still incompletely understood, were supposed to be responsible for intolerance as well. Moreover, adaptation.of intestinal microbiota by regular ingestion of lactose, resulting in an increase of bacterial $\beta$-galactosidase activity, is recognised as a cause of reduction of symptoms of lactose intolerance.

For the diagnosis lactose (fructose) intolerance, the method used in this study, relying on consistency of symptoms, is probably not the most accurate way. These uncertainties warrant further studies, designed to establish the role of factors that could influence the consequences of a carbohydrate load in patients with carbohydrate malabsorption and to find an explanation for the possible inconsistency of symptoms as suggested in this study. Especially faecal retention is suggested as a potential factor that could play a role, which could challenge the validity of a DBPC provocation in the diagnosis of carbohydrate intolerance.

For clinical practice, we conclude, that breath tests can be useful to find the patients who could have good result from elimination of lactose or fructose. A trial with a lactose or free fructose restricted diet could be performed during 2 weeks, if properly supported by a dietician. In case of a good result, further diagnostics should be done as appropriate. 


\section{CHAPTER 8}

Chapter 8 describes the role of (occult) constipation in chronic abdominal pain. In this study, a causal relation of abdominal pain and (occult) constipation is defined as abdominal pain that disappears with laxative treatment. The pain does not reappear within a 6 month follow-up period. Treatment may need to be continued throughout follow-up period. Pain may return upon reduction or discontinuation of treatment, but disappears again with laxative treatment. The term 'constipation' is used for those children who fulfilled the Rome II criteria for functional constipation. 'Occult constipation' concerns those children who did not fulfil the Rome II criteria for functional constipation, but who showed relieve of symptoms with laxative treatment.

Rome II criteria were used in this chapter, because Rome III criteria were not yet published at the time of inclusion of patients, and because Rome III criteria for functional constipation contained several items that were not included in the standardized history of this study.

In every patient with persistent abdominal pain following a diagnostic work-up and interventions for potential causes of the pain as described in chapter 4, a trial with laxatives was performed, in combination with dietary advice and toilet training, irrespective of history, physical examination and the outcome of plain abdominal X-ray. Oral macrogol 4000 (polyethylene glycol 4000) was prescribed in a daily dose of $1 \mathrm{~g} / \mathrm{kg}$ (maximum $40 \mathrm{~g}$ ), with the advise to the parents to adjust the dose according to the resulting defaecation pattern. They could give a double dose for some days as a "mini lavage" if they preferred fast result. Some patients used other laxatives, especially lactulose or lactitol, as to their preference, with the same instructions. Frequent telephone contacts were used to support the parents with respect to the laxative dosage. In case of therapy-resistant constipation, lavage of the colon was performed with polyethylene glycol-electrolyte solution.

This therapy was advised to 111 patients and was successful in 92 patients (83\%), being about half of all patients; 18 of these already had persistent considerable relief of pain with treatment for a somatic cause, but experienced complete relief only after laxative measures; they were considered to have two diagnoses.

Using multivariate analysis, a simple model could be developed with cystitis in past history, early satiety and flatulence as predictors for constipation. The risk of constipation ranged from $31 \%$ (18/58) if no predictor was present to $100 \%$ (4/4) if all three were present. We concluded that disappearance of RAP with laxative therapy for at least 6 months was found in a considerable percentage of patients. They were considered to have constipation as the cause of the pain. Many of these did not fulfil the criteria for functional constipation: they were considered to have 'occult constipation'. We propose a first simple model to identify patients at high risk of having constipation, who might benefit from laxative treatment.

Patients with (occult) constipation were considered to have a functional diagnosis; therefore they were assigned one of the functional gastrointestinal pain syndromes according to the Rome criteria. Notably, patients recovered with laxative therapy irrespective of their Rome diagnosis: IBS, FAP(S) or FD.

\section{NEW PERSPECTIVES FOR THE PATIENT AND THE DOCTOR}

From this study, we learned that most patients with abdominal pain can recover and be pain free with better diagnostic efforts or with - sometimes aggressive - laxative therapy. The result of this approach is better than the results in the studies that have been published until now, with better perspective for the patients as a consequence. 
The consequence for the doctor is that more effort is needed.

More research is needed with respect to the processes underlying these results on the level of basic science, in the first place with respect to (occult) constipation. We do not yet understand why some patients with (occult) constipation have abdominal pain, while others have proximal gastrointestinal symptoms or have no symptoms at all, other than difficulties with defaecation. Undoubtedly, hypersensitivity plays a role, but not all patients present with the symptom cluster of IBS.

In clinical practice, as shown in this thesis, the Rome criteria do not provide any help in the approach of patients with chronic abdominal pain in children: we found no benefit in the differentiation of abdominal pain into IBS, FD and FAP(S). Patients with the same functional or organic clinical diagnosis present with the symptom cluster of different Rome pain syndromes. Laxative therapy is roughly equally successful in all four Rome pain diagnoses. Therefore, Rome diagnoses are not useful in clinical practice in children. However, the Rome classification can be useful for research on pathophysiology, and to answer questions about differences in presentation of children with same clinical diagnoses.

It is noteworthy that alarm symptoms did not distinguish organic from functional disorders. Organic diagnoses often present without alarm symptoms. Therefore, absence of alarm symptoms does not exclude organic disease. This leaves intact that specific alarm symptoms are important for detection of inflammatory bowel disease, celiac disease and other organic diseases.

The consequence of these data is that proper investigation is indicated in each patient with chronic abdominal pain.

Each patient with chronic abdominal pain should have a thorough history (with questions appropriate for food allergy) and physical examination. In case of suspicion of an organic disease or concern of parents, proper ancillary investigations have to be performed, directed to the suspected disease. When there is no reason for ancillary investigations, a trial with a macrogol (polyethylene glycol) based laxative should be performed.

It is important that the dosage of the laxative therapy is high enough (dose adjusted according to the resulting defaecation pattern), and that the therapy is maintained for at least 4 weeks.

When insufficient result is achieved with laxative therapy, ancillary investigations are indicated, at least aimed at gastrointestinal infections (especially protozoa), inflammatory bowel disease, celiac disease, and other diseases, according to the differential diagnosis as appropriate; psychological investigations are indicated in case of suspected psychological pathology.

Importantly, a definitive diagnosis, organic or psychological, should only be made when intervention results in disappearance of the pain and a pain free follow-up (or confirmation of the diagnosis during follow-up by same result with same intervention).

Most important is that nearly all patients can become pain free when doctors are prepared to find a solution for each individual patient. The doctor should see the patient on a regular base until the problem is solved or, alternatively, refer the patient to an expert on abdominal pain. 
Samenvatting en discussie 


\section{INLEIDING}

Sinds de publicatie van John Apley in 1958 wordt aangenomen, dat chronische buikpijn bij kinderen meestal functioneel is. Sindsdien zijn er echter diverse nieuwe mogelijke oorzaken van chronische buikpijn gevonden, zoals de atypische presentatie van coeliakie, gastro-oesophageale reflux, infecties met Helicobacter pylori of Dientamoeba fragilis en de eosinofiele gastrointestinale aandoeningen. Opmerkelijk is, dat deze nieuwe potentiële oorzaken van chronische buikpijn in de literatuur worden beschreven zonder dat dit gevolgen heeft voor de diagnostische benadering van chronische buikpijn zoals die geadviseerd wordt in overzichts-artikelen.

Functionele buikpijn wordt gedefinieerd als pijn waarvoor geen lichamelijke oorzaak gevonden kan worden. Niemand weet echter, naar welke lichamelijke oorzaken gezocht moet worden. Bovendien zullen er in de komende 50 jaar -net als in de afgelopen 50 jaar ongetwijfeld weer nieuwe ziektes gevonden worden, die chronische buikpijn kunnen veroorzaken. Deze definitie van functionele buikpijn beschrijft dus een restgroep in plaats van een entiteit.

Functionele buikpijn wordt ook wel gezien als pijn die het gevolg is van een gestoorde functie, in tegenstelling tot een anatomische afwijking of een ontstekingsproces.

Het is echter de vraag hoe de functionele gastrointestinale aandoeningen zich verhouden tot de microscopische en moleculaire bevindingen bij basale research, zoals geformuleerd werd door Douglas Drossman in een editorial in Gastroenterology in 2003, getiteld "The organification of functional gastrointestinal disorders". Functionele buikpijn wordt in verband gebracht met stress van diverse aard, variërend van sexueel misbruik tot pesten en leerproblemen. Hoewel veel dokters de indruk hebben, dat een oorzakelijk verband tussen stress en buikpijn aannemelijk is bij veel patiënten, is een direct oorzakelijk verband nooit duidelijk aangetoond, zoals is beschreven in een evidence based rapport van een commissie van de NASPGHAN (North American Society for Gastroenterology Hepatology and Nutrition) in 2005. Bovendien hoort stress bij het leven; mensen zijn daarvoor toegerust met adrenerge systemen en coping mechanismen. Alle mensen, inclusief kinderen, kennen stress, sommigen meer dan anderen, variërend van sexueel misbruik tot het gebruikelijke gevecht om de pikorde. Het herkennen van stress bij een individuele patiënt is daarom onvoldoende reden om er van uit te gaan, dat dit de oorzaak van de buikpijn is.

Sommigen beschouwen functionele buikpijn als een middel voor patiënten om aan hun omgeving kenbaar te maken, dat ze een psychisch probleem hebben. Het doen verdwijnen van de buikpijn leidt dan tot symptoomverschuiving. In een dergelijke situatie is er echter sprake van een vorm van psychopathologie, die niet verondersteld kan worden aanwezig te zijn bij alle kinderen met chronische buikpijn.

\section{HOOFDSTUK 3 EN 4}

Een onderzoek naar de oorzaken van chronische buikpijn werd opgezet om de vraag te beantwoorden welke oorzaken van chronische buikpijn gevonden kunnen worden bij kinderen met chronische buikpijn, als gezocht wordt op basis van de hedendaagse kennis met betrekking tot de verschillende mogelijke oorzaken en met hedendaagse onderzoekstechnieken. Hoofdstuk 3 en 4 samen beschrijven dat onderzoek.

In hoofdstuk 3 wordt de patiëntengroep beschreven, inclusief alle diagnostische bevindingen. In een periode van 2 jaar werden alle achtereenvolgende patiënten 
(leeftijd 4-16 jaar) met chronische buikpijn, die voldeden aan de criteria voor chronische buikpijn van Apley (tenminste 3 aanvallen van buikpijn, ernstig genoeg om de dagelijkse bezigheden te beïnvloeden, gedurende een periode van tenminste 3 maanden) en verwezen waren door de huisarts naar een 2e lijns ziekenhuis, in het onderzoek geïncludeerd en onderzocht. In totaal werden 220 kinderen in het onderzoek ingesloten (92 jongens en 128 meisjes, gemiddelde leeftijd 8,8 [spreiding 4-16] jaar). Ze werden onderzocht door middel van een gestandaardiseerde anamnese, lichamelijk onderzoek en een aanvullend onderzoeksprotocol.

De gemiddelde leeftijd bij het begin van de buikpijn was 6 jaar (spreiding "sinds de geboorte" tot 15 jaar). De gemiddelde duur van de buikpijn was 2,6 jaar (spreiding 3 maanden tot 15 jaar); $20 \%$ had pijn gedurende 5 jaar of langer. Honderdachttien kinderen (54\%) waren tenminste een maal's nachts wakker geworden van de buikpijn; bij $12 \%$ van de kinderen was het een onderdeel van het pijnpatroon, dat ze's nachts wakker werden van de buikpijn. Drieëndertig kinderen (15\%) verzuimden tenminste een dag(deel) per week van school.

Het diagnostisch onderzoeksprotocol resulteerde in 'voorlopige diagnoses', zoals Helicobacter pylori $(\mathrm{Hp})$ gastritis of coeliakie (beide endoscopisch bevestigd), en tot aanknopingspunten voor verder onderzoek zoals koolhydraatmalabsorptie. Bij $88 \%$ van de patiënten werden op deze wijze afwijkingen gevonden die verwezen naar mogelijke oorzaken van de pijn, met een gemiddelde van 1,8 per patiënt (spreiding $0-5$ ).

In hoofdstuk 4 wordt de klinische betekenis van deze bevindingen beschreven. Criteria werden geformuleerd voor een causaal verband tussen de afwijkende bevindingen en de buikpijn; deze waren gebaseerd op de resultaten van therapeutische interventies die tenminste 6 maanden moesten stand houden. De uitkomstmaat voor de studie was verdwijnen van de pijn, hetzij spontaan hetzij door een specifieke interventie. Interventies werden uitgevoerd in een vaste volgorde, zonder klinische interpretatie of weging van gegevens uit anamnese of lichamelijk onderzoek.

Succes van een interventie werd gedefinieerd als een pijnvrije periode (te beginnen op een adequaat moment na interventie) van tenminste 6 maanden, op basis van de beschrijving door patiënt of ouders. Als de buikpijn gedurende deze follow-up periode terug kwam, werden testen of interventies herhaald voor zover van toepassing. Recidiveren van dezelfde aandoening en verdwijnen van de pijn met dezelfde interventie werd beschouwd als een bevestiging van de oorspronkelijke diagnose.

Een pijnscore werd niet gebruikt als instrument om het resultaat van een interventie te bepalen, omdat het doel van de interventie was, dat de patiënt pijnvrij was.

De diagnoses van alle patiënten werden onafhankelijk herbeoordeeld door 2 kinder-MDL artsen; in geval van verschillende conclusies werd gediscussieerd tot overeenstemming was bereikt.

Twintig van de 220 patiënten vielen af. Bij de overige 200 patiënten leidde deze benadering tot verdwijnen van de pijn en een pijnvrije follow-up van tenminste 6 maanden (gemiddelde follow-up 18 maanden) bij 198 patiënten (99\%), van wie 54 (27\%) spontaan herstelden en $139(70 \%)$ in directe relatie met een therapeutische interventie [somatische oorzaken bij 34 patiënten, (occulte) obstipatie bij 74, een combinatie van somatisch en obstipatie bij 18, onduidelijke diagnose bij 13], terwijl bij $5(2,5 \%)$ stress werd gevonden als oorzaak van de pijn. 
Wij concluderen, dat bij adequate diagnostiek bij kinderen met chronische buikpijn meer somatische oorzaken worden gevonden dan vaak wordt aangenomen: bij 52 patiënten (26\%) was er zeer waarschijnlijk sprake van een somatische oorzaak - al of niet in combinatie met (occulte) obstipatie. Tweeënnegentig patiënten (46\%) met (occulte) obstipatie - al of niet in combinatie met een somatische oorzaak - werden pijnvrij met laxerende maatregelen. Slechts 2 patiënten werden niet buikpijnvrij.

Een beperking van dit onderzoek is, dat het moeilijk is om met zekerheid een oorzakelijk verband vast te stellen tussen een abnormale bevinding en de buikpijn. Het is mogelijk, dat de buikpijn bij een therapeutische interventie toevallig verdwijnt; er kan ook sprake zijn van een placebo-effect. Het placebo effect is een bekende oorzaak van afname van symptomen bij een interventie. Spiller beschreef de ervaring van 25 gerandomiseerde studies met controlegroep; de mediane placebo-respons was $47 \%$ (spreiding $0-84 \%$ ). Dit effect begon echter af te nemen na 3 maanden en kon na 6 maanden als 'verdwenen' worden beschouwd. Wij kozen in dit onderzoek een follow-up van tenminste 6 maanden om de mogelijkheid te beperken, dat een placebo-effect of een toevallige tijdelijke verbetering ten onrechte gezien zou worden als het resultaat van een therapeutische interventie.

De diagnoses die in dit patiëntencohort gevonden werden, kunnen worden ingedeeld in gastrointestinale infecties, voedselintoleranties en overige diagnoses.

\section{Gastrointestinale infecties}

Gastrointestinale infecties werden bij veel patiënten als de oorzaak van de pijn beschouwd. Dit betrof protozoa, Helicobacter pylori en Yersinia enterocolitica. Kennis over deze infecties in dit verband is beperkt.

Protozoa

Infecties met protozoa worden verder beschreven in de samenvatting van hoofdstuk 6 .

\section{Helicobacter pylori ( $\mathrm{Hp})$}

Het advies in de recente richtlijn (2011) van de ESPGHAN en NASPGHAN (European/North American Society for Pediatric Gastroenterology, Hepatology and Nutrition) om niet te werken volgens het principe "test and treat" bij kinderen met chronische buikpijn is gebaseerd op onvoldoende studies om tot een definitieve conclusie te komen: enkele case-control-studies en een studie met controlegroep met aanzienlijke methodologische onvolkomenheden wezen niet op een rol van $\mathrm{Hp}$ bij chronische buikpijn. In enkele studies (zonder controlegroep) werd echter een pijnvrije follow-up van 6 maanden tot 2 jaar na therapie gevonden. Bij onderzoek naar de rol van $\mathrm{Hp}$ bij chronische buikpijn moet er rekening mee gehouden worden, dat slechts een klein percentage van de patiënten met buikpijn een infectie met $\mathrm{Hp}$ heeft en dat bij slechts een deel daarvan de $\mathrm{Hp}$ de oorzaak van de buikpijn is; de overigen zijn symptoomloze dragers van de bacterie. In ons onderzoek hadden 22 van de 200 patiënten een endoscopisch bevestigde $\mathrm{Hp}$ infectie. Slechts 5 van de 22 geïnfecteerde patiënten werden pijnvrij na eradicatie van de bacterie; 4 anderen hadden een dubbele diagnose: $\mathrm{Hp}$ en obstipatie ( 3 patiënten) of $\mathrm{Hp}$ en parasieten (1 patiënt). Als bij onderzoek naar de rol van Hp bij buikpijn deze nuances over het hoofd worden gezien, zal de werkelijke rol van $\mathrm{Hp}$ bij chronische buikpijn, indien überhaupt aanwezig, niet worden herkend. In dit onderzoek zijn de aantallen patiënten met een $\mathrm{Hp}$ infectie te klein om een uitspraak te kunnen doen over een werkelijk causaal 
verband. Betere studies dan de nu beschikbare, zijn nodig om de rol van Hp vast te stellen bij chronische buikpijn - ook bij bovenbuikspijn - bij kinderen.

\section{Yersinia enterocolitica}

Een kenmerk van Yersinia enterocolitica is de neiging om - met name bij oudere kinderen - zich te nestelen in lymfklieren en lymfe weefsel in de darm en zich van daaruit te ontwikkelen tot een chronische infectie met opvlammingen. Buikpijn is een klacht die daarbij op de voorgrond staat, vaak meer uitgesproken dan diarree. Systematisch onderzoek naar de rol van Yersinia enterocolitica bij kinderen met buikpijn is nooit gedaan. Wij deden serologisch onderzoek (een immunoblot) bij alle patiënten en behandelden de patiënten die positief waren, volgens protocol. Tweeëntwintig patiënten werden als positief beschouwd voor Yersinia; 13 werden behandeld, waarvan er 4 buikpijnvrij werden en 4 werden geacht naast Yersinia nog een tweede diagnose te hebben.

De Yersinia-serologie is echter vrij gecompliceerd en bovendien ontbreekt informatie over de snelheid waarmee symptomen verdwijnen na therapie, wat in ons onderzoek ongeveer 4-6 weken duurde na een kuur antibiotica. Bovendien duurt het enkele maanden voordat de IgA antistoffen verdwijnen na eradicatie van het micro-organisme. Meer, systematisch onderzoek zou gedaan moet worden naar de relatie tussen Yersinia enterocolitica en chronische buikpijn.

\section{Voedselintoleranties}

De voedselintoleranties die in deze studie werden onderzocht zijn lactose intolerantie, fructose intolerantie, coeliakie en voedselallergie.

\section{Lactose en fructose intolerantie}

Lactose en fructose intolerantie worden verder beschreven in de samenvatting van hoofdstuk 7.

\section{Coeliakie}

Coeliakie kan zich presenteren met chronische buikpijn. Volgens de literatuur wordt coeliakie echter niet vaker gevonden bij kinderen met chronische buikpijn dan in gezonde controlegroepen.

In ons onderzoek vonden we endoscopisch bewezen coeliakie in één patiënt. Hoewel met een glutenvrij dieet de serologie en de histologie van het duodenum normaliseerden, verminderde haar buikpijn niet. Met laxerende maatregelen verdween de buikpijn. De diagnose occulte obstipatie werd gesteld; de coeliakie werd beschouwd als een toevalsbevinding.

\section{Voedselallergie}

De diagnose voedselallergie kan alleen met zekerheid gesteld worden door eliminatie en dubbelblinde provocatie. Omdat gastrointestinale voedselallergieën vaak niet lgEgemedieerd zijn, dragen bloedtesten voor specifiek IgE en huidpriktesten niet erg bij aan het opsporen van antigenen die mogelijk een rol spelen bij de buikpijn, en kan het - na eliminatie van verdachte voedingsmiddelen - enkele weken duren voordat de symptomen verdwijnen en - na provocatie - vele uren tot enkele dagen voordat de symptomen weer terugkomen. De consequentie is, dat verdenking van voedselallergie moet worden ontleend aan de anamnese (associatie van symptomen met specifieke voedingsmiddelen of aversie van specifieke voedingsmiddelen). Voedselallergie kan daarom makkelijk over het hoofd gezien worden. Bovendien is de weg naar de diagnose 
voedselallergie lang en gecompliceerd: een dubbelblinde provocatie is niet zo eenvoudig uit te voeren als bij IgE-gemedieerde allergie.

In ons onderzoek hebben wij de patiënten gevraagd naar een associatie van buikpijn met ingestie van bepaalde voedingsmiddelen, naar specifieke voedselaversies en naar voedselallergie in de voorgeschiedenis en in de familieanamnese. In geval van een verdenking van voedselallergie werd het verdachte voedingsmiddel 5-6 weken geëlimineerd, gevolgd door open provocatie. Wanneer de open provocatie positief was, werd een dubbelblinde provocatie uitgevoerd. Zoals bij alle diagnoses in deze studie, moesten de patiënten bovendien tenminste 6 maanden pijnvrij zijn met eliminatie van het desbetreffende voedingsmiddel.

In ons onderzoek werden bij alle patiënten specifieke IgE-antistoffen tegen een panel van voedselallergenen bepaald. Van de patiënten met een positieve test had niemand voedselallergie. We vonden 5 patiënten, die allergisch waren voor één of meer voedingsmiddelen. Geen van hen had positieve lgE-antistoffen tegen voedingsmiddelen; ze werden verdacht op basis van de anamnese. Twee van deze patiënten hadden ook (occulte) obstipatie: alléén interventie voor obstipatie was onvoldoende effectief, eliminatie van het desbetreffende allergeen was eveneens onvoldoende; pas bij interventie voor zowel voedselallergie als obstipatie werden zij buikpijnvrij. Hoewel de procedure voor de diagnose voedselallergie lastig is, zowel voor de patiënt als voor de dokter, is het resultaat erg belangrijk voor de patiënt. Patiënten met chronische buikpijn moet gevraagd worden naar de mogelijkheid van voedselallergie. Wanneer een eliminatie-provocatie procedure wordt overwogen, moeten de patiënten echter wel goed worden geïnformeerd over de procedure, inclusief de mogelijkheid dat het resultaat van de procedure uiteindelijk negatief is.

Of de voedselallergie in de loop van de tijd verdwijnt, moet blijken uit pogingen tot reïntroductie, desgewenst.

\section{Overige diagnoses}

Appendicopathie

Er zijn veel case-reports gepubliceerd over chronische appendicitis en diverse andere vormen van appendicopathie.

In onze studie werden 3 patiënten pijnvrij na appendectomie. Twee van hen waren deelnemers aan het onderzoek, toen ze naar de Spoedeisende Hulp kwamen in verband met acute buikpijn; er werd toen een appendectomie gedaan op verdenking van een acute appendicitis. Direct na de appendectomie waren ze pijnvrij en ze bleven pijnvrij gedurende de follow-up. Histologie liet bij beiden een acute ontsteking zien met fecaal materiaal in de appendix. Een derde patiënt werd geopereerd vanwege chronische buikpijn in de rechter onderbuik. Hij werd geopereerd in een "rustige periode" van zijn chronische buikpijn; de patholoog vond desalniettemin enige acute ontsteking. Hij was eveneens pijnvrij, kort na de operatie.

Wij concluderen, dat - na adequaat onderzoek ter uitsluiting van andere oorzaken van pijn in de rechter onderbuik, inclusief ileocoloscopie - appendectomie geïndiceerd kan zijn bij patiënten met consistente pijn in de rechter onderbuik.

\section{Bijwerkingen van geneesmiddelen}

Twee patiënten hadden buikpijn als bijwerking van een geneesmiddel. Opmerkelijk is, dat dit bij één van hen amitriptyline betrof, een tricyclisch antidepressivum, dat vaak wordt voorgeschreven aan patiënten met chronische buikpijn. 


\section{HOOFDSTUK 5}

In de tachtiger jaren werden de Manning criteria ontwikkeld voor het prikkelbare darm syndroom (irritable bowel syndrome, IBS) bij volwassenen. Het doel hiervan was om tot een positieve diagnose te kunnen komen zonder de noodzaak om veel diagnostische testen te doen ter uitsluiting van lichamelijke oorzaken van buikpijn. De expert-based Rome criteria, die voor het eerst werden gepubliceerd in de negentiger jaren, voorzagen in een methode om diverse functionele aandoeningen van het maag-darmkanaal vast te stellen, inclusief IBS, bij volwassenen. In 1999 en 2006 volgden de 2e en 3e versie hiervan, de Rome II en Rome III criteria; bij deze versies werden ook criteria voor kinderen geformuleerd. De Rome criteria waren bedoeld om structuur aan te brengen in het gebied van functionele gastrointestinale aandoeningen door middel van classificatie, waardoor meer homogene patiëntengroepen zouden ontstaan. De Rome-diagnoses, die hier uit voortvloeiden, waren gebaseerd op specifieke clusters van symptomen en uitsluiting van lichamelijke oorzaken. Deze Rome diagnoses zouden kunnen dienen als basis voor onderzoek naar pathofysiologie en klinisch onderzoek en tevens voor gebruik in de patiëntenzorg. In de praktijk werd geadviseerd de Rome-diagnoses te baseren op de symptoom-clusters en afwezigheid van alarmsymptomen. De Rome Working Teams stelden, dat valideren van de Rome criteria nodig was, omdat ze gebaseerd waren op consensus, niet op wetenschappelijke bewijsvoering.

Met de gegevens uit ons onderzoek, waaruit klinische diagnoses voortkwamen voor patiënten met chronische buikpijn, was het mogelijk om de Rome criteria voor de functionele pijnsyndromen te valideren.

Alarmsymptomen die als aanwijzing gezien worden dat een lichamelijke oorzaak meer waarschijnlijk is, zijn sinds ongeveer 20 jaar in gebruik; hun betrouwbaarheid is echter nooit geëvalueerd. In dit onderzoek werden de alarm symptomen gevalideerd, tezamen met de validering van de Rome criteria.

Beide valideringsprocessen zijn beschreven in hoofdstuk 5 .

Voor het valideren van de Rome criteria werden door een kinderarts MDL onafhankelijk de symptomen van alle patiënten geclassificeerd als 'irritable bowel syndrome' (IBS), functionele dyspepsie (FD), 'functional abdominal pain syndrome' (FAPS) en 'functional abdominal pain' (FAP) of "geen Rome pijn syndroom".

Nachtelijke buikpijn, lokalisatie van de buikpijn in de rechter bovenbuik of rechter onderbuik, rectaal bloedverlies, koorts (anamnestisch), gewichtsverlies (anamnestisch), een positieve familie anamnese voor chronische darmontsteking of coeliakie of - in de eerste graads familie - maagzweren, een hemoglobine van $<7,0 \mathrm{mmol} / \mathrm{l}$ en een bezinking van $>20 \mathrm{~mm}$ werden beschouwd als alarmsymptomen (zoals beschreven bij de Rome III criteria). Eén of meer alarm symptomen waren aanwezig bij 115 van de 200 patiënten (58\%).

Alarmsymptomen bleken aanwezig te zijn bij $56 \%$ van de patiënten met een organische oorzaak van de buikpijn en bij $65 \%$ van de patiënten met een functionele oorzaak (obstipatie, occulte obstipatie of 'stress').

De geringe specificiteit van de alarmsymptomen kan verklaard worden met het karakter van de symptomen en de organische oorzaken die gevonden werden: de alarmsymptomen zijn vooral gericht op het opsporen van chronische darmontsteking. Dit is echter een zeldzame diagnose bij kinderen die zich presenteren met chronische buikpijn als hoofdklacht. De organische ziektes die bij dit onderzoek werden gevonden, 
waren infecties, met name protozoa, voedselallergie en enkele andere diagnoses, die alle niet typisch gepaard gaan met deze alarmsymptomen. Bovendien blijken nachtelijke buikpijn en lokalisatie van de buikpijn in de rechter bovenbuik of rechter onderbuik vaak aanwezig te zijn bij patiënten met functionele buikpijn. Sensitiviteit, specificiteit en positieve en negatieve voorspellende waarde van de Rome criteria (Rome diagnoses gedefinieerd als Rome-symptoom-clusters in afwezigheid van alarmsymptomen) wat betreft hun vermogen om te differentiëren tussen organische en functionele klinische diagnoses, waren laag (globaal 30-70\%). De Rome criteria moeten daarom als onvoldoende specifiek worden beschouwd om - bij presentatie - een organische oorzaak van buikpijn uit te sluiten. De klinische diagnoses hebben geen specifieke symptomatologie, wat resulteert in presentatie met willekeurige Rome-symptoom-clusters.

Wij concluderen, dat de aanwezigheid van een of meer alarmsymptomen niet differentieert tussen organische en functionele aandoeningen. Bovendien blijkt uit dit onderzoek niet, dat differentiëren tussen de functionele pijnsyndromen consequenties heeft voor therapie of uitkomst. Voor klinisch gebruik is de toegevoegde waarde van de Rome criteria daarom beperkt.

In hoofdstuk 6, 7 en 8 worden parasitaire infecties, koolhydraatintoleranties en obstipatie beschreven als capita selecta uit dit onderzoek.

\section{HOOFDSTUK 6}

Hoofdstuk 6 beschrijft de rol van protozoa bij chronische buikpijn.

Doel van dit deel van het onderzoek was om te onderzoeken of protozoa als oorzaak van chronische buikpijn kunnen worden aangewezen en of infecties met protozoa kunnen worden herkend door een specifieke klinische presentatie.

Alle patiënten werden onderzocht op de aanwezigheid van parasieten (Giardia lamblia (Gl), Dientamoeba fragilis (Df) en Blastocystis hominis (Bh)) door middel van een triple feces test (TFT) en behandeld indien positief. Controle van de ontlasting volgde tenminste 10 dagen na het einde van de kuur. Verdwijnen van de pijn bij eradicatie en een pijnvrije follow-up van tenminste 6 maanden werd beschouwd als een aanwijzing voor een causaal verband met de buikpijn.

De voorspellende waarde van de pijnkenmerken bij infecties met protozoa werd berekend. Fecesmonsters werden ontvangen van 215 patiënten; 73 patiënten (34\%) hadden een parasitaire infectie, waarvan 10 patiënten 2 parasieten hadden en 2 patiënten 3 parasieten. Bij 8 van deze 73 patiënten was de pijn inmiddels spontaan verdwenen; 65 werden behandeld. Hiervan werden 25 patiënten (11\%) pijnvrij na eradicatie (21 hadden Df, 8 hadden $\mathrm{Bh}, 4$ hadden Gl), van wie 11 nog een andere infectie (2) of obstipatie (9) hadden als een tweede diagnose voor de pijn. Vijf hadden een recidief infectie met Df; zij waren opnieuw pijnvrij met eradicatie van de parasiet. Patiënten met een parasitaire infectie als de oorzaak van de pijn hadden geen noemenswaardig andere presentatie van de pijn dan patiënten met een asymptomatische parasitaire infectie of patiënten zonder parasiet. Wij concluderen, dat protozoa werden gevonden bij ongeveer een derde van de patiënten en dat bij ongeveer een derde daarvan de protozoa konden worden beschouwd als de oorzaak van de buikpijn, al met al omstreeks $10 \%$ van de totale populatie. Ten gevolge van ontbreken van specifieke symptomen is het niet mogelijk om patiënten met een parasitaire infectie bij presentatie te herkennen.

Wij vonden, dat een opmerkelijk hoog percentage patiënten die verwezen waren naar de tweede lijn, een parasiet had. De prevalentie in de algemene bevolking in ons land en in onze regio is echter niet bekend. Een dubbelblinde placebo-gecontroleerde studie 
is nodig om deze resultaten te bevestigen. Daarbij moet rekening gehouden worden met het percentage asymptomatische dragers.

\section{HOOFDSTUK 7}

Hoofdstuk 7 beschrijft de rol van incomplete absorptie van koolhydraten bij chronische buikpijn. Doel van dit deel van de studie was om te onderzoeken of malabsorptie van lactose en fructose kunnen worden beschouwd als een valide oorzaak van chronische buikpijn. Waterstofademtesten $\left(\mathrm{H}_{2} \mathrm{BT}\right.$; afwijkend indien $\left.\Delta \mathrm{H}_{2}>30 \mathrm{ppm}\right)$ werden uitgevoerd met lactose en fructose. Verdwijnen van de buikpijn bij eliminatie, recidiveren van de buikpijn bij provocatie en verdwijnen bij re-eliminatie, gevolgd door een pijnvrije followup van tenminste 6 maanden, werd beschouwd als een indicatie voor een causaal verband met de buikpijn. Voor een definitief bewijs werd een dubbelblinde placebo-gecontroleerde (DBPC) provocatie uitgevoerd. Malabsorptie van lactose werd gevonden bij 57/210 (27\%), van fructose bij 79/121 (65\%) van de patiënten. Eliminatie en open provocatie met lactose en fructose waren positief bij respectievelijk 7 en 13 patiënten. DBPC provocatie bij 6/7 en $8 / 13$ patiënten was negatief bij allen. Desondanks bleven enkele kinderen buikpijn aangeven bij gebruik van melk respectievelijk fructose.

Wij concluderen, dat noch lactose intolerantie noch fructose intolerantie kon worden vastgesteld als oorzaak van buikpijn, volgens de door ons opgestelde criteria. In de praktijk moeten persisterende gevoelens van intolerantie, die bij sommige patiënten optreden, serieus genomen worden; meer uitgebreide eliminatie en provocatie kunnen geïndiceerd zijn. Een gouden standaard voor de diagnose lactose (fructose) intolerantie bestaat niet, evenmin als voor lactose (fructose) malabsorptie. Er is geen vaste relatie tussen koolhydraatmalabsorptie en intolerantie. Vonk et al suggereerden, dat de mate van lactose vertering bij volwassenen met genetisch bepaalde lage lactase activiteit wordt bepaald door rest-activiteit van lactase en door de tijd die beschikbaar is voor hydrolyse (orocoecale passagetijd). Andere, nog incompleet begrepen gastheer-specifieke factoren werden door hen verondersteld medeverantwoordelijk te zijn voor intolerantie. Daarnaast wordt adaptatie van de intestinale microbiota door regelmatige inname van lactose, leidend tot toename van bacteriële $\beta$-galactosidase activiteit herkend als een oorzaak van reductie van symptomen van lactose intolerantie.

Voor de diagnose lactose (fructose) intolerantie is de methode die in deze studie gebruikt is, gebaseerd op consistentie van symptomen, mogelijk niet de juiste weg. Deze onduidelijkheid rechtvaardigt verder onderzoek, gericht op de factoren die bepalend zijn voor de gevolgen van een koolhydraat-belasting bij patiënten met koolhydraatmalabsorptie; dergelijk onderzoek moet opgezet worden om een verklaring te vinden voor de mogelijke inconsistentie van symptomen, zoals gesuggereerd in deze studie. Met name fecesretentie wordt gesuggereerd als een factor die hierbij een rol kan spelen.

Voor de praktijk concluderen wij, dat ademtesten zinvol kunnen zijn om de patiënten op te sporen die baat zouden kunnen hebben bij eliminatie van lactose of fructose. Een trial met een lactose of fructose beperkt dieet zou kunnen worden uitgevoerd gedurende 2 weken, met goede ondersteuning door een diëtist. In geval van een goed resultaat, is er reden voor verder onderzoek.

\section{HOOFDSTUK 8}

Hoofdstuk 8 beschrijft de rol van (occulte) obstipatie bij chronische buikpijn. In dit onderzoek werd een causaal verband tussen buikpijn en (occulte) obstipatie gedefinieerd als buikpijn, die verdwijnt met laxerende maatregelen. De pijn recidiveert 
niet binnen een follow-up periode van 6 maanden. Voortzetting van de therapie tijdens de follow-up kan nodig zijn. De pijn kan terug komen bij verminderen of staken van de therapie, maar verdwijnt weer bij laxerende maatregelen. De term obstipatie werd gebruikt voor kinderen die voldeden aan de Rome II criteria voor functionele obstipatie. De term "occulte obstipatie" werd gebruikt voor kinderen die niet voldeden aan de Rome II criteria voor functionele obstipatie, maar die klachtenvrij werden met laxerende maatregelen.

In dit hoofdstuk werden de Rome II criteria gebruikt, omdat de Rome III criteria nog niet waren gepubliceerd ten tijde van de inclusie van patiënten en omdat de Rome III voor functionele obstipatie diverse criteria bevatten die niet opgenomen waren in de gestandaardiseerde anamnese van deze studie.

Bij iedere patiënt met persisterende buikpijn na een diagnostische procedure en interventies voor potentiële oorzaken, zoals beschreven in hoofdstuk 4, werd een proefbehandeling met laxantia uitgevoerd, in combinatie met dieet-advies en toilettraining, ongeacht anamnese, lichamelijk onderzoek en het resultaat van een buikoverzichtsfoto.

Macrogol 4000 (polyethyleenglycol 4000) per os werd voorgeschreven in een dosering van $1 \mathrm{~g} / \mathrm{kg}$ (maximaal $40 \mathrm{gram}$ ), met het advies aan de ouders om de dosering aan te passen op geleide van het resultaat. Zij konden gedurende enkele dagen een dubbele dosis geven, bij wijze van "mini-lavage", als ze snel resultaat wilden bereiken. Enkele patiënten gebruikten andere laxantia, met name lactulose of lactitol, naar keuze, met dezelfde instructies. Frequent telefonisch contact vond plaats ter ondersteuning van de ouders met betrekking tot de te gebruiken dosering. In geval van therapieresistente obstipatie werd lavage van het colon uitgevoerd met een polyethyleenglycol-elektroliet oplossing.

Deze therapie werd geadviseerd aan 111 patiënten en was succesvol bij 92 patiënten (83\%), zijnde ongeveer de helft van alle patiënten. Achttien hiervan hadden al aanzienlijke blijvende verbetering met behandeling voor een lichamelijke aandoening, maar waren volledig pijnvrij met laxerende maatregelen; zij werden geacht 2 diagnoses te hebben. Met multivariate analyse kon een eenvoudig model worden ontwikkeld, met blaasontsteking in de voorgeschiedenis, snelle verzadiging en flatulentie als predictoren voor obstipatie. De kans op obstipatie was 31\% (18/58), als geen predictor aanwezig was, tot $100 \%(4 / 4)$, als alle drie aanwezig waren.

Wij concluderen, dat de chronische buikpijn bij een aanzienlijk percentage van de patiënten met laxerende therapie verdween voor de duur van tenminste 6 maanden. Zij werden geacht obstipatie te hebben als oorzaak van de pijn. Velen hiervan voldeden niet aan de Rome criteria voor functionele obstipatie: voor hen werd de term "occulte obstipatie" gebruikt. De aanwezigheid van blaasontsteking in de voorgeschiedenis, snelle verzadiging en flatulentie bleken vaker voor te komen bij patiënten met (occulte) obstipatie dan bij andere oorzaken van buikpijn; patiënten met twee of drie van deze symptomen zouden vaker dan gemiddeld baat hebben bij laxerende therapie.

(Occulte) obstipatie werd beschouwd als een functionele diagnose. Deze patiënten kregen een Rome diagnose, als zij bij presentatie een symptomencomplex hadden dat paste bij een van de functionele pijnsyndromen. Vermeldenswaard is, dat de patiënten pijnvrij werden met laxerende maatregelen ongeacht de aard van hun Rome diagnose: IBS, FAP(S) of FD. 


\section{NIEUWE PERSPECTIEVEN VOOR DE PATIËNT EN DE DOKTER}

Wij leerden van dit onderzoek, dat de meeste patiënten met buikpijn pijnvrij kunnen worden met meer diagnostische inspanning (en behandeling van de gevonden potentiële oorzaken van de pijn) respectievelijk met - soms agressieve - laxerende therapie. Het resultaat van deze benadering is beter dan de resultaten van tot nog toe gepubliceerde onderzoeken, met betere perspectieven voor de patiënten als gevolg.

De consequentie voor de dokter is, dat meer inspanning moet worden geleverd.

Meer onderzoek is nodig naar de onderliggende processen, op het niveau van basaal wetenschappelijk onderzoek, in de eerste plaats met betrekking tot (occulte) obstipatie. We begrijpen nog niet waarom sommige patiënten met (occulte) obstipatie buikpijn hebben, terwijl anderen symptomen hebben van het bovenste deel van het maagdarmkanaal of helemaal geen klachten hebben anders dan problemen met defecatie. Ongetwijfeld speelt hypersensitiviteit hierbij een rol. Het is echter niet zo, dat al deze patiënten zich presenteren met de symptomen van IBS.

In de praktijk, zoals aangetoond in dit proefschrift, bieden de Rome criteria geen steun bij de aanpak van chronische buikpijn bij kinderen: wij vonden geen voordeel van de differentiatie van chronische buikpijn in IBS, FAP(S) en FD. Patiënten met dezelfde functionele of somatische klinische diagnose presenteren zich met de symptomen van verschillende Rome pijnsyndromen. Laxerende therapie is globaal even succesvol bij alle Rome pijnsyndromen. De Rome diagnoses leveren daarom geen bijdrage aan de behandeling van chronische buikpijn bij kinderen.

Dit sluit niet uit, dat de Rome classificatie een functie kan hebben bij onderzoek naar de pathofysiologie en bij het zoeken naar antwoorden op de vragen naar verschillen in presentatie bij kinderen met dezelfde klinische diagnoses.

Opgemerkt moet worden, dat met alarm symptomen geen onderscheid gemaakt kon worden tussen lichamelijke en functionele oorzaken. Organische aandoeningen presenteren zich vaak zonder alarmsymptomen. Daarom sluit de afwezigheid van alarmsymptomen een lichamelijke oorzaak niet uit. Dit laat onverlet, dat specifieke alarmsymptomen belangrijk zijn voor het opsporen van chronische darmontsteking, coeliakie en andere organische aandoeningen.

De consequentie van deze gegevens is, dat bij elke patiënt met chronische buikpijn adequaat onderzoek verricht moet worden.

Een goede anamnese (inclusief vragen met betrekking tot eventuele voedselallergie) en lichamelijk onderzoek zijn vereist. In geval van verdenking van een lichamelijke oorzaak of bezorgdheid van de ouders daarover moet passend aanvullend onderzoek worden verricht. Als er geen reden is om direct aanvullend onderzoek te verrichten, is een proefbehandeling met een laxans op macrogolbasis op zijn plaats. De dosering daarvan moet hoog genoeg zijn (dosis aan te passen op geleide van het defecatiepatroon) en de therapie tenminste 4 weken worden volgehouden. Wanneer hiermee onvoldoende resultaat wordt bereikt, is aanvullend onderzoek geïndiceerd, tenminste gericht op infecties van het maag-darmkanaal (met name infecties met protozoa), chronische darmontsteking, coeliakie en andere aandoeningen op geleide van de differentiaal diagnose. Psychologisch onderzoek is geïndiceerd in geval van vermoeden van psychopathologie.

Een definitieve diagnose, lichamelijk of psychisch, dient alleen gesteld te worden, als een gerichte interventie resulteert in verdwijnen van de pijn en een pijnvrije follow-up 
(of bevestiging van de diagnose gedurende de follow-up door een zelfde resultaat bij dezelfde interventie). Belangrijk is, dat bijna alle patiënten pijnvrij kunnen worden, als dokters bereid zijn een oplossing te zoeken voor iedere individuele patiënt of anders door te verwijzen naar een expert op het gebied van chronische buikpijn. 
Dankwoord

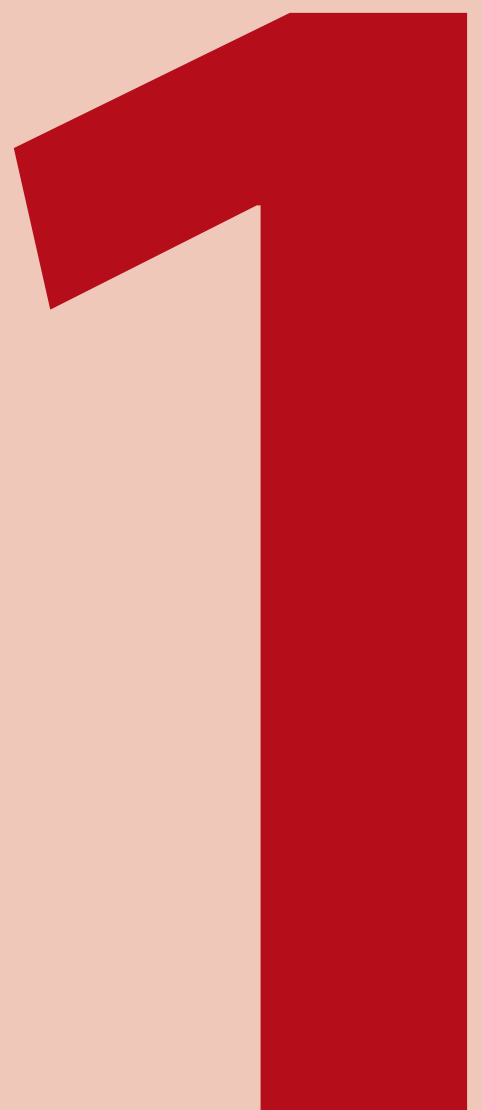


Velen hebben in woord en/of daad bijgedragen aan het tot stand komen van dit boekje.

Prof dr HA Büller, beste Hans,

Lang geleden vroeg ik je of je mee wilde doen aan het project, dat ik in mijn hoofd had. Je zei direct ja. Ik had me geen betere promotor kunnen wensen. Je was er altijd als het nodig was en altijd snel en ter zake. Toen tenslotte voor de zomervakantie in korte tijd nog heel veel ingeleverd en geregeld moest worden, zei je "aan mij zal het niet liggen" en wat heb je dat waar gemaakt! Je hebt mij altijd het gevoel gegeven, dat jij het ook de moeite waard vond en dat was heel prettig. Heel veel dank voor je niet aflatende steun en voor je verdere bijdragen! Ik heb veel van je geleerd!

Dr CMF Kneepkens, beste Frank,

Wij kennen elkaar al sinds onze studententijd en kwamen elkaar daarna in alle fasen van onze opleiding weer tegen alvorens de contacten binnen de kinder-MDL pas echt intensief werden. Toen je hoorde waar ik mee bezig was, bood jij aan om mee te doen aan dit plan. Dat heb ik in dank aanvaard. En zo werd je copromotor. Je hebt je grote redactionele vaardigheden ruimschoots kunnen uitleven en onze bijeenkomsten waren altijd zeer aangenaam en productief. Veel dank daarvoor en minstens zo veel dank voor je steun in de loop van de tijd.

Dr JJ Schweizer, beste Joachim,

Halverwege het onderzoek ben jij er bij betrokken geraakt: we wilden graag een "panel" ter controle van de diagnoses. Je hebt je heel snel ingewerkt en hebt later ook nog mee gedaan aan het parasieten-artikel. Veel dank voor je praktische, constructieve, altijd heel directe en immer gezellige inbreng.

Prof dr MA Benninga, beste Marc,

Ook jij raakte betrokken in de loop van het onderzoek: om de Rome criteria toe te kennen. Je hebt met je grote ervaring op dit gebied bijgedragen aan het Rome-artikel en de eerste twee artikelen die daar de aanloop toe waren. Je was altijd snel, mailwisselingen vonden plaats in de nachtelijke uren en we hebben diverse zondagavonden met Hans bij jou thuis gewerkt. Veel dank voor je inzet.

DrY Vergouwe, beste Yvonne,

Jouw inbreng, betreffende de statistische aspecten van enkele hoofdstukken, was meer dan welkom. Je was buitengewoon efficiënt. Ik heb nooit eerder iemand met zo weinig tekst zo veel nuttige informatie zien inbrengen. Ook onze mondelinge contacten waren altijd 'to the point'. Het was prettig samenwerken, waarvoor veel dank.

Prof dr D Tibboel, Prof dr AJ van der Heijden, Prof dr MY Berger, beste Dick, Bert en Marjolein, hartelijk dank voor het beoordelen van dit proefschrift.

Collega's in het JKZ, kinderartsen en assistenten, die 2 jaar lang alle patiënten met chronische buikpijn naar mij doorverwezen voor dit onderzoek: dank voor jullie medewerking. Zonder dat was het nooit wat geworden. 
Sarita en Rosanna, jullie hebben enorm geholpen met het verwerken van de extra patiënten voor het onderzoek, waarvoor veel dank.

Gijs de Kort en medewerkers van het lab, dank voor jullie medewerking bij het realiseren van alle ademtesten. Sarita en Carla, dank voor jullie bereidheid de uitvoering van de ademtesten te leren en dat vervolgens te praktiseren. Dankzij jullie aller inzet konden de grote aantallen ademtesten zonder wachttijd worden uitgevoerd!

Judith Schornagel, dank voor het mee-denken en uitvoeren van de dubbelblinde provocaties met lactose en fructose, inclusief het (gezellig samen) proeven, randomiseren en leveren van de potjes.

Vele OK-medewerkers, dank voor jullie (altijd aanwezige!) flexibiliteit waardoor de extra scopieën schijnbaar moeiteloos werden ingepast.

Esther, jij hebt met grote nauwgezetheid de dubbelblinde provocaties voor de voedselallergieën opgezet en georganiseerd met de keuken. Dat was echt maatwerk. Veel dank daarvoor!

Dank ook aan Cees en zijn collega's in de keuken, die de recepten met grote toewijding hebben uitgevoerd en de pakketjes met eten hebben klaargemaakt.

Vele medewerkers van diverse afdelingen van het JKZ en elders uit het HagaZiekenhuis hebben geholpen met het bezorgen van de voedselpakketten bij de patiënten thuis: José, Jenny, Suzanne, Marijke, Sarita, Rosanna, Carla, Vivian, Jan Willem, Leonie, Esther, Sonja, Margot, Annemarie, Adri, Maria, Jan. Dank voor jullie onmisbare hulp; zonder jullie waren deze testen niet uitvoerbaar geweest.

Mieke en Fréderique, lieve collega's, dank voor het opvrolijken van al die avonden. Lachen is toch wel een eerste levensbehoefte! Vele andere collega's, eveneens dank voor het meeleven en de'JKZ-gezelligheid', die het leven dragelijk houdt, ook als het soms wat erg intensief is.

Jan Hein, dank voor je aanmoedigingen. Zonder jou en Gerda had ik bovendien die appendixen er niet zo makkelijk uit gekregen. Dank aan jullie beiden voor het meedenken en -doen.

Rimke, dankzij jouw hulp is het uiteindelijk gelukt SPSS aan de praat te krijgen op mijn computer. Wat leuk, dat je later in het Haga terug kwam als wetenschapscoördinator, zodat ik vervolgens weer gebruik kon maken van je statistische adviezen, waarvoor veel dank.

Jolt, dank voor je statistische hulp bij hoofdstuk 3.

Danielle, je hebt het laatste stukje van dit project nog mee gemaakt. Jouw aanwezigheid maakte het mogelijk om mij enkele malen een paar weken terug te trekken om te schrijven. Dat was heerlijk. Dank daarvoor. 
Margot, zonder jouw bijdrage aan de gastroenterologie in het JKZ was het nooit gelukt om tijd vrij te maken voor dit onderzoek zonder dat de patiëntenzorg in de knel kwam. Dank daarvoor en voor alle gezelligheid. Ik vind het heel leuk, dat jij mijn paranimf wilt zijn.

Lieve familie en vrienden, ik ben mij pijnlijk bewust van mijn asociale gedrag gedurende de afgelopen jaren. Het is een wonder, dat ik nog steeds gewoon bij jullie aan kan kloppen. Heel veel dank voor jullie begrip en geduld.

Lieve pap, mijn bezoekfrequentie aan jullie liet al die jaren ernstig te wensen over. Dat moet nu maar snel gaan veranderen! Jammer dat mama het slot van dit project niet meer meemaakt. Heel veel dank voor je (jullie) onvoorwaardelijke steun in de loop der jaren.

Lieve Annemieke, Lisa en Hanne, een noemenswaardig deel van jullie leven heeft in het teken van chronische buikpijn gestaan. Alsof het er bij hoorde. Jullie moesten mijn aandacht delen met die 200 andere kinderen. Gezien jullie - vaak hilarische commentaren en sinterklaasgedichten geloof ik, dat jullie dat goed verwerkt hebben. Ik verheug mij er op meer tijd te krijgen om jullie, inmiddels met Frederik en Peter, te zien en mij nog meer dan tot nu toe met Olivia bezig te houden.

Lieve Jan, als ik bij iemand heel erg in het krijt sta, ben jij het wel. Je hebt - toen je met pensioen ging - allerlei taken geruisloos van mij overgenomen. Dat was wel heel fijn. Dank ook voor al je heerlijke koppen koffie. Met eindeloos geduld heb je bovendien geholpen bij alle (vele!) computerproblemen waar ik op stuitte. Dit alles heeft je er niet van weerhouden toch altijd achter mij te blijven staan, in figuurlijke betekenis en straks als paranimf ook letterlijk. Wie kon ik beter als paranimf hebben dan jou!?

Daarna ga ik eindelijk maar eens met je mee fietsen! 
Curriculum vitae 


\section{Curriculum vitae}

Carolien Gijsbers werd geboren in Zierikzee en groeide op Gorcum en Voorburg. $\mathrm{Na}$ het eindexamen Gymnasium $\beta$ (Christelijk Lyceum Voorburg) studeerde zij geneeskunde in Leiden. Zij volgde de opleiding kindergeneeskunde in het St Joseph Ziekenhuis te Eindhoven (opleider dr C de Monchy) en in het Wilhelmina Kinderziekenhuis te Utrecht (opleider Prof dr JW Stoop). Hierna volgde deelspecialisatie in de kindergastroenterologie in het Wilhelmina Kinderziekenhuis (opleiders drs EAK Wauters en drs JEAR de Schryver). Zij heeft als kindergastroenteroloog / kinderarts maag-darm-leverziekten gewerkt in het Academisch Ziekenhuis van de Vrije Universiteit te Amsterdam (1982-1984) en werkt sinds 1983 in het Juliana Kinderziekenhuis/ Hagaziekenhuis te Den Haag.

Het buikpijn-onderzoek is door haar opgezet en uitgevoerd in het Juliana Kinderziekenhuis/HagaZiekenhuis, met medewerking van collega's uit het VUmc ( $d r$ CMF Kneepkens), het AMC (Prof dr MA Benninga) en het LUMC (dr JJ Schweizer). $\mathrm{Zij}$ is gehuwd met Jan Kouwenberg en heeft 3 dochters, 2 schoonzonen en 1 kleindochter. 




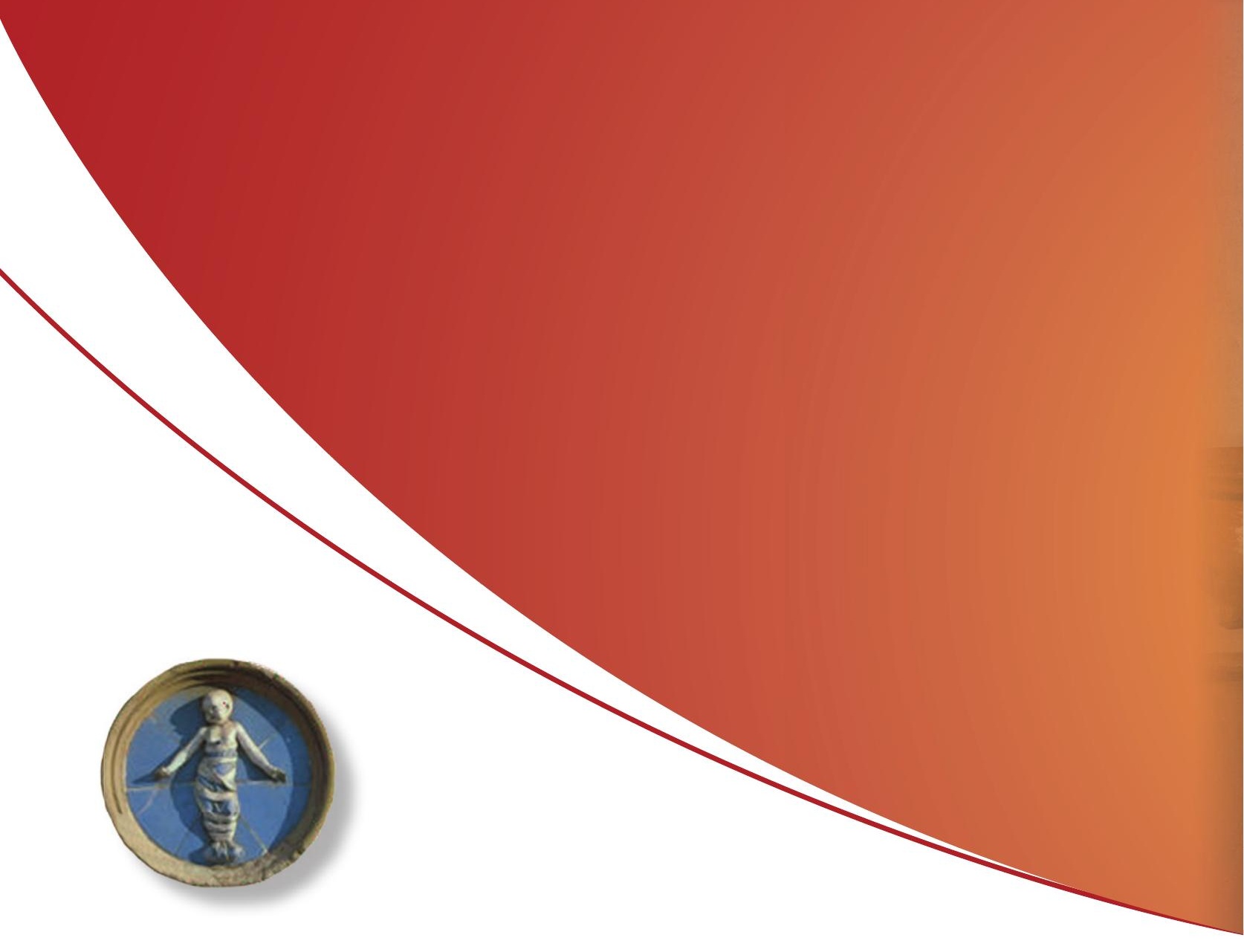

ISBN 978-90-365-3435-2 